\title{
Evaluating strategies for integrating bacterial cells into a biosensor designed to detect electrophilic toxins
}

\author{
Katherine A. Linares
}

\author{
Thesis submitted to the Faculty of the \\ Virginia Polytechnic Institute and State University \\ in partial fulfilment of the requirements for the degree of \\ Master of Science \\ in \\ Environmental Engineering \\ Dr. Nancy G. Love, Chairperson \\ Dr. Brian J. Love \\ Dr. John C. Little \\ Dr. Kathleen Meehan \\ June 3, 2004 \\ Blacksburg, Virginia
}

Keywords: biosensor, microbial stress response, potassium efflux, bacterial immobilization 


\title{
Evaluating strategies for integrating bacterial cells into a biosensor designed to detect electrophilic toxins
}

\author{
Katherine A. Linares
}

\begin{abstract}
To improve the process stability of wastewater treatment plants, the construction of a whole-cell bacterial biosensor is explored to harness the natural stress response of the bacterial cells. The stress response selected in this work is the glutathione-gated potassium efflux (GGKE) system, which responds to electrophilic stress by effluxing potassium from the interior to the exterior of the cell. Thus, the bulk potassium in solution can be monitored as an indicator of bacterial stress. By utilizing this stress response in a biosensor, the efflux of potassium can be correlated to the stress response of the immobilized culture, providing an early warning system for electrophilic shock. This type of shock is a causative factor in many process upset events in wastewater treatment plants, so the application of the sensor would be an early warning device for such plants.

The research conducted here focused on the biological element of the biosensor under development. Three immobilization matrices were explored to determine the cell viability and potassium efflux potential from immobilized cells: a calcium alginate, a photopolymer, and a thermally reversible gel. The calcium alginate was unstable, and dissolved after five days, such that the long-term impact of immobilization on the cells could not be determined in the matrix. The photopolymer resulted in very low actvity and viability of immobilized cellsOf the three matrices tested, indicating that the composition of the polymer was toxic to the cells. Of the matrices tested, the thermallyreversible gel showed the best response for further study, in that the matrix did not inhibit cell activity or potassium efflux.
\end{abstract}




\section{Acknowledgements}

I would like to thank the funding sources that made this work possible: the Charles E. Via, Jr. Department of Civil and Environmental Engineering Endowment, the Paul L. Busch Award, and the EPA Midwest Hazardous Substances Research Center.

I would like to thank the members of my advisory committee, Dr. Nancy Love, Dr. Brian Love, Dr. Kathleen Meehan, and Dr. John Little for their guidance and assistance throughout my research.

I would like to thank our Laboratory Manager, Julie Petruska; Analytical Chemist, Jody Smiley; and media man, Phil Wunderly for their assistance and guidance in the laboratory. 


\section{Table of Contents}

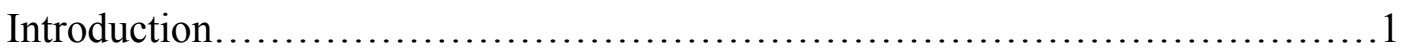

Chapter 1: Literature Review ............................................ 5

Introduction.................................................... 5

Toxic shocks cause treatment upset.................................5

Bacterial stress responses............................................ 7

Real time information on wastewater toxicity.........................11

Immobilized cells as biological elements in biosensors...................12

Microfluidic sensors..............................................21

Matrices for immobilization.......................................23

Scope of Research...............................................26

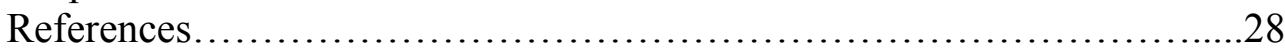

Chapter 2: Evaluating strategies for integrating bacterial cells into a biosensor designed to detect process upset

Part A: viability and activity

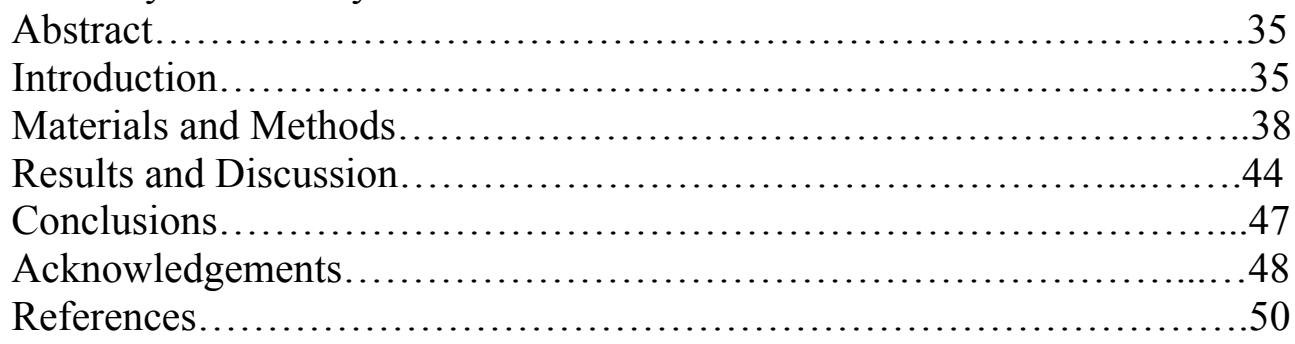

Chapter 3: Evaluating strategies for integrating bacterial cells into a biosensor designed to detect electrophilic toxins

Part B: potassium efflux

Abstract............................................................ 55

Introduction....................................................... 55

Materials and Methods................................................ 58

Results and Discussion............................................64

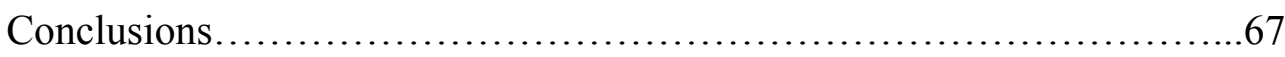

Acknowledgements..............................................67

References.....................................................69

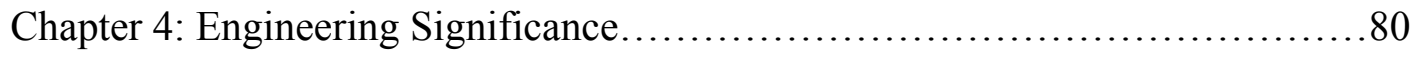

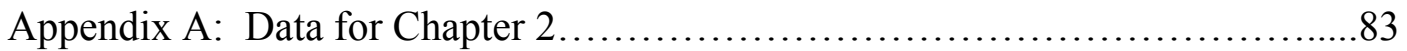

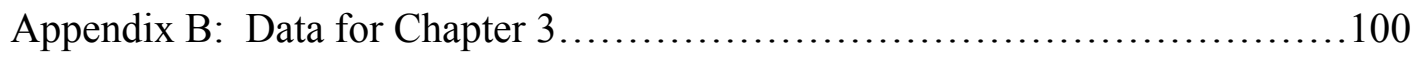




\section{List of Tables}

Chapter 3: Evaluating strategies for integrating bacterial cells into a biosensor designed to detect electrophilic toxins

Part B: potassium efflux

Table 1. Efflux potential from immobilized cells.........................66 


\section{List of Figures}

Chapter 2: Evaluating strategies for integrating bacterial cells into a biosensor designed to detect process upset

Part A: viability and activity

Figure 1. Diagram of the OUR experiment protocol .........................52

Figure 2. OUR tests for cells immobilized in each polymer matrix..................53

Figure 3. Representative LIVE/DEAD ${ }^{\circledR}$ stains of immobilized cells ................54

Chapter 3: Evaluating strategies for integrating bacterial cells into a biosensor designed to detect electrophilic toxins

Part B: potassium efflux

Figure 1. The glutathione-gated potassium efflux (GGKE) system.................71

Figure 2. The experimental setup for potassium efflux experiments...............72

Figure 3. Batch potassium efflux experiment from planktonic culture .............73

Figure 4. Batch potassium efflux experiments across the growth curve for planktonic cultures.......................................................... 74

Figure 5. Effect of potassium on alginate stability ............................. 75

Figure 6. Potassium efflux from alginate-immobilized culture: Initial..............76

Figure 7. Potassium efflux from alginate-immobilized culture: Day Five..............77

Figure 8. Potassium efflux from thermal gel-immobilized culture: Initial............78

Figure 9. Potassium efflux from thermal gel-immobilized culture: Day Three.......79 


\section{Introduction}

Process upset in wastewater treatment plants results in permit violations, low quality effluent, and detrimental impacts on receiving waters. Even the most well-designed plant may experiment occasional process upset due to shock loads of toxic and/or inhibitory compounds. Unfortunately, the precise causes of these upset events are often unclear, and due to the lack of real-time monitoring, operators are typically unaware that upset is occurring until the biomass is already damaged. The implementation of a real-time sensing system would provide operators with warning that a toxin is approaching and give them time to proactively respond to reduce the impact of the shock, instead of merely reacting to an upset event already underway.

In a survey performed by Love and Bott in 2000, operators reported that the most common modes of process upset are ineffective biological oxygen demand (BOD) removal, ineffective nitrification, deflocculation, and sludge bulking. Although the causes of these upsets have been speculated, operators generally do not have sufficient information to identify the source of the problem. However, when asked, operators suggested that heavy metals and toxic organic compounds (which include electrophilic chemicals) are among the most common sources of these upsets (Love and Bott, 2000). Thus, the major types of upset events are thought to be due in part to electrophilic shock loads. Creating a sensor for electrophilic compounds would provide warning of these types of upset events, although it would not be useful for upsets due to other classes of compounds, such as oil and grease.

Because electrophiles elicit a natural stress response from bacterial cells, this stress response can be harnessed to create a biosensor for electrophilic toxins. During an

electrophilic toxin upset event, the bacterial biomass initiates the glutathione-gated potassium 
efflux (GGKE) system (Bott and Love, 2002), in which potassium ions are effluxed from within the cell (Apontoweil and Berends, $1975 \mathrm{a}$ and b). By creating a biosensor with bacterial cells containing the GGKE response, the intrinsic stress response of the bacterial culture is harnessed and genetic engineering of the bacteria is not required. Many existing biosensors have been slow to commercialize, mostly due to the limitations on genetically engineered organisms. The commercial Microtox ${ }^{\circledR}$ assay, which uses naturally luminescent Vibrio fischerii bacteria, is widely used as an indicator of toxicity, whereas many promising biosensors with better response times and repeatability that use genetically modified bacteria remain limited to laboratory use (for example, Philp et al., 2003; Gu and Choi, 2002). Because the sensor developed in this work sensor does not require genetic modification, it has an advantage in terms of eventual commercialization and field application.

By monitoring bulk potassium as an indicator of cellular stress, the biosensor will monitor for electrophilic compounds that have been shown to cause upset in the activated sludge process. The microscale biosensor under development includes a whole cell biological element, potassium detection membranes, and microfluidic componentry that compose a lab-on-a-chip device. The biological element consists of bacterial cells immobilized in a hydrogel polymer matrix. Immobilization of the bacterial cells is important because it keeps the cell concentration constant by maintaining the viability of the immobilized cells while reducing cell division. Additionally, immobilized cells cannot slough off as a biofilm layer could and clog the microfluidic channels in the device.

A series of screening experiments were conducted in this work to select an appropriate polymer matrix for bacterial cell immobilization within the biosensor under development, and are discussed in Chapter 2. The ideal matrix is physically and chemically 
stable over several weeks, non-toxic to the cells, and does not limit the diffusion of oxygen, compounds that are necessary for cell growth, the electrophiles that would trigger a stress response, or the potassium that would indicate that a stress response has been initiated. Three matrices were examined here, including calcium alginate, several photopolymerizable hydrogels, and a thermal polymer. The alginate showed good viability, but poor mechanical stability, while the photopolymerizable polymers showed poor viability. The thermal polymers were the best choice for continued study, in that the bacterial culture showed extended viability after immobilization and the matrix did not inhibit the efflux response.

\section{Experimental Objectives}

The overall objectives of this research were:

- Elucidate potassium efflux in response to a model electrophile from planktonic cultures of $P$. aeruginosa and $E$. coli at various growth states

- Select the growth state and the strain with maximal potassium efflux per cell for further study

- Screen a series of immobilization hydrogels for cell viability within the matrix

- Quantify potassium efflux from immobilized bacterial culture selected

The specific results and methods used to meet these objectives will be discussed within the following chapters of the thesis. 


\section{References}

Apontoweil, P., Berends, W. (1975a). Glutathione biosythesis in Escherichia coli K-12: properties of the enzymes and regulation. Biochimica et Biophysica Acta, 399 (1), 1-9.

Apontoweil, P., Berends, W. (1975b). Isolation and initial characterization of glutathionedeficient mutants of Escherichia coli K-12. Biochimica et Biophysica Acta. 399(1), 10-22.

Bott, C. B. and Love, N. G. (2002) Investigating a mechanistic cause for activated sludge deflocculation in response to shock loads of toxic electrophilic chemicals. Water Environment Research. 74:306-315.

Gu, Man Bock, and Sue Hyung Choi. A portable toxicity biosensor using freeze-dried recombinant bioluminescent bacteria. Biosensor and Bioelectronics. 17 (2002) 433-440

Love, N. G., Bott, C.B. (2000). WERF Project 99-WWF-2 Report: A review of and needs survey of upset early warning devices. Water Environment Research Foundation.

Philp, Jim C., Severine Balmand, Eva Hajto, Mark J. Bailey, Siouxsi Wiles, Andrew S. Whiteley, Andrew K. Lilley, Janos Hajto, and Sandra A. Dunbar. (2003). Whole cell immobilized biosensor for toxicity assessment of a wastewater treatment plant treating phenolics-containing waste. Analytica Chimica Acta. 


\section{Chapter 1: Literature Review}

\section{Introduction}

Process upset events in wastewater treatment plants result in high nutrient and pathogen loading to receiving waters, endangering public heath and stability of waterways. Electrophilic compounds are one cause of upset events, typically resulting in deflocculation, which is thought to be due to potassium efflux through the glutathione-gated potassium efflux (GGKE) mechanism (Bott and Love, In Press). Controls to eliminate such upset events are limited by the scarcity of real-time toxicity monitoring devices. Biosensors show promise in the field and have been developed to respond to specific compounds (for example, Strachan et al., 2001 and Reid et al., 1998) as well as general stress and oxidative damage (for example, Belkin et al., 1997 and Elasri et al., 2000). Most biosensors employ genetically modified bacteria, which limits their potential for commercialization. Nonengineered strains have been used to some degree, but more work is needed in this area. To create a real-time live cell sensor, a flow-through system is required. Microfluidic technology can be applied to create micro-scale sensors containing bacteria immobilized in hydrogels (for example, Heo et al., 2003), because these sensors provide rapid response and require low sample volumes. Incorporating these microfluidic sensors into a real-time monitoring system can provide forewarning of toxic shock loads to treatment plants, allowing operators time to proactively mitigate the threat.

\section{Toxic shocks cause treatment upset}

Wastewater treatment plants employing biological treatment schemes to reduce or remove organic and inorganic pollutants play a pivotal role in pollution reduction. The 
optimal functioning of these plants is critical for receiving stream health and downstream water reuse capacity. Despite the dependence on these plants for pollutant removal, even the most well designed plant may experience occasional process upset events due to changes in flow pattern or waste composition, or due to toxic loads of inhibitory chemicals.

A survey of Water Environment Research Foundation subscribers revealed that the common modes of process upset are ineffective BOD removal, deflocculation, ineffective nitrification, and sludge bulking (Love and Bott, 2000). Some survey responders reported that the most common causes of upsets they experienced were high flow, toxic organics, oil and grease, and heavy metals (Love and Bott, 2000). Unfortunately, in most cases, the cause of the upset is commonly not discovered until well after the event, if at all. Interestingly, several of the purported causative factors can be grouped as electrophiles, such as the heavy metals and selected toxic organics.

During process upset from a shock load of an electrophilic compound, the treatment plant loses treatment efficiency because the chemical stressors cause deflocculation of the activated sludge flocs. This loss of biomass from the system is believed to occur because stress response mechanisms cause bacteria to efflux potassium (Bott and Love, 2002). The additional monovalent cations in the floc matrix is believed to increase the intrafloc divalent to monovalent cation ratio (Bott and Love, 2002), which is an important predictor of floc strength (Higgins and Novak, 1997a and 1997b). Disrupting this balance causes the flocs to lose stability and results in loss of biomass from the system (Murthy et al., 1998). 


\section{Bacterial stress responses}

Oxidative stress mechanisms in bacteria

Damaging oxidative (electrophilic) chemicals enter cells either from the outer environment or are generated internally as part of cellular metabolism. The types of oxidative stressors generated within the cell (reviewed in Storz and Imlay, 1999) are superoxide anions, hydrogen peroxide, and hydroxyl radicals, as well as methylglyoxal (Kalapos, 1999). Superoxide anions, $\mathrm{O}_{2}{ }^{-}$, are reduced to $\mathrm{O}_{2}$ and $\mathrm{H}_{2} \mathrm{O}_{2}$ by superoxide dismutase. Hydrogen peroxide originates from the reduction of superoxide by its dismutase or by reduction of oxygen. Hydroxyl radicals $\left(\mathrm{HO}^{\circ}\right)$ are produced from superoxide and $\mathrm{H}_{2} \mathrm{O}_{2}$, and are very reactive with and damaging to DNA. Example equations illustrating these reactions (reviewed in Storz and Imlay, 1999) are provided below. Equation 1 shows the complete stepwise reduction of the superoxide radial through peroxide and hydroxyl radical to water. Equation 2 shows the reduction of the oxygen radial to peroxide, a reaction catalyzed by superoxide dismutase. Equation 3 shows the reduction of peroxide to water, a reaction catalyzed by catalase.

$$
\mathrm{O}_{2} \rightarrow \mathrm{O}_{2}{ }^{-} \rightarrow \mathrm{H}_{2} \mathrm{O}_{2} \rightarrow \mathrm{HO}^{\bullet}+\mathrm{H}_{2} \mathrm{O} \rightarrow \mathrm{H}_{2} \mathrm{O}
$$

$$
\mathrm{O}_{2}{ }^{--}+2 \mathrm{H}_{2} \rightarrow \mathrm{H}_{2} \mathrm{O}_{2}+\mathrm{O}_{2}
$$

The types of damage caused by oxidative stress include DNA damage and mutagenesis, as well as membrane and protein damage.

The presence of these electrophiles changes the intracellular oxidation state. Two genes, oxyR and soxR, exist to detect such shifts in redox potential. Redox regulation is defined as the control of protein activity by oxidation and reduction and is a major means of 
cellular control (as reviewed in Demple, 1996 and Pomposiello and Demple, 2001). The first step in protecting cells against damage is sensing the oxidants, achieved by the proteins OxyR and SoxR. These proteins are bound to the promoter region of the genes under their control such that the conformational change occurring upon oxidation allows transcription of these response genes (as reviewed in Pomposiello and Demple, 2001).

As reviewed in, for example, Storz and Imlay (1999) and Pomposiello and Demple (2001), OxyR is activated and deactivated by the formation and reduction of disulfide bonds. Peroxide exercises direct control over the activation of OxyR by reducing pairs of sulfurhydrogen bonds to disulfide bonds. When oxidized by an electrophilic compound, the OxyR protein self-regulates the $\operatorname{oxy} R$ gene, as well as $d p s$ (protein to bind iron and DNA), gorA (GSH reductase), grxA (glutaredoxin), $k a t G$ (peroxidase), ahpCF (NADPH reductase), and fur (iron binding protein to prevent iron transport). Additionally, through its control of oxyS and production of OxyS protein, OxyR controls other regulatory genes such as rpoS and flhA. The majority of the information on the OxyR system has been obtained from E. coli, but homologs have been found in many other species. After oxidation, OxyR is returned to the reduced state by the GSH-glutaredoxin-1 ( $\operatorname{rrx} A$ ) system (as reviewed in Storz and Imlay, 1999 and Pomposiello and Demple, 2001).

The SoxR protein is constitutively expressed at a minimal level within the cell and functions through the activity of its [2Fe-2S] centers, which can be oxidized and reduced by a one-electron shift (Ding and Demple, 1997) as reviewed in, for example, Storz and Imlay (1999) and Pomposiello and Demple (2001). Superoxide exercises direct control over the activation of SoxR by shifting the oxidation state of $\mathrm{Fe}^{+}$to $\mathrm{Fe}^{2+}$ in the iron-sulfur centers. The controlling compound for oxidation may be superoxide or depletion of NADPH. The 
SoxR responds in the presence of heavy metals, antibiotics, and organic compounds, all superoxide-generating compounds, and also responds to nitric oxide (Zheng and Storz, 2000). When activated by an oxidant, SoxR initiates expression of the soxS gene. The genes under control of the soxRS regulon are sodA (superoxide dismutase to deactivate oxidants), $z w f$ (glucose-6-phosphate dehydrogenase to recreate the NADPH pool), fldA and fldB (flavodoxins to reduce metals in constituent groups on intracellular molecules), fpr (NADPH reductase), fur (iron binding protein to prevent iron transport), nfo (DNA repair gene), $\operatorname{arc} A B$ (efflux pump to remove toxic chemicals), and micF (reduces porin expression and thus cell permeability). All of these genes that are controlled by SoxR work to prevent or mitigate damage caused by oxidants. These genes were elucidated in E. coli, but many other bacterial strains contain SoxR homologs (as reviewed in Storz and Imlay, 1999 and Pomposiello and Demple, 2001).

Another type of intracellular oxidative stress arises from methylglyoxal, an electrophilic byproduct of metabolism, also called pyruvaldehyde, pyruvic aldehyde, 2oxopropanal, 2-ketoproprion-aldehyde, or acetyl-formaldehyde. Methylglyoxal generation occurs during upswings in the electron donor concentration, accumulating in starving cells that are suddenly exposed to high concentrations of carbon source. The pathways for glucose oxidation become overwhelmed, and methylglyoxal is formed to release some of the excess carbonaceous energy (Kalapos, 1999). It has been shown (Ness et al., 1997) that the glutathione-gated potassium efflux system evolved as a mechanism of protecting the cell from electrophilic damage from methylglyoxal. 


\section{Glutathione-gated potassium efflux (GGKE)}

Reduced glutathione (GSH) (N-(N-L- $\gamma$-glutamy-L-cysteinyl)glycine) is constitutively expressed in the cell (reviewed in Storz and Imlay, 1999). Due to the activity of its sulfhydryl group, GSH acts in a sacrificial role to bind electrophiles and oxidizes into GSSG, as well as oxidized glutathione-S-conjugates (GSX) (Apontoweil and Berends, $1975 \mathrm{a}$ and b). GSX triggers the cell stress response of potassium efflux through the glutathione-gated potassium efflux (GGKE) mechanism controlled by the KefB and KefC membrane transport proteins (Apontoweil and Berends, $1975 \mathrm{a}$ and b; Booth et al., 1993; Elmore et al., 1990, Ferguson et al., 1995; Munro et al., 1991). GGKE shuttles potassium ions out of the cell in an ion exchange for hydrogen into the cell. The transport of these hydrogen ions dissipates the proton gradient, but acidifies the cytoplasm, causing the DNA to supercoil protecting it from oxidative damage (Ferguson et al., 2000).

The glutathione control system is involved in the OxyR stress response, in that OxyR is reduced by enzymatic reaction with glutaredoxin 1 (Grx1), produced through OxyR control to reduce oxidized glutathione back to the reduced form, GSH (Zheng et al., 1998). Because the production of Grx1 is regulated by OxyR, the reduction of OxyR is autoregulated. Zheng and Storz (1998) presented a conceptual equation for this reaction obtained through both molecular and biochemical studies:

$$
\text { OxyR (ox) }+8 \text { GSH } \leftrightarrow \text { OxyR (red) }+4 \text { GSSG }
$$

Interestingly, OxyR is reduced by sacrificially oxidizing GSH into GSSG (Zheng and Storz 1998). Further, the redox potential of OxyR was found to be $-185 \mathrm{mV}$, much higher than the typical unstressed cell redox potential, indicating that OxyR is primarily in the reduced form normally (Zheng and Storz, 1998). 
Overall, bacteria respond to electrophilic stress, detected by OxyR, SoxR, and glutathione, by a number of protective mechanisms. The GGKE system is linked to the OxyR system through the reduction of the oxidized proteins back to their reduced forms. Although SoxR and OxyR control many intracellular responses, such as the activation of protective genes, the GGKE system differs in its interaction with the Kef potassium efflux channels because the system triggers an observable extracellular effect. The efflux of potassium appears to cause deflocculation in wastewater sludge flocs, a typical symptom of process upset caused by toxic shock.

\section{Real time information on wastewater toxicity}

The key to successful control of toxic shock events is awareness of their impending arrival at the plant as well as the causative toxin and its potential effect. Recognizing that a threat is approaching gives the operators time to respond in order to mitigate the threat. Control of wastewater plants is typically performed by operators with the help of computerized systems such as the Supervisory Control and Data Acquisition (SCADA) system. However, these systems are limited by the lack of real-time monitoring devices (for example, Dieu, 2001). Parameters that can be evaluated quickly include flowrate, $\mathrm{pH}$, temperature, and dissolved oxygen, which are inadequate to accurately predict plant functionality (Bungay and Andrews, 1970, Olsson and Andrews, 1981). The five-day BOD test clearly takes too much time to be helpful in identifying problems in treatment. Even the chemical oxygen demand (COD) test, which can be completed in a few hours, is too long to wait to mediate an upset because the upset has already begun by the time the effluent COD spike is seen. Therefore, these tests fail as process control techniques. One simple way to 
use existing technology to improve process control is the use of the dissolved oxygen (DO) profile. The variations in DO along the length of the biological reactor comprise the DO profile. Monitoring this profile permits operators to reduce the energy used to aerate the tank and to estimate the oxygen uptake rate. Shifts in the uptake rate as an alteration in the respirometry response can signal process upset (Olsson and Andrews, 1981, Bergeron and Paice, 2001).

Most control systems use "feed-back" setups, in that data from the effluent determines if treatment is effective (Bungay and Andrews, 1970). In order to effectively control plant function, "feed-forward" control is necessary to alert operators to potential problems, which would link real-time on-line sensors to global control systems within the plant (Bungay and Andrews, 1970). The limitation on these control systems is the lack of real-time sensors for causative factors in process upset. Lab analyses of the components in the influent are time consuming and costly, particularly when the target compound is unknown. The use of biosensors to provide real-time feedback on toxicity or process conditions shows promise for improving process control in wastewater treatment.

\section{Immobilized cells as biological elements in biosensors}

A biosensor is generally defined as an analytical tool that pairs a biological component with a detection system to produce a measurable response, which can be quantified into the amount of analyte present in a sample (Belkin, 2003). The response is often measured electrochemicalyl or optically. The types of biological components that can be used are enzymes, antibodies, proteins, nucleic acids, or whole cells. Whole cells are less expensive to use because their components require no isolation and purification, as in the cell 
component assay systems. Also, whole cells provide information on the bioavailability of the toxins within the sample instead of simply reporting the concentration present. However, whole cells have a certain limited lifespan, require longer response times than isolated components, and may show significant variability between cell batches (Ramanathan, 2000).

\section{Reporter genes}

Much work to date with whole cell biosensors has focused on genetically engineering bacterial strains to elicit specific responses to particular compounds. Three types of reporter genes are typically used: lux, luc, and gfp. First, bacterial luciferase (lux) produces the oxyluciferin protein by combining the substrate luciferin with oxygen in the presence of the luciferase enzyme. The oxyluciferin product is in the excited state and produces a photon, which can be detected and used to quantify the response (Hastings, 1983). The yield of this reaction is low, only about 0.1 yield units, and it consumes reducing power, the precursor to ATP formation. Further, the reaction requires a substantial amount of oxygen to proceed, limiting its use to aerobic conditions only (Lewis et al., 1998). The lux gene was originally isolated from three bacterial species: Vibrio and Photobacterium, both marine, and Photoorhabdus, a terrestrial species (Keane et al., 2002). Second, firefly luciferase (luc) was isolated from the beetle Photinus pyralis and also produces oxyluciferin, but requires a twostep enzyme reaction and consumes ATP. This reaction has a yield of 0.88 (Lewis et al., 1998) and a wide linear range. However, the reaction only proceeds below $30^{\circ} \mathrm{C}$ (Keane et al., 2002), so it is less frequently used in bacterial work, as the cells typically require higher temperatures for optimal growth. Third, green fluorescent protein $(g f p)$ from the jellyfish Aequorea victoria requires a much smaller amount of oxygen than luc or lux and the light 
chromophore is directly incorporated within the crystal structure. Production of the response protein is much slower than the luciferase-based systems (Keane et al., 2002).

The selection of the reporter gene for a particular application is typically based on the desired time response of the reporter. Luciferase systems, in which the fluorescent proteins are broken down in a short time, are used for time-based assays in which repeated measurements are needed. Green fluorescent protein systems are best for single measurement studies where one yes or no answer is desired because hours are required to produce and properly fold the protein. Additionally, once generated, the fluorescent signal remains robust for much longer than the luciferase signals, resulting in a longer measuring window with a constant signal output (Keane et al., 2002).

Two methods exist for adding response genes to cells, which can be classified as "lights on" and "lights off", or induced and constitutive. Inserting the reporter gene into a general cell maintenance section of the genome will result in constant production of green fluorescence, while reduced intensity indicates some type of insult has occurred (Belkin, 2003). Alternately, the reporter can be linked with a promoter that regulates gene expression of a desired reporting characteristic, such as DNA repair. In this setup, an increase in light level functions as the indicator (Belkin, 2003).

\section{Genetically engineered strains in biosensors}

Several groups have used genetically modified strains to create biosensors specific to certain chemicals. A biosensor using Pseudomonas aeruginosa containing the lux operon to respond to polycyclic aromatic hydrocarbons (PAHs) was created by immobilizing the cells in poly(vinyl alcohol) (Philp et al., 2003), which showed good repeatability on standards but 
variable results on real samples. Also, E. coli, P. fluorescens, and P. putida with a lux reporter gene were used to construct a biosensor to respond to PAHs via bioluminescence (Reid et al., 1998) and, although real samples were not tested, the sensor showed a stable, linear, and dose-dependent response to standards. A heavy metal responsive plasmid was constructed using luc to respond with production of luciferase and inserted into Stapholococcus aureus and Bacillis subtilis (Taurianinen et al., 1998). This sensor responded within three hours to lab samples and responsitivity was not reduced by freezedrying the cells before use. Kohler et al. (2000) used E. coli modified with the lux operon to make a biosensor for detecting 4-chlorobenzoic acid by immobilizing cells in alginate in a microtiter plate, but more work was needed to optimize the system before real samples can be tested. Strains of Pseudomonas and Archromobacter were used to perform preliminary work towards creating a biosensor for surfactants using amperometric detection (Taranova et al. 2002). Gu and Choi (2002) used freeze-dried E. coli with a reporter bound to the phenol degradation pathway to create a biosensor for phenol detection in a complete portable fieldready kit. A range of phenols were tested with rapid, repeatable results, but no results from field samples were reported.

Hansen et al. (2000) used E. coli to create a biosensor for detecting mercury by fusing the $\mathrm{P}_{\text {mer, }}$, p promoter induced by $\mathrm{Hg}$, and the mer reporter gene for $\mathrm{Hg}$ to luxCDABE, lacZYA, and $g f p$. These constructs produce luminescence, beta-galactosidase, and green fluorescent protein, respectively. Each construct was cloned into a delivery vector to permit its insertion into any bacterial strain desired. P. aeruginosa was used as an example. Other groups (Ramanathan et al., 1997; Lyngberg et al., 1999; Rasmussen et al., 2000; Selifonova et al., 1993) had performed similar research with the mer reporter gene encoded on a plasmid, but 
mixed results were obtained because the plasmids were unstable. However, Petanen and Romantschuk (2002) used plasmids with a luc response to mercury and arsenite in $P$. fluorescens and obtained results comparable to traditional analytical methods, but much faster.

Howbrook et al. (2001) created a whole cell biosensor for glucose using E. coli with a luminescence reporter bound to the $k a t G$ gene, which is tightly controlled by the OxyR system such that it responds to oxidative stress. As proof of concept, the glucose oxidase enzyme was added to the sensor to produce $\mathrm{H}_{2} \mathrm{O}_{2}$ when glucose is present, thus creating oxidative stress within the cell to trigger the OxyR response system and initiating the lux reporter. Any such oxidase enzyme could be included to target sensor specificity for a wide variety of compounds. The assays were conducted in liquid culture with samples generated in the laboratory.

Creating a general response biosensor is typically approached by developing a panel of bacteria, each responsive to a different threat. Panels of E. coli bacteria were engineered to create sensors for heat shock, oxidative stress, and protein damage (Belkin et al., 1997), DNA damage (Belkin, 2003), oxidative damage, membrane damage, DNA damage, and protein damage (Kim and Gu, 2003), and heat shock, oxidative stress, fatty acids, peroxides, and genotoxicity (Premkumar et al., 2003). A lux-containing E. coli strain immobilized in poly (vinyl alcohol) (PVA) was used to create a slow release biosensor for general stress where the PVA matrix was dissolved using $\mathrm{KCl}$ over time so that new cells were being used for each toxicity test (Horsburgh et al., 2002). Biosensors for genotoxicants were created by inserting a lux reporter into the recA promoter region for DNA damage repair in E. coli. 
(Polyak et al., 1997; Belkin, 2003; Polyak, 2001). Elasri et al. (2000) created a similar sensor using $P$. aeruginosa.

Two well-known assays for genotoxicants and cytotoxicants are the SOS-Lux test and the Lac-Fluoro test. The SOS-Lux test was created by adding the lux reporter under the control of the SOS DNA damage repair system to identify genotoxicants. The Lac-Fluoro test uses constitutive expression of $g f p$, which is inserted to report cell maintenance function and to indicate cytotoxins. Decreases in fluorescence shows cytotoxicity, or impacts to cell metabolism and function (Baumstark-Khan et al., 2001).

The toxicity of heavy metals (chromium, zinc, copper, nikel, and arsenic) was evaluated using a microtiter plate setup and two strains of Salmonella typhimurion, one modified for the SOS-Lux and one for the Lac-Fluoro test (Rabbow et al., 2002). Improvements to the sensitivity of the SOS-Lux test were obtained by inserting the reporter plasmid into E. coli containing a tolC mutation, which made the membrane more permeable to hydrophobic substances. The sensitivity was further improved by using a S. typhimurion strain with a defect in the cell membrane, which again increases the membrane permeability (Rettberg et al., 2001). The SOS-Lux and the Lac-Fluoro tests developed by Rabbow et al. (2002) have been applied in practice on the international space station to determine toxicity of recycled water supplies on the station. A different sensor formulation with the similar genetic modifications has been used to determine the threat from radiation on the space station (Rabbow et al., 2003).

On the whole, genetically engineered strains used in biosensors have not been commercialized to a large degree. The difficulty in overcoming the genetically modified organism (GMO) regulations makes such sensors primarily useful only in laboratory settings, 
where the threat of accidental release is not applicable. Despite their advantages in terms of robust, repeatable responses, engineered strains have yet to be widely commercialized.

\section{Non-engineered strains}

One drawback of the majority of work to date is that most sensors employ genetically modified bacteria as the reporter. A notable exception is the commercial Microtox ${ }^{\circledR}$ assay, which uses naturally luminescent Vibrio fischerii bacteria. Non-engineered cells do not mandate such strict controls on release as those that have genetic modifications. While engineered cells may yield a more robust response, wild-type cells facilitate eventual commercialization of a sensor. Additionally, the use of indigenous wild type cells more accurately reflects the conditions under observation than the use of an engineered lab strain. Using wild-type cells means that the intrinsic cell processes must be harnessed to detect the compounds of interest or to determine if the cells are inhibited.

BOD sensors typically do not require genetic engineering to create a functional sensor since the concentration of oxygen in a sample can be easily monitored. These sensors are typically constructed using an immobilized bacterial culture contained between a dialysis membrane and a gas permeable membrane. The sample fluid diffuses through the dialysis membrane and passes through the culture where some of the oxygen in the sample is consumed. The amount of oxygen remaining in the sample is measured using a dissolved oxygen electrode placed above the gas permeable membrane. The respiration rate of the culture is calculated from the difference in oxygen concentrations between the amount in the sample initially and that detected by the electrode after exposure to the cells (Liu and Mattiasson 2002). Current work (Heim et al. 1999) has focused on combining two pure 
cultures to expand the limited range of compounds detected when one pure culture is used, or an ensemble of bacteria, which shows unstable response over time as different species dominate (Tan and $\mathrm{Wu}$ 1999). In general, these sensors are complicated to apply because the respiration rate shifts depending on the amount of substrate present in the sample. Adjusting for this variation, this type of BOD sensor has been shown to be as effective as the traditional five-day BOD test but with a response within minutes. However, the variability between sensors of the same construction is significant (Liu and Mattiasson 2002).

In addition to BOD sensors, amperometric biosensors have been developed that function by binding cells to a screen printed electrode to measure the transfer of electrons during substrate consumption. One example of this type of sensor was developed by Skladal et al (2002) to create a phenol sensitive biosensor. Pseudomonas strains were immobilized on a screen-printed electrode such that the uptake of phenol as a carbon and energy source by the cells can be detected by the electrode as electrons are transferred. The sensor showed a rapid, reproducible response. However, the sensing surface had to be prepared and used on the same day and the response varied depending on the ionic strength of the sample.

Natural products of cells can also be monitored to determine if they are inhibited. For example, Guven et al. (2003) created a bioassay for inhibition of enzyme biosynthesis to monitor the concentrations of two enzymes, one produced by E. coli and the other produced by Bacillus subtilis. Colorimetric tests were used to monitor beta-galactosidase synthesis in E coli, which is created during consumption of glucose and is metabolism related, and alphaamylase synthesis in B. subtilis, which is created during late log stage and is growth phase related. Changes in the concentrations of these enzymes indicated the presence of toxic compounds. The system worked very well for pesticides, the model organics tested, but was 
less repeatable with heavy metals. This type of assay takes much longer than an engineered "lights on" or "lights off" strain, because up to eight hours are required to determine if a decrease has occurred in the enzyme synthesis.

\section{Cell components in biosensors}

The use of cell components (purified enzymes) in biosensors is an attractive alternative to whole, living cells, which require a constant supply of nutrients and oxygen. These systems typically consist of the sensing element (enzyme) bound to an electrode such that the change in concentration of a product is converted into an electric signal monitored by a detector (reviewed in Karube and Nomura, 2000). An example of such a system was created by Moser et al. (2002) in which oxidase enzymes specific to glucose, lactate, glutamate, and glutamine were immobilized into a flow through microfluidic device. The response was rapid and repeatable and a single sensor could perform continuous monitoring of all four compounds of interest. However, isolation of the enzymes used in this type of sensor is costly and time consuming and enzymes alone are less stable than whole cells (Karube et al., 1995).

Using whole cells that have been killed provides a useful method of preserving the enzymes and eliminates the purification step. Tan and Zhenrong (1998) used thermally killed Bacillus subtilis cells immobilized in a membrane bound to the end of a DO probe to create a sensor for BOD. The BOD reported by the sensor correlated well with $\mathrm{BOD}_{5}$ assays performed on identical samples, with results available within half an hour. This type of biosensor functions by incorporating the active components necessary to catalyze the 
oxidation of carbon sources, specifically, enzymes and cofactors, but without including the difficult and time consuming step of isolating these enzymes from living cells.

\section{Microfluidic sensors}

These macroscale sensors using whole cells or cell components can be improved by miniaturization. Reducing the size of a sensor to the microscale to create microelectromechanical systems (MEMS) presents several advantages in sensing ability. Microsensors require much lower sample and analyte volumes, present a more rapid response than full-scale sensors, and can be made disposable because of the small size and volumes involved, thus creating a highly cost-effective analysis system. However, the robustness of these systems to harsh environments has not been proven and they have also been slow to commercialize.

Several groups have used microfluidic technology to create biosensors. One prominent example relavent to environmental engineering is the class of BOD sensors created by Yang et al. $(1996,1997)$, where whole cells were immobilized directly onto the surface of a microscale DO probe. The cells used were Trichosporon cutaneum, useful for BOD sensors because they consume a wide range of carbon sources, not a limited few compounds. In this way, they report a $\mathrm{BOD}$ closer to the $\mathrm{BOD}_{5}$ than what would be reported by a sensor using a strain such as Pseudomonas, which prefers to grow on acetate. With the sensor, this group was able to achieve sensor $\mathrm{BOD}$ to $\mathrm{BOD}_{5}$ ratios of 0.65 to 1.70 with real wastewater samples and a repeatability of plus or minus eight percent was reported. The response time was twenty minutes and the sensor was linear for a BOD range of 0.2 to 18 $\mathrm{mg} / \mathrm{L}$ BOD. Additionally, because it is on the microscale, the device is smaller and easy to 
handle. Such a sensor would be useful to indicate spikes in influent and effluent BOD; for such an application, the limited precision of the device is less of a factor because the purpose of the sensor is to provide nearly real-time monitoring, not reportable BOD values.

In addition to whole cells, enzymes are commonly used within the microscale sensors as reporters for the presence of certain compounds. Zhan et al. (2002) immobilized a pH reporting dye and enzymes to catalyze specific reactions in a microreactor within a microfluidic channel array to create a biosensor for potentially any compound of interest. Adding the correct enzymes created a pH shift, reported by the dye, and the magnitude of the shift correlated to the concentration of the analyte that reacted with the enzymes. Moser $e t$ al. (2002) created a bio-MEMS using enzymes bound within a flow channel with electrodes to report changes in current as the enzymes reacted with the species of interest, which were glucose, lactate, glutamate, and glutamine. Petrou et al. $(2002,2003)$ created a bio-MEMS sensor for glucose and lactate by immobilizing enzymes in a microchannel and measuring the response with a dialysis probe made of polyacrilonitrile fiber. Zimmerman et al. (2003) created a flow-through glucose sensor by immobilizing glucose oxidase enzyme in polyvinyl alcohol (PVA) polymerized by UV light within a microfluidic system. Due to high fabrication temperatures associated with the anodic bonding between wafer sheets, it was important that the enzymes were immobilized in situ after device fabrication.

These types of sensors were designed for medical applications, such as monitoring the concentrations of sugars in blood samples. Although the concept could be modified for application in environmental engineering processes by changing the enzymes used in the sensors, this design is less useful for general monitoring. Such sensors are primarily useful for monitoring the concentration of a few known compounds, and so could be applied to 
sensing compounds known to be present in environmental samples. However, such sensors do not address the need for monitoring a wide range of toxic compounds.

\section{Immobilization Matrices}

The immobilization of cells within a microfluidic sensor is critical to the functionality of the system. Using a biofilm of cells adhered to the bottom of the flow channel is likely to be unstable, as cells and chunks of film can slough off with time and foul the detector or clog the channel. Immobilizing cells within hydrogels prevents sloughing, provides some degree of protection for the cells, and exposes the cells to an environment similar to that within a biofilm (Junter et al., 2002). There are two primary types of hydrogels, those that are chemically polymerizable and those that are photopolymerizable.

Chemically polymerized hydrogels, such as sodium alginate, are useful for macroscale work by forming beads from the gel precursor solution (Drury et al., 2004). However, downsizing the bead to microscale may prove difficult to form. Therefore, photopolymerized polymers are typically used for microfluidic applications because they can easily be formed into a variety of shapes in situ by using various photomasks to control what areas of the polymer precursor are polymerized. First, Beebe et al. (2000) created various shapes of hydrogels by polymerizing acrylic acid and methacrylate in situ in a microchannel, showing the ease of handling with the photopolymer. Further, this group used $\mathrm{pH}$-sensitive polymers to control flow within a microfluidic channel matrix by placing polymers of varying compositions at critical points in the flow matrix such that shifts in $\mathrm{pH}$ would cause expansion or contraction of the polymer patch and, thus, either allow or block flow through particular regions of the channels. This passive method of flow control simplifies 
microfluidic componentry, but for biological systems, the $\mathrm{pH}$ extremes required to change the flow regime would prove detrimental to the cells in the system. Moving from flow control to the development of a reporting system, Zhan et al. (2002) immobilized the glucose oxidase enzyme within several micropatches in a microfluidic device. The device reported the concentration of glucose by shifts in the intensity of the reporter dye co-immobilized with the enzyme. This sensor would be used for medical applications, but still shows the usefulness of the photopolymer in microfluidic work.

Enzymes as well as viable cells have been immobilized within photopolymers. Koh et al. (2002) encapsulated mammalian cells within polyethylene glycol (PEG) diacrylate (PEG-DA) with Darocure 1173 as the photoinitiator polymerized with UV light. Cells were viable up to a week after polymerization based on observations using the LIVE/DEAD viability/cytotoxicity fluorescence staining. This application was for tissue engineering and not biosensor development. However, Heo et al. (2003) immobilized E. coli cells in PEGDA within a microfluidic channel constructed of polydimethylsiloxane (PDMS) using photopolymerized micropatches of gel spanning the height of the channel, but not the width, to permit flow around the edges of the hydrogels. The authors attempted to prove cell viability using LIVE/DEAD staining and 2', 7'-bis-(2-carboxyethyl)-5-(and-6)carboxyfluorescein (BCECF-AM) staining. The LIVE/DEAD stain was ineffective because the hydrogel fluoresced strongly green, so live cells could not be observed above the background fluorescence. Additionally, the BCECF-AM stain indicated enzyme activity, not true viability, because enzymes remain active after a cell is no longer considered viable. This work did not develop a field-deployable sensor with the photopolymer, but simply tried to prove viability within the matrix. 
One difficulty associated with the photopolymerizable systems is mixing the cells with the gel precursor solution because the components are highly viscous and the shear stresses on the cells during mixing may increase cell mortality. Modifications to the gel structure have been undertaken in an attempt to create a low molecular weight hydrogel based on alginate. Kong et al. (2003) created different molecular weight alginates by irradiation and the viscosity of each was measured by shear stress and shear rate. Results showed that higher radiation doses reduced the molecular weight most significantly, but doses in the mid-range of those tested made the gels stiffer because only the flexible connectors of the gel matrix broke during radiation, leaving the strong bonds intact. At low doses, no change in stiffness was observed. Osteoblasts were mixed with the gels before polymerization. The lower molecular weight gels resulted in greatly improved viability as measured visually by microscopy using the Trypan blue stain, which cannot enter cells with intact membranes, but stains the nuclei of cells with compromised membranes.

Overall, the photopolymerizable system is preferable for microfluidic work because it can be formed into a variety of shapes by changing the photomask prior to polymerization. Photopolymerizable polymers have been used to successfully immobilize both eukaryotic and prokaryotic cells, as well as to immobilize enzymes for the creation of a sensor. However, the major challenges that users of photopolymerizable polymers face are the toxicity of the polymer components and the difficulty visualizing cells within the polymer microscopically, because the polymer tends to absorb stains such as the green stain of the LIVE/DEAD package. 


\section{Scope of Research}

Based on this review of biosensors developed previously, it is clear that the need for a non-engineered bacterial sensor for a range of toxic compounds has not yet been addressed. Many groups have created compound-specific sensors using both whole cells as well as purified enzymes, but no general stress response sensor has been developed yet. Microtox ${ }^{\circledR}$ uses a non-engineered strain, but quantifies toxicity, not stress. In wastewater treatment, electrophilic stress results in process upset and reduced treatment capacity. To reduce instances of process upset, a sensor that responds to electrophilic insult quantified by monitoring the intrinsic stress response of the immobilized cells, not by engineering a known response into the cells, can be developed.

The objective of this work is to evaluate the performance of an immobilized bacterial culture that will comprise the biological sensing element within a biosensor for detecting electrophilic compounds based on activation of the GGKE mechanism. The biosensor will consist of bacterial cells immobilized in a hydrogel matrix in a microfluidic flow through setup. In its ultimate application, the biosensor will direct water to be monitored over the immobilized cells. Any electrophilic toxins in the flow will trigger potassium efflux from the cells. The potassium concentration will be measured using an ion-selective film (Kopelman et al., 1997) over which the flow will pass both before and after contacting the cells. The change in potassium will be monitored and, if efflux is indicated, the device will implicate the presence of electrophilic toxins. For wastewater treatment applications, electrophilic toxins have been linked to deflocculation and, thus, to process upset. A positive response by the sensor would give plant operators early warning of process upset potential in the influent so that the toxic slug could be rerouted to storage and slowly fed in for treatment to avoid 
upset. For surface, ground, or drinking water applications, many chemical agents that could be used to threaten homeland security are classified as electrophiles, such as nerve agents, and could be effectively sensed. On the whole, the sensor under development would improve process stability at wastewater plants and improve confidence in water supply at drinking water plants.

To determine the feasibility of a biosensor based on the intrinsic potassium efflux stress response, the potassium efflux potential of polymer-immobilized bacterial culture was evaluated experimentally by comparing to non-immobilized planktonic cultures. Furthermore, a model was developed to determine of the number of cells needed to efflux detectable levels of potassium, while estimating the oxygen requirement for these cells to determine if oxygen would be limiting within the system. Three matrices, alginate, a photopolymerizable polymer, and a thermally reversible gel, were evaluated as possible hydrogels for immobilization. Both the viability and the potassium efflux from immobilized cells were elucidated. This work will become the basis for the incorporation of the immobilized cells into the microfluidic device. 


\section{References}

Apontoweil, P. and W. Berends. (1975a) Glutathione biosythesis in Escherichi coli K-12: properties of the enzymes and regulation. Biochimica et Biophysica Acta 399 (1), 1-9

Apontoweil, P. and W. Berends. (1975b) Isolation and initial characterization of Glutathionedeficient mutants of Escherichia coli K-12. Biochimica et Biophysica Acta. 399 (1), 10-22

Baumstark-Khan, Christa, Angela Rode, Petra Rettberg, and Gerda Horneck. (2001) Application of the Lux-Fluoro test as bioassay for combined genotoxicity and cytotoxicity measurements by means of recombinant Salmonella typhimurium TA1535 cells. Analytica Chimica Acta 437, 23-30

Baumstark-Khan, Christa, Riaz A. Khan, Petra Rettberg, and Gerda Horneck. (2003) Bacterial Lux-Fluoro test for biological assessment of pollutants in water samples from urban and rural origin. Analytica Chimica Acta 487, 51-60

Booth, Ian R., R.M. Douglas, G.P. Ferguson, A.J. Lamb, A.W. Munro, and G.Y. Ritchie. (1993) Chapter 11E: $\mathrm{K}^{+}$Efflux systems. Bakker, Evert P., Editor. Alkali Cation Transport Systems in Prokaryotes. Boca Raton, Florida: CRC Press, Inc. (291-308)

Bott, Charles B., and Nancy G. Love. (In Press) Implicating the Glutathione-Gated Potassium Efflux System as a Cause of Electrophile-Induced Activated Sludge Deflocculation. Applied and Environmental Microbiology

Bott, Charles B., and Nancy G. Love. (2002) Investigating a mechanistic cause for activated-sludge deflocculation in response to shock loads of toxic electrophilic chemicals. Water Environment Research (74) 3, 306-315

Beebe, David J., Jeffrey S. Moore, Joseph M. Bauer, Qing Yu, Robin H. Liu, Chelladural Devadoss, and Byung-Ho Jo. (2000) Functional hydrogel structures for autonomous flow control inside microfluidic channels. Letters to Nature 404 588-590

Belkin, Shimshon. (2003) Microbial whole-cell sensing systems of environmental pollutants. Current Opinion in Microbiology 6 206-212.

Belkin, Shimshon, Dana R. Smulski, Sara Dadon, Amy C. Vollmer, Tina K. Van Dyk, and Robert A. Larossa. A panel of stress-responsive luminous bacteria for the detection of selected classes of toxicants. (1997) Water Research (31) 12, 3009-3016

Bergeron, J., M. Paice. (2001) Monitoring of Activated Sludge Systems Using a Combination of Specific Oxygen Uptake Rates and Specific Adenosine Triphosphate Measurements. Water Qual. Res. J. Can. (36) 4, 659-685 
Bott, Charles B. and Nancy G. Love. (2002) Investigating a mechanistic cause for activatedsludge deflocculation in response to shock loads of toxic electrophilic chemicals. Water Environment Research (74) 3, 306-315

Bungay, HR and JF Andrews. (1970) Dynamics of microbial processes. Water and Sewage Works (117) 3, p 77-80

Demple, Bruce. (1996) Redox signaling and gene control in the Escherichia coli soxRS oxidative stress regulon-a review. Gene 179, 53-57.

Dieu, Ba. (2001) Application of the SCADA system in wastewater treatment plants. ISA Transactions 40, 267-281

Ding, H.G. and Demple, B. (1997) In vivo kinetics of a redox-regulated transcriptional switch. Proc. Natl. Acad. Sci. U.S.A. 94, 8445-8449

Drury, Jeanie L., Robert G. Dennis, David J. Mooney. (2004) The tensile properties of alginate hydrogels. Biomaterials 24, 3187-3199

Elasri, Mohamed O., Tricia Reid, Steven Hutchens, Robert V. Miller. (2000) Response of a Pseudomonas aeruginosa biofilm community to DNA-damaging chemical agents. FEMS Microbiology Ecology 33, 21-25

Elmore, J.J., A.J. Lamb, G.Y. Ritchie, R.M. Douglas, A.W. Munro, A. Gajewska, and I.R. Booth. (1990) Activation of potassium efflux from Escherichia coli by glutathione metabolites. Molecular Microbiology. 4(3) 405-412

Ferguson, Gail P., John R. Battista, Annettee T. Lee, and Ian R. Booth. (2000) Protection of the DNA during the exposure of Escherichia coli cells to a toxic metabolite: the role of the KefB and KefC potassium channels. Molecular Microbiology 35(1), 113-122

Ferguson, Gail, P. D. McLaggan, and I.R. Booth. (1995) Potassium channel activation by glutathione-S-conjugates in Escherichia coli. Moecular Microbiology 17(6), 1025-1033

Ferguson, Gail P., A.W. Munro, R.M. Douglas, D. McLaggan, and I.R. Booth. (1993) Activation of potassium channels during metabolic detoxifiction in Escherichia coli. Molecular Microbiology. 9(6) 1297-1303

Gu, Man Bock, and Sue Hyung Choi. (2002) A portable toxicity biosensor using freezedried recombinant bioluminescent bacteria. Biosensor and Bioelectronics 17 433-440

Guven, Kemal, Songul Togrul, Fikret Uyar, Sifa Ozant, David I. De Pomerai. (2003) A comparative study of bioassays based on enzyme biosynthesis in Escherichia coli and Bacillus subtilis exposed to heavy metals and organic pesticides. Enzyme and Microbial Technology 32, 658-664 
Hansen, Lars Hestbjerg and Soren Johannes Sorensen. (2000) Versatile biosensor vectors for detection and quantification of mercury. FEMS Microbiology Letters 193, 123-127.

Hastins, J.W. (1983) Biological diversity, chemical mechanisms, and the evolutionary origins of bioluminescent system. J. Mol. Evol. 19, 309-321

Heim S, Schnieder I, Binz D, Vogel A, Bilitewski U. (1999) Development of an automated microbial sensor system. Biosens Bioelectron 14, 187-93.

Heo, Jinseok, K. Joseph Thomas, Gi Hun Seong, and Richard M. Crooks. (2003) A microfluidic bioreactor based on hydrogel-entrapped E. coli: cell viability, lysis, and intracellular reactions. Anal. Chem.

Higgins, M.J. and Novak, J.T. (1997a) Dewatering and settling of activated sludges: The case for using cation analysis. Water Environment Research 69 (2), 225-232

Higgins, M.J. and Novak, J.T. (1997b) The effect of cations on the settling and dewatering of activated sludges: Laboratory results. Water Environment Research 69 (2), 215-224

Horsburgh, Alison M., D.P. Mardlin, N.L. Turner, R. Henkler, N. Strachan, L.A. Glover, G.I. Paton, K. Kilham. (2002) On-line microbial biosensing and fingerprinting of water pollutants. Biosensors and bioelectronics 17, 495-501

Howbrook, D. N., J.M. Lynch, N.J. Bainton. (2001) An oxidative stress-responsive biosensor: responses to hydrogen peroxide generated by an extracellular enzyme. Enzyme and Microbial Technology 29, 521-526

Junter, GA, I Coquet, S Vilain, T Jouenne. (2002) Immobilized-cell physiology: current data and the potentialities of proteomics. Enzyme Microb Technol 31, 201-212

Kalapos, M.P. (1999) Methylglyoxal in living organisms chemistry, biochemistry, toxicology and biological implications. Toxicology Letters 110 145-175.

Karube, Isao, and Yoko Nomura. (2000) Enzyme sensors for environmental samples. Journal of Molecular Catalysis B: Enzymatic 10, 177-181

Karube, Isao, Yoko Nomura, and Yoshiko Arikawa. (1995) Biosensor for environmental control. Trends in Analytical Chemistry. 14 (7), 295-299

Keane, Angela, Pauline Phoenix, Subhasis Ghoshal, Peter C.K. Lau. (2002) Exposing culprit organic pollutants: A review. Journal of Microbiological Methods 49, 103-119

Kim, Byoung Chan, and Man Bock Gu. (2003) A bioluminescent sensor for high throughput toxicity classification. Biosensors and Bioelectyronics 18, 1015-1021

Koh, Won-Gun, Alexander Revzin, and Michael V. Pishko. (2002) Poly(ethylene glycol) hydrogel microstructures encapsulating living cells. Langmuir 18, 2459-2462. 
Kohler, Sabine, Till T. Bachmann, Jutta Schmitt, Shimshon Belkin, Rolf D. Schmid. (2000) Detection of 4-chlorobenzoate using immobilized recombinant Escherichia coli reporter strains. Sensors and Actuators B 70, 139-144.

Kong, Hun Joon, Molly K. Smith, and David J. Mooney. (2003) Designing alginate hydrogels to maintain viability of immobilized cells. Biomaterials 24, 4023-4029

Kopelman, Raoul, Michael Shortreed, and Sunil Dourado. (1997) Development of a fluorescent optical potassium-selective ion sensor with ratiometric response for intracellular applications. Sensors and Actuators B 38-39 8-12

Lewis, J.C., A. Feltus, C.M. Ensor, S. Ramanathan, S. Daunert. (1998) Applications of reporter genes. Anal. Chem. 70, 579A-585A

Liu, Jing and Bo Mattiasson. (2002) Microbial BOD sensors for wastewater analysis. Water Research 36, 3786-3802

Love, Nancy G. and C.B. Bott. WERF Project 99-WWF-2 Report: A review of and needs survey of upset early warning devices. Water Environment Research Foundation (2000)

Lyngberg, O.K., Stemke, D.J., Schottel, J.L. and Flickinger, M.C. (1999) A single-use luciferase-based mercury biosensor using Escherichia coli HB101 immobilized in a latex copolymer film. J. Ind. Microbiol. Biotechnol. 23 668-676.

Munro, Andrew W., G.Y. Ritchie, A.J. Lamb, R.M. Douglas, and Ir. R. Booth. (1991) The cloning and DNA sequence of the gene for the glutathione-regulated potassium efflux system KefC of Escherichia coli. Molecular Microbiology. 5(3) 607-616

Murthy, SN, JT Novak, RD De Haas. (1998) Monitoring cations to predict and improve activated sludge settling and dewatering properties of industrial wastewaters. Water Science and Technology. 38 (3), 119-126

Moser, Isabella, Gerhard Jobst, and Gerald A. Urban. (2002) Biosensor arrays for simultaneous measurement of glucose, lactate, glutamate, and glutamine. Biosensors \& Bioelectronics 17, 297-302.

Ness, L.S., Ferguson, G.P., Nikolaev, Y., and Booth, I.R. (1997) Survival of Escherichia coli cells exposed to iodoacetate and chlorodinitrobenzene is independent of the glutathione-gated $\mathrm{K}+$ efflux systems KefB and KefC. Applied and Environmental Microbiology 63 (10), 40834086.

Olsson G. and J.F. Andrews. (1981) Dissolved Oxygen Control in the Activated Sludge Process. Water Science and Technology 13 (10), 341-347 
Petanen, Tiina and Martin Romantschuk. (2002) Use of bioluminescent bacterial sensors as an alternative method for measuring heavy metals in soil extracts. Analytica Chimica Acta 456, 55-61

Petrou, P.S., I. Moser, G. Jobst. (2002) BioMEMS device with integrated microdialysis probe and biosensor array. Biosensors and Bioelectronics 17, 859- 865

Petrou, P.S., I. Moser, G. Jobst. (2003) Microdevice with integrated dialysis probe and biosensor array for continuous multi-analyte monitoring. Biosensors and Bioelectronics 18, 613- 619

Philp, Jim C., Severine Balmand, Eva Hajto, Mark J. Bailey, Siouxsi Wiles, Andrew S. Whiteley, Andrew K. Lilley, Janos Hajto, and Sandra A. Dunbar. (2003) Whole cell immobilized biosensor for toxicity assessment of a wastewater treatment plant treating phenolics-containing waste. Analytica Chimica Acta

Polyak, B., E. Bassis, A. Novodvorets, S. Belkin, and R.S. Marks. (1997) Optical fiber bioluminescent whole-cell microbial biosensors to genotoxicants. Water Science and Technology 42 (1-2), 305-311

Polyak, Boris S., Efim Bassis, Alex Novodvorets, Shimshon Belkin, Robert S. Marks. (2001) Bioluminescent whole cell optical fiber sensor to genotoxicants: system optimization. Sensors and Actuators B 74, 18-26

Pomposiello, Pablo J and Bruce Demple. (2001) Redox operated genetic switches: the SoxR and OxyR transcription factors. Trends in Biotechnology 19 (3), 109-114

Premkumar, J. Rajan, Rachel Rosen, Shimshon Belkin, and Ovadia Lev. (2002) Sol-gel luminescence biosensors: Encapsulation of recombinant E. coli reporters in thick silicate films. Analytica Chimica Acta 462, 11-23

Rabbow, Elke, Petra Rettberg, Christa Baumstark-Khan, and Gerda Horneck. (2002) SOS$L U X$ - and LAC-FLUORO-TEST for the quantification of genotoxic and/or cytotoxic effects of heavy metal salts. Analytica Chimica Acta 456, 31-39

Rabbow, E., P. Rettberg, C. Baumstark-Khan, G. Homeck. (2003) The SOS-LUX-LACFLUORO toxicity test on the international space station (ISS). Adv. Space Res. 31(6) 15131524

Ramanathan, S., M. Ensor, and S. Daunert. (1997) Bacterial biosensors for monitoring toxic metals. Trends Biotechnol. 15, 500-506

Rasmussen, L.D., S.J. Strensen, R.R. Turner, and T. Barkay. (2000) Application of a merlux biosensor for estimating bioavailable mercury in soil. Soil Biol. Biochem. 32, 639-646 
Reid, Brian J., Kirk T. Semple, Christopher J. Macleod, Jedda J. Weitz, Graeme I. Paton. (1998) Feasibility of using prokaryote biosensors to assess acute toxicity of polycyclic aromatic hydrocarbons. FEMS Microbiology Letters 169, 227-233

Rettberg, P., K. Bandel, C. Baumstark-Khan, and G. Horneck. (2001) Increased sensitivity of the SOS-LUX-Test for the detection of hydrophobic genotoxic substances with Salmonella typhimurium TA1535 as host strain. Analytica Chimica Acta 426, 167-173

Selifonova, O., R. Burlage, and T. Barkay. (1993) Bioluminescent sensors for detection of bioavailable mercury(II) in the environment. Appl. Environ. Microbiol. 59, 3083-3090

Skladal, Petr, Natalya O. Morozova, and Anatoly N. Reshetilov. (2002) Amperometric biosensors for detection of phenol using chemically modified electrodes containing immobilized bacteria. Biosensors and Bioelectronics 17, 867-873

Storz, Gisela and James A Imlay. (1999) Oxidative stress. Current Opinion in Microbiology 2, 188-194

Strachan, Gillian, Sara Preston, Helena Maciel, Andrew J. R. Porter, and Graeme I. Paton. (2001) Use of bacterial biosensors to interpret the toxicity and mixture toxicity of herbicides in freshwater. Wat. Res. 35 (14), 3490-3495

Tan, T.C., F. Li, K.G. Neoh, Y.K. Lee. (1992) Microbial membrane modified dissolved oxygen probe for rapid biochemical oxygen demand measurement. Sens Actuators B 8, 167172.

Tan, T. C. and Quan Zhenrong. (1998) Response characteristics of a dead-cell BOD sensor. Water Research 32 (3), 801-807

Tan, T.C., and C. Wu. (1999) BOD sensors using multi-species living or thermally killed cells of a BODSEED microbial culture. Sens Acutators B 54, 252-260.

Taranova, L., I. Semenchuk, T. Manolov, P. Iliasov, and A. Reshetilov. (2002) Bacteriadegraders as the base of an amperometric biosensor for detection of anionic surfactants. Biosensors and Bioelectronics 17, 635- 640

Taurianinen, Sisko, Matti Karp, Wei Chang, and Marko Virta. (1998) Luminescent bacterial sensor for cadmium and lead. Biosensor and Bioelectronics 13, 931-938

Yang, Z., H. Suzuki, S. Sasaki, I. Karube. (1996) Disposable sensor for biochemical oxygen demand. Appl Microbiol Biotechnol 46 (1), 10-14.

Yang, Z., H. Suzuki, S. Sasaki, S. McNiven, I. Karube. (1997) Comparison of the dynamic transient- and steady-state measuringmethods in a batch type BOD sensing system. Sens Acutators B 45, 217-222. 
Zhan, Wei, Gi Hun Seong, and Richard M. Crooks. (2002) Hydrogel-based microreactors as a functional component of microfluidic systems. Anal Chem 74, 4647-4652

Zheng, M., Aslund F, Storz G. (1998) Activation of the OxyR transcription factor by reversible disulfide bond formation. Science 279, 1718-1721

Zheng, Ming and Gisela Storz. (2000) Redox sensing by prokaryotic transcription factors. Biochemical Pharmacology 59, 1-6

Zimmerman, Stefan, Doerte Feinbork, Albert W. Flounders, and Dorian Liepmann. (2003) In-device enzyme immobilization: wafer-level fabrication of an integrated glucose sensor. Sensors and Actuators B 99(1), 163-173 


\title{
Evaluating strategies for integrating bacterial cells into a biosensor designed to detect process upset Part A: viability and activity
}

\author{
K. Linares*, D. Fleming**, Y. Xu***, N. Love*, B. Love**, K. Meehan*** \\ Departments of *Civil \& Environmental Engineering, **Materials Science and Engineering, \\ and *** Electrical and Computer Engineering, Virginia Tech, Blacksburg, VA 24061 \\ Planned for submission to Sensors and Actuators B
}

\begin{abstract}
The biological element of a biosensor to predict process upset in wastewater treatment plants is characterized. The bacterial culture was immobilized in a range of hydrogel polymers: a calcium alginate, a series of photopolymerizable polymers, and a thermally-reversible gel. Oxygen uptake rates and LIVE/DEAD staining were used to determine the activity and viability of the immobilized cultures. The alginate showed good viability, but poor mechanical stability in that the matrix dissolved after five days. The photopolymerizable polymers resulted in high mortality, although the matrix remained stable. The thermal polymer showed extended viability up to 12 days after immobilization, and the material did not deteriorate with time.
\end{abstract}

\section{Introduction}

Biosensors show promise for real time monitoring of toxicity in environmental samples. A biosensor is generally defined as an analytical tool that pairs a biological element with a detection system to produce a measurable response, which can be quantified into the amount of analyte present in a sample (Belkin, 2003). The response is typically measured by electrochemical or optical means. Biological elements are typically enzymes, antibodies, proteins, nucleic acids, or whole cells (Belkin, 2003). Whole cells have a certain limited lifespan, have longer response times than isolated components, and may show significant variability between cell batches (Ramanathan et al., 2000). On the other hand, whole cells are less expensive to use because their components require no isolation and purification as in the cell component assay systems. Also, whole cells provide information on the bioavailability of toxins being monitored instead of simply reporting the concentration present. Overall, whole cell biological elements provide a means to monitor more elaborate biological responses than biosensors based on in vitro biochemical responses. 
For general environmental monitoring, many compounds may be responsible for the toxicity of a sample, and so development of sensors that indicate many different toxic compounds are required. Creating a general response biosensor is typically approached by developing a panel of bacteria, each responsive to a different threat. Panels of E. coli bacteria were engineered to create sensors for heat shock, oxidative stress, and protein damage (Belkin et al., 1997), DNA damage (Belkin, 2003), and oxidative damage, membrane damage, DNA damage, and protein damage (Kim and Gu, 2003). A field-ready biological element was developed by Premkumar et al. (2003), who immobilized bacteria that were engineered to report on heat shock, oxidative stress, fatty acids, peroxides, and genotoxicity in thick silicate films, which maintained viability and activity for over a month (Premkumar et al., 2003).

On the whole, genetically engineered strains used in biosensors have not been commercialized to a large degree. The difficulty in overcoming the genetically modified organism (GMO) regulations makes such sensors primarily useful only in laboratory settings, where the threat of accidental release is minimized. Despite their advantages in terms of robust, repeatable responses, engineered strains have yet to be widely commercialized.

Non-engineered cells do not mandate such strict controls on release as those that have genetic modifications. While engineered cells may yield a more robust response, wild-type cells facilitate eventual commercialization of a sensor, exemplified by the Microtox ${ }^{\circledR}$ assay, which uses naturally luminescent Vibrio fischerii bacteria. Additionally, the use of indigenous, wild-type cells may more accurately reflect the conditions under observation than the use of an engineered lab strain. Using wild-type cells means the intrinsic cell 
processes must be harnessed to detect the compounds of interest or determine if the cells are inhibited.

The purpose of this work was to explore strategies for immobilizing non-engineered bacterial cells for inclusion into a biosensor designed to predict process upset in wastewater treatment plants. Process upset is commonly characterized by such symptoms as ineffective biological oxygen demand (BOD) removal, ineffective nitrification, deflocculation, and sludge bulking (Love and Bott, 2000). These process effects observed during an upset event result in poor treatment and possibly permit violations. Developing a biosensor based on the natural cell physiological response to chemical insult would give an early warning that toxic chemicals were present. This warning would significantly benefit wastewater treatment operations by allowing operators time to respond to the approaching threat, and could also clarify the type of operational adjustment needed to prevent or remediate treatment process damage.

For this study, bacterial cells were immobilized in a range of polymer matrices and cell viability and activity was assessed. Immobilization of the bacterial cells was important because it keeps the cell concentration relatively constant by maintaining cell viability while reducing cell division. Additionally, immobilized cells cannot slough off as a biofilm layer and clog downstream channels in the device. Such clogging is particularly problematic if a liquid microfluidic conveyance system is used. Chemically polymerized hydrogels, such as sodium alginate, are useful for macroscale work and form beads from the gel precursor solution (Drury et al., 2004). Photopolymerized polymers have also been used for microfluidic applications because they can easily be formed into a variety of shapes in situ by using various photomasks to control the areas of the precursor that are polymerized (Beebe et 
al., 2000; Heo et al., 2003). Further, viable cells have been immobilized within photopolymers. One type of photopolymer, polyethylene glycol (PEG) diacrylate (PEG-DA) with Darocure 1173 as the photoinitiator polymerized with UV light, has been used to immobilize E. coli cells (Heo et al., 2003) within a microfluidic channel constructed of polydimethylsiloxane (PDMS). The authors attempted to prove cell viability using LIVE/DEAD staining, but found the stain ineffective because the hydrogel fluoresced strongly green, so live cells could not be observed above the background fluorescence. Overall, photopolymers have been used for cell immobilization because it is easy to form them into a variety of shapes in situ, while the alginate is suited only for macroscale applications because the ability to control the shape of the polymerized product is limited.

In the current work, a set of three polymers was investigated for use as the immobilization matrix in the biological element of the biosensor: a calcium alginate, a series of photopolymerizable polymers, and a thermally-reversible gel. The specific goals of the work were to evaluate viability and activity of immobilized cells to determine a preferred matrix for further study of detectable physiological responses to chemical perturbations.

\section{Materials and Methods}

\subsection{Bacterial culturing}

\subsubsection{Growth conditions}

Pseudomonas aeruginosa was isolated previously from a local wastewater treatment plant and was grown in a mineral salt medium denoted PA M9. This medium consisted of $\mathrm{NaH}_{2} \mathrm{PO}_{4}, 3.0 \mathrm{~g} ; \mathrm{Na}_{2} \mathrm{HPO}_{4} * 7 \mathrm{H}_{2} \mathrm{O}, 6.0 \mathrm{~g} ; \mathrm{NH}_{4} \mathrm{Cl}, 1.0 \mathrm{~g} ; \mathrm{NaCl}, 0.50 \mathrm{~g} ; \mathrm{MgSO}_{4}{ }^{2-*} 7 \mathrm{H}_{2} \mathrm{O}, 0.246$ $\mathrm{g} ; \mathrm{CaCl}_{2}, 0.0147 \mathrm{~g} ; \mathrm{FeSO}_{4} * 7 \mathrm{H}_{2} \mathrm{O}, 2.5 \mathrm{mg} ; \mathrm{ZnCl}_{2}, 0.25 \mathrm{mg} ; \mathrm{MnSO}_{4} * \mathrm{H} 2 \mathrm{O}, 0.185 \mathrm{mg} ; \mathrm{CuSO}_{4}$,

$0.030 \mathrm{mg} ; \mathrm{NaMoO}_{4} * 2 \mathrm{H}_{2} \mathrm{O}, 0.006 \mathrm{mg} ; \mathrm{CoCl}_{2} * 6 \mathrm{H}_{2} \mathrm{O}, 0.001 \mathrm{mg} ; \mathrm{H}_{3} \mathrm{BO}_{3}, 0.03 \mathrm{mg}$; glacial 
acetic acid, $0.89 \mathrm{~mL}$ per liter solution. A second medium denoted PA BT was used to improve alginate stability when it was the immobilizing hydrogel. The PA BT media consisted of: $\mathrm{NaH}_{2} \mathrm{PO}_{4}, 0.3 \mathrm{~g} ; \mathrm{Na}_{2} \mathrm{HPO}_{4} * 7 \mathrm{H}_{2} \mathrm{O}, 0.6 \mathrm{~g} ; \mathrm{NH}_{4} \mathrm{Cl}, 0.1 \mathrm{~g} ; \mathrm{NaCl}, 0.05 \mathrm{~g}$; Bis Tris, $1.0 \mathrm{~g} ; \mathrm{MgSO}_{4}{ }^{2-} * 7 \mathrm{H}_{2} \mathrm{O}, 0.246 \mathrm{~g} ; \mathrm{CaCl}_{2}, 0.0147 \mathrm{~g} ; \mathrm{FeSO}_{4} * 7 \mathrm{H}_{2} \mathrm{O}, 2.5 \mathrm{mg} ; \mathrm{ZnCl}_{2}, 0.25 \mathrm{mg}$; $\mathrm{MnSO}_{4} * \mathrm{H} 2 \mathrm{O}, 0.185 \mathrm{mg} ; \mathrm{CuSO}_{4}, 0.030 \mathrm{mg} ; \mathrm{NaMoO}_{4} * 2 \mathrm{H}_{2} \mathrm{O}, 0.006 \mathrm{mg} ; \mathrm{CoCl}_{2} * 6 \mathrm{H}_{2} \mathrm{O}$, $0.001 \mathrm{mg} ; \mathrm{H}_{3} \mathrm{BO}_{3}, 0.03 \mathrm{mg}$; and glacial acetic acid, $0.89 \mathrm{~mL}$ per liter solution. After preparing media but before autoclaving, the $\mathrm{pH}$ was adjusted to $7.0 \mathrm{using} 50 \% \mathrm{w} / \mathrm{v} \mathrm{NaOH}$ (approximately $3 \mathrm{~mL}$ per liter PA M9 media, and about $4.5 \mathrm{~mL}$ per liter PA BT media).

Escherichia coli strain K-12, ATCC 29947, was grown on mineral salt medium M9. This media consisted of $\mathrm{NaH}_{2} \mathrm{PO}_{4}, 3.0 \mathrm{~g} ; \mathrm{Na}_{2} \mathrm{HPO}_{4} * 7 \mathrm{H}_{2} \mathrm{O}, 6.0 \mathrm{~g} ; \mathrm{NH}_{4} \mathrm{Cl}, 1.0 \mathrm{~g} ; \mathrm{NaCl}, 0.50 \mathrm{~g}$; $\mathrm{MgSO}_{4}{ }^{2-*} 7 \mathrm{H}_{2} \mathrm{O}, 0.246 \mathrm{~g} ; \mathrm{CaCl}_{2}, 0.0147 \mathrm{~g}$; Thiamine $\mathrm{HCl}, 1.0 \mathrm{mg}$; and D-glucose, $2.0 \mathrm{~g}$ per liter solution. No $\mathrm{pH}$ adjustment was required for this media. All media components were obtained from Fisher Scientific (Pittsburgh, PA).

Potassium stock was eliminated from the culture media to reduce the dilution required for the potassium efflux experiments. Potassium contamination from the sodium phosphate buffers, sodium chloride, and sodium hydroxide appeared to be adequate for growth requirements, and resulted in media concentration of about $2 \mathrm{mg} / \mathrm{L}$.

Cultures were maintained in $250 \mathrm{~mL}$ Erlenmeyer flasks using a gyratory water bath shaker (Model G76, New Brunswick Scientific, Edison, NJ) set at $37^{\circ} \mathrm{C}$ and were transferred to fresh media every two days using a 1:100 dilution factor. To expand the volume of culture, cells were transferred at the appropriate dilution to a five liter jug that was aerated using an aquarium pump and diffuser with magnetic stirring placed in an incubator at $37^{\circ} \mathrm{C}$. Monthly, cultures were restarted from frozen stock by streaking frozen culture on Luria- 
Bertani (LB) agar plates consisting of: $\mathrm{NaCl}, 10 \mathrm{~g}$; tryptone/peptone, $10 \mathrm{~g}$; yeast extract, $5 \mathrm{~g}$; and Bacto agar, $10 \mathrm{~g}$ per liter solution. The streaked plate was incubated overnight at $37^{\circ} \mathrm{C}$. Then, a single colony was placed aseptically into fresh sterile media.

\subsubsection{Growth Curve Preparation}

A growth curve was determined for each strain using sidearm flasks containing 100 $\mathrm{mL}$ growth media incubated in a rotary water bath shaker maintained at $37^{\circ} \mathrm{C}$. Transmittance through the media was measured at $590 \mathrm{~nm}$ on a spectrophotometer (Spectronic 20, Bausch and Lomb, Philadelphia, PA). Separate growth curves were determined spectrophotometrically for cultures grown in five liter batches.

\subsection{Immobilization polymer preparations}

\subsubsection{Alginate immobilization}

The calcium alginate hydrogel matrix, a copolymer of $\beta$-D-mannuronate (M-residue) and $\alpha$-L-guluronate (G-residue) (reviewed in Rehm 1998), was used as the preliminary immobilization matrix for the cells because this matrix has been used extensively by others (for example, Elasri et al., 2000; Kohler, 2000; Polyak et al., 1997, 2001; Webb et al., 1997). To form alginate beads, five liters $P$. aeruginosa were grown overnight to mid-log growth state. The cells were concentrated by centrifugation in multiple bottles for 20 minutes at $4420 \mathrm{x}$ g and the supernatant was discarded. The cells were resuspended in about $20 \mathrm{~mL}$ of fresh media and divided into aliquots of equal cell number for the immobilization. The resuspended bacterial concentrate was added to a $2 \%$ solution (w/v) of sodium alginate (Protanal LF10/60, FMC BioPolymer, Philadelphia, PA, USA) in water using approximately a 10:1 (v/v) ratio of alginate to cell solution. The solution was well mixed and slowly 
dropped by a 21 -gauge syringe into a $10 \%$ solution $(\mathrm{w} / \mathrm{v})$ of calcium chloride in water to form spheres. The beads were rinsed with nanopure water and placed in PA BT media.

PA BT media was used for alginate bead experiments because the beads were found to be unstable in the PA M9 media. The central modification for the BT media was the substantial reduction in sodium concentration. Because the alginate polymerizes by substitution of calcium for sodium within the polymer matrix, it was thought that ion exchange could compromise alginate stability and return the beads to the liquid state, which occurred within an hour in the PA M9 media.

The number of cells per batch was determined by dividing the cell concentration by the number of beads per batch. Cell concentration was determined by plating triplicate serial dilutions in sterile nanopure water of the resuspended culture on Luria-Bertani (LB) agar. The plates were incubated overnight at $37^{\circ} \mathrm{C}$, and the cell count was determined by counting the number of colonies per plate and correcting for the dilution factor.

\subsubsection{Photo-polymer immobilization}

The photopolymerization procedure made it very difficult to create immobilizing beads; therefore, flat disks approximately $0.5 \mathrm{~cm}$ in diameter and $0.1 \mathrm{~cm}$ in thickness were formed instead. The resuspended bacterial concentrate was added to one of two versions of the photopolymer:

- Photo 1 contained a pre-mixed solution of $5 \%(\mathrm{w} / \mathrm{v})$ bis $(2,4,6-$ trimethylbenzoyl)-phenylphophineoxide (Irgacure 819, Ciba, Suffolk, VA, USA) with poly(ethylene glycol) (PEG) (MW 400) containing acrylate ends (SR 344, Sartomer, Exton, PA, USA) mixed with the bacterial concentrate to yield a $25 \%(\mathrm{w} / \mathrm{v})$ polymer solution. 
- Photo 2 contained a pre-mixed solution of $1 \%$ (w/v) Irgacure 819 with PEG mixed with the bacterial concentrate to yield a $22 \%(\mathrm{w} / \mathrm{v})$ polymer solution.

For both compositions, the cells were concentrated into a volume of about $8 \mathrm{~mL}$ of media as described in Section 2.2.1, and the concentrated cell solution was mixed with the polymer precursor. The mixture was dropped by pipette onto a plastic sheet and cured for 10 minutes using an aquarium lamp with peak emission at $420 \mathrm{~nm}$. The cured disks were removed from the sheet and rinsed with nanopure water, and then placed in PA M9 media.

A third photopolymer composition, Photo 3, was created using a different initiator. This solution contained the initiator 2-hydroxy-1-[4-(2-hydroxyethoxy)phenyl]-2-methyl-1propanone (sold as Irgacure 2959, Ciba, Suffolk, VA, USA) in the Irgacure 819 PEG monomer base. The solutions were premixed as 1\% (w/v) of Irgacure 2959 in PEG. The bacterial concentrate was then added and mixed as described above to yield a $22 \%(\mathrm{w} / \mathrm{v})$ polymer solution. Curing was performed using the same lamp with a cure time of 15 minutes. The disks were rinsed and placed in PA M9 media immediately afterwards. The cell concentration per batch was calculated as described in Section 2.2.1.

\subsubsection{Thermal polymer immobilization}

A thermal polymer was also tested. As with the photopolymer, small beads were difficult to generate. To form the thermal polymer sphere, the cells were concentrated into about $20 \mathrm{~mL}$ of media as described in Section 2.2.1. The concentrated cell solution was mixed at room temperature in a scintillation vial with a $15 \%(\mathrm{w} / \mathrm{v})$ solution of liquid thermal polymer, $\mathrm{N}$-isopropylacrylamide-co-acrylic acid (NIPA-co-Aac), a copolymer with 98 mole percent NIPA and 2 mole percent AAc, to result in a $10 \%(\mathrm{w} / \mathrm{v})$ polymer solution. The vial was equilibrated in a water bath at $40^{\circ} \mathrm{C}$ for about five minutes until the mixture solidified 
into a white gel-like sphere about $1.5 \mathrm{~cm}$ in diameter. The somewhat spherical gel was removed from the vial and wrapped in single mesh fabric ( 21 holes per inch) to facilitate handling. The gel was then placed in the gyratory water bath shaker in PA M9 media at $40^{\circ} \mathrm{C}$ to maintain the polymer in the gelled state. The cell concentration in the matrix was determined by cell counts, as described in Section 2.2.1.

\subsection{Cell activity and viability experiments}

Bacterial activity and viability within the planktonic and immobilized cultures were evaluated respirometrically using oxygen uptake rates and microscopically using a LIVE/DEAD ${ }^{\circledR}$ stain, respectively. The LIVE/DEAD ${ }^{\circledR}$ stain has been widely used to determine the viability of cells in a population by comparing the number that stain red, representing dead cells, to the number that stain green, representing live cells.

\subsubsection{Oxygen uptake rates}

Oxygen uptake rates (OURs) were used to determine the activity of planktonic and immobilized bacteria over time, with the procedure shown schematically in Figure 1. Measurements were performed with planktonic cultures in parallel with immobilized cultures at time zero, and continued with immobilized cultures over time. For alginate-immobilized cultures, beads were prepared and wrapped in mesh fabric ( 21 holes per inch) to facilitate handling. Beads were maintained aerobically under sterile conditions in $250 \mathrm{~mL}$ Erlenmeyer flasks containing $100 \mathrm{~mL}$ of PA BT media, and were transferred to fresh media daily. To determine the OUR, the mesh-bundled beads were transferred from the growth flask to a 300 $\mathrm{mL}$ BOD bottle, which was brought to a volume of $300 \mathrm{~mL}$ with media and sealed with the dissolved oxygen (DO) probe (Orion 97-08-99, Beverly, MA). The decrease in dissolved oxygen concentration was monitored over time using a computerized data acquisition system 
(LabView version 6.0, National Instruments, Austin, TX) with data collected by an attached meter (Accument Research AR25 Dual Channel ph/Ion Meter, Fisher Scientific, Pittsburgh, PA). After the oxygen uptake rate analysis, the mesh-bundled beads were transferred to a sterile flask with fresh media so that measurements could be performed at a later time using the same immobilized cells. All SOUR tests were performed in duplicate.

To determine OURs for the photopolymer immobilized cells, the disks were placed in $300 \mathrm{~mL}$ BOD bottles and PA M9 media was added. The bottles were sealed with the DO probes, and the experiment proceeded as described above.

To determine OURs for the thermal polymer immobilized cells, the fabric-bundled gel was removed from its maintenance flask and transferred to a $300 \mathrm{~mL}$ BOD bottle. PA M9 media at $40^{\circ} \mathrm{C}$ was added to the bottles, which were sealed with the DO probes. The test proceeded as above, except that the bottle was immersed in a $40^{\circ} \mathrm{C}$ water bath for the duration of the SOUR test. To compensate for the temperature variation, a planktonic control tested at day zero was evaluated at the same temperature.

\subsubsection{LIVE/DEAD ${ }^{\circledR}$ staining}

The LIVE/DEAD ${ }^{\circledR}$ BacLight $^{\text {TM }}$ Bacterial Viability Kit (Molecular Probes, Eugene, Oregon, USA) was used with a fluorescent microscope (Zeiss Axioscope 2 Plus, Thornwood, NY, USA) and camera system (Zeiss AxioCam MRm, Thornwood, NY, USA) to visually compare the numbers of viable and nonviable cells at 20 and 40x magnification. The kit contents were mixed 1:1 and three microliters of the mixture were added to each milliliter of cells to be stained. To stain all gels, an aliquot of the gel was placed in a microcentrifuge tube with $1 \mathrm{~mL}$ of water and stained with the same amount of dye. 


\section{Results and Discussion}

3.1 Oxygen uptake rates (OURs) show extended activity in thermal gels, low activity in photopolymer, and activity until material failure in alginate gels

OURs performed on cells immobilized in the first formulation of the photopolymer (Photo 1) showed near-zero activity after polymerization, as shown in Figure 2. Therefore, the concentration of initiator was reduced as much as possible without compromising curing quality or time. This new formulation, which contained $1 \%$ rather than $5 \%$ initiator, was polymer Photo 2. Unfortunately, this reduction still resulted in very low activity (Figure 2). Therefore, the initiator was changed to Irgacure 2959 at 1\% (w/v) (polymer Photo 3), but the results continued to show low activity (Figure 2). Changing the cell type may improve the activity, but the current combination of cells and photo-matrices resulted in an immediate and severe reduction in cell respirometric activity when immobilized in the matrix.

In comparison, cell activity was good in the alginate and thermal matrices, although the OUR results indicated more limited activity initially as compared to planktonic controls containing the same number of cells. Figure 2 summarizes the OUR results from these matrices relative to planktonic controls measured at $\mathrm{t}=0$. Because several groups show elevated OURs relative to control, oxygen diffusion into the polymers appeared uninhibited. In the alginate, the increased OURs probably indicate cell division and colonization within the structure, as observed by Mater et al. by microscopy of alginate beads containing immobilized Pseudomonas strains. This colonization occurs within the pores of the alginate matrix, which are large enough to permit cell division. The pore size of the thermal polymer is unknown. Because the OURs in the thermal gel also increase over the control, cell division may also be occurring within the polymer structure. In the alginate matrix, the rates 
increase consistently, which supports the hypothesis that the cells are using the alginate as a carbon source, creating space for cell division as they consume the structure within which they are contained. Perhaps because of this consumption, the matrix deteriorated within a week of bead manufacture, preventing quantification of the long-term viability of the alginate-immobilized cells. However, an experiment performed to determine whether the cells could use alginate as a sole carbon source showed no difference in initial oxygen uptake rates between immobilized cells ( $0.050 \mathrm{mg}$ DO per cell per minute) and planktonic cells (0.045 mg DO per liter per minute), both in media without the acetate carbon source. By day two, the OUR for immobilized cells had dropped to $0.019 \mathrm{mg}$ DO per cell per minute, much lower than control, indicating that the cells were losing activity because the carbon source was unacceptable. Perhaps the alginate is metabolized along with HAC, but alone the cells do not consume the polymer.

The thermal polymer showed excellent material stability, with no deterioration observed for over two weeks. The oxygen uptake rates fluctuate relative to the control, as shown in Figure 2, but on the whole the cells remained viable. Clearly, the thermal polymer is a good choice for the immobilization matrix because it is nontoxic to the cells and supports extended viability. However, integrating the thermal polymer into the biosensor is a challenge because of the temperature requirements of this matrix. To overcome this constraint, the sensor requires a small heater to maintain the temperature at the appropriate level (for example, by incorporating titanium/platinum films to permit temperature measurement and regulation, as reviewed in Erickson and Li, 2004). Alternately, the polymer could be modified to shift the critical temperature to a range below ambient (about $25^{\circ} \mathrm{C}$ ). In either case, the thermal polymer showed the most promise for cell activity and, 
thus, for inclusion in the biosensor.

\subsection{LIVE/DEAD ${ }^{\circledR}$ staining is effective in determining immobilized viability in thermal} polymer

The stain was applied to cells immobilized in all matrices tested, but was only effective for the thermal polymer. The spherical bead structure of the alginate prevented the microscope camera from focusing on a single plane of bacteria. Attempts to flatten to beads to permit adequate observation showed a strong background fluorescence with the green stain, making observations of live cells difficult (Figure 3). The photopolymer matrix also fluoresces very strongly green, making observations of live cells difficult, as shown in Figure

3. The thermal polymer showed the ideal response to the dye, in that zero background fluorescence was observed after allowing the polymer to liquefy at room temperature.

The staining of the thermal and photopolymers reinforces the results obtained from the OUR experiments. As shown in Figure 3, all the bacteria immobilized in the photopolymer stain red, whether or not the cells were dropped on the surface of the polymer or mixed with it prior to polymerization. The images shown are typical of those from the other photopolymer formulations. Because the background fluorescence is so strongly green, one could argue that live cells are present that cannot be observed with this method. While that is possible, the extremely low OURs combined with the number of red cells observed in the photopolymers support the conclusion that the survivability in the matrix was very low. The thermal polymer shows good viability, even after 10 days within the matrix, because green cells dominate over red. On the whole, these results replicate the SOUR data, showing that the photopolymer has low viability, while the thermal polymer cells remain mostly viable. 


\section{Conclusions}

A series of experiments were conducted in this work to identify the most appropriate polymer matrix for bacterial cell immobilization for a biosensor. The ideal matrix is physically and chemically stable over several weeks, non-toxic to the cells, and will not limit the diffusion of oxygen, compounds necessary for cell growth, or compounds, which would trigger a stress response. Three matrices were examined here: a calcium alginate, several photopolymerizable hydrogels, and a thermal polymer.

The sodium alginate matrix was unstable, although bacterial consumption of the matrix as a substrate was not validated as the cause. The material degraded within a week, rendering it incapable of containing the bacteria. The photopolymer was toxic to the cells, resulting in significant cell death immediately after polymerization. Changes to the concentration and the composition of the initiator did not reduce the matrix toxicity. Finally, the thermal polymer matrix was non-toxic, stable, and did not hinder oxygen diffusion. The only limitation on the incorporation of the thermal polymer within the microfluidic sensor is the need to maintain a higher-than-ambient temperature in the cell chamber $\left(40^{\circ} \mathrm{C}\right)$.

However, adding a micro-scale heater such as that reviewed in Erickson and Li (2004) would meet this need. Alternatively, the polymer could be modified to change its immobilization temperature. By modifying the polymer structure, the critical temperature could be reduced below ambient, and thus reduce the need for a heating element. On the whole, even without such chemical modifications the thermal polymer shows great potential for incorporation in the biosensor.

\section{Acknowledgements}


The project was supported by the Paul L. Busch Award and the EPA Midwest Hazardous Substances Research Center. KAL acknowledges the support of the Charles E. Via, Jr. Department of Civil and Environmental Engineering Endowment. The authors would like to thank Julie Petruska, Jody Smiley, and Phil Wunderly for analytical and laboratory support. 


\section{References}

Beebe, David J., Jeffrey S. Moore, Joseph M. Bauer, Qing Yu, Robin H. Liu, Chelladural Devadoss, and Byung-Ho Jo. (2000) Functional hydrogel structures for autonomous flow control inside microfluidic channels. Letters to Nature 404 588-590

Belkin, Shimshon. (2003) Microbial whole-cell sensing systems of environmental pollutants. Current Opinion in Microbiology 6 206-212

Belkin, Shimshon, Dana R. Smulski, Sara Dadon, Amy C. Vollmer, Tina K. Van Dyk, and Robert A. Larossa. A panel of stress-responsive luminous bacteria for the detection of selected classes of toxicants. (1997) Water Research (31) 12, 3009-3016

Drury, Jeanie L., Robert G. Dennis, David J. Mooney. (2004) The tensile properties of alginate hydrogels. Biomaterials 24, 3187-3199

Elasri, Mohamed O., Tricia Reid, Steven Hutchens, Robert V. Miller. (2000) Response of a Pseudomonas aeruginosa biofilm community to DNA-damaging chemical agents. FEMS Microbiology Ecology 33, 21-25

Erickson, David, and Dongqing Li. (2004) Integrated microfluidic devices. Analytica Chimica Acta 507, 11-26

Gu, Man Bock, and Sue Hyung Choi. (2002) A portable toxicity biosensor using freezedried recombinant bioluminescent bacteria. Biosensor and Bioelectronics. 17, 433-440

Heim S, Schnieder I, Binz D, Vogel A, Bilitewski U. (1999) Development of an automated microbial sensor system. Biosens Bioelectron 14, 187-93

Heo, Jinseok, K. Joseph Thomas, Gi Hun Seong, and Richard M. Crooks. (2003) A microfluidic bioreactor based on hydrogel-entrapped E. coli: cell viability, lysis, and intracellular reactions. Anal. Chem. 75(1) 22-26

Horsburgh, Alison M., D.P. Mardlin, N.L. Turner, R. Henkler, N. Strachan, L.A. Glover, G.I. Paton, K. Kilham. (2002) On-line microbial biosensing and fingerprinting of water pollutants. Biosensors and bioelectronics 17, 495-501

Kim, Byoung Chan, and Man Bock Gu. (2003) A bioluminescent sensor for high throughput toxicity classification. Biosensors and Bioelectyronics 18, 1015-1021

Kohler, Sabine, Till T. Bachmann, Jutta Schmitt, Shimshon Belkin, Rolf D. Schmid. (2000) Detection of 4-chlorobenzoate using immobilized recombinant Escherichia coli reporter strains. Sensors and Actuators B 70, 139-144

Liu, Jing and Bo Mattiasson. (2002) Microbial BOD sensors for wastewater analysis. Water Research 36, 3786-3802 
Love, N. G., Bott, C.B. (2000). WERF Project 99-WWF-2 Report: A review of and needs survey of upset early warning devices. Water Environment Research Foundation.

Mater, Denis D.G., Jose E. Nava Saucedo, Nicole Truffaut, Jean-Noel Barbotin, Daniel Thomas. (1999) Conjugative plasmid transfer between Pseudomonas strains wtihin alginate bead microcosms: effect of the internal gel structure. Biotechnology and Bioengineering 65(1), 34-42

Philp, Jim C., Severine Balmand, Eva Hajto, Mark J. Bailey, Siouxsi Wiles, Andrew S. Whiteley, Andrew K. Lilley, Janos Hajto, and Sandra A. Dunbar. (2003). Whole cell immobilized biosensor for toxicity assessment of a wastewater treatment plant treating phenolics-containing waste. Analytica Chimica Acta 487(1) 61-74

Polyak, B., E. Bassis, A. Novodvorets, S. Belkin, and R.S. Marks. (1997) Optical fiber bioluminescent whole-cell microbial biosensors to genotoxicants. Water Science and Technology. 42 (12), 305-311

Polyak, Boris S., Efim Bassis, Alex Novodvorets, Shimshon Belkin, Robert S. Marks. Bioluminescent whole cell optical fiber sensor to genotoxicants: system optimization. (2001) Sensors and Actuators B 74, 18-26

Premkumar, J. Rajan, Rachel Rosen, Shimshon Belkin, and Ovadia Lev. (2002) Sol-gel luminescence biosensors: Encapsulation of recombinant E. coli reporters in thick silicate films. Analytica Chimica Acta 462, 11-23

Ramanathan, S., M. Ensor, and S. Daunert. (1997) Bacterial biosensors for monitoring toxic metals. Trends Biotechnol. 15, 500-506

Rehm, Bernd H.A. (1998) Alginate lyase from Pseudomonas aeruginosa CF1/M1 prefers the hexameric oligomannuronate as substrate. FEMS Microbiology Letters 165, 175-180

Reid, Brian J., Kirk T. Semple, Christopher J. Macleod, Jedda J. Weitz, Graeme I. Paton. (1998) Feasibility of using prokaryote biosensors to assess acute toxicity of polycyclic aromatic hydrocarbons. FEMS Microbiology Letters 169, 227-233

Tan, T.C., and C. Wu. (1999) BOD sensors using multi-species living or thermally killed cells of a BODSEED microbial culture. Sens Acutators B 54, 252-260

Taurianinen, Sisko, Matti Karp, Wei Chang, and Marko Virta. (1998) Luminescent bacterial sensor for cadmium and lead. Biosensor and Bioelectronics 13, 931-938

Webb O. F., P.R. Beinkowski, U. Matrubutham, F.A. Evans, A. Heitzer, G.S. Sayler. (1997) Kineticis and response of a Pseudomonas fluorescens HK44 biosensor. Biotechnology and Bioengineering. 54 (5), 491-502 


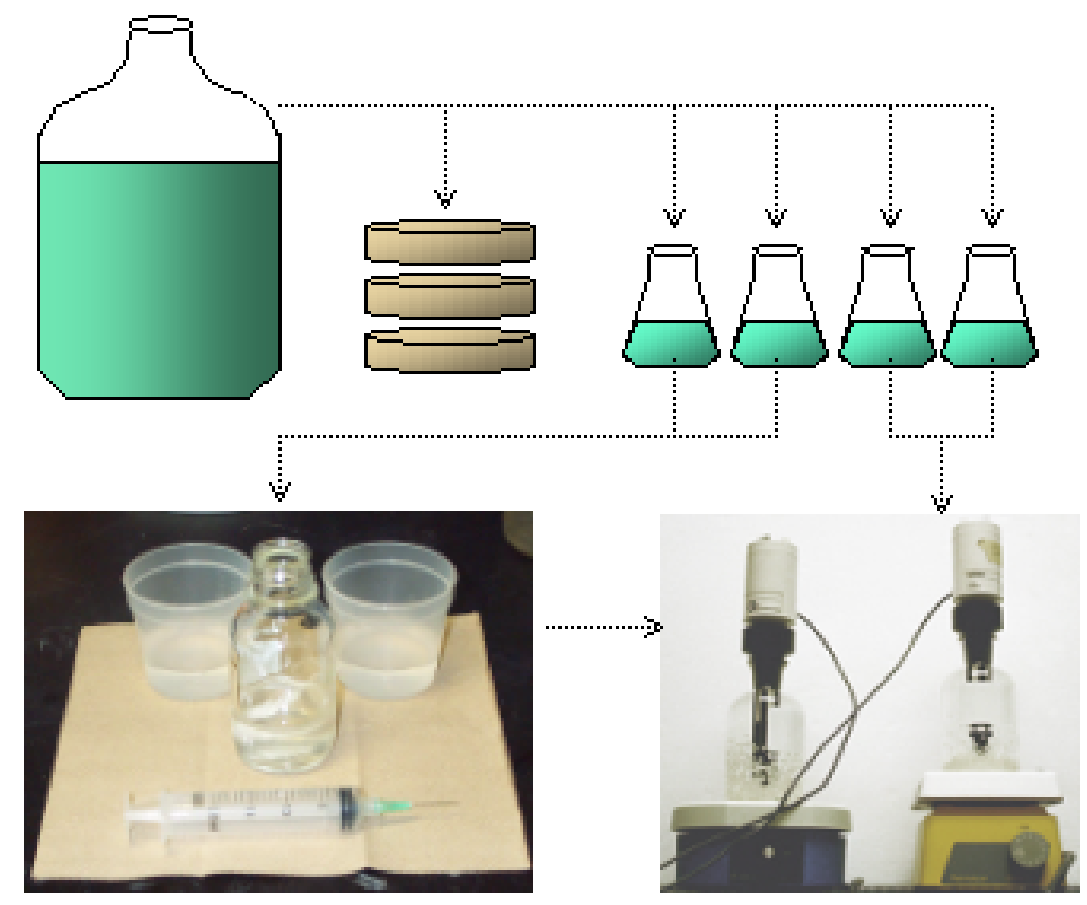

Figure 1: Diagram of the OUR experiment protocol. Cells were grown up in $5 \mathrm{~L}$ jugs, concentrated by centrifugation, resuspended, and an aliquot was taken for plate counts. Next, the concentrated cells were divided into four equal batches, with two sets being immobilized in the polymer, and two remaining in the planktonic state. Here, alginate immobilization is shown as an example. The oxygen uptake rates were determined using oxygen probes and a computerized data acquisition system in duplicate for the immobilized cells as well as the planktonic cells. 


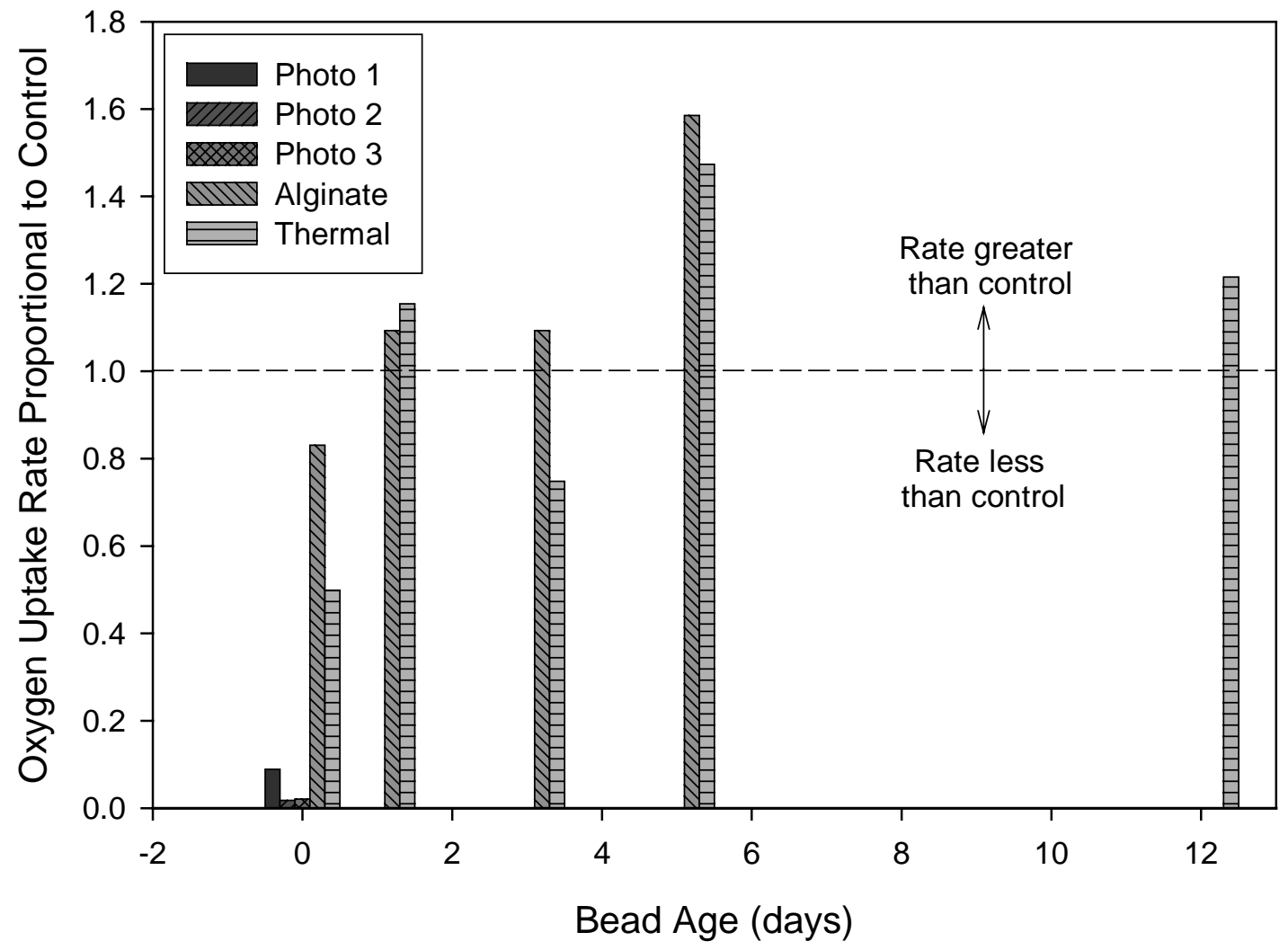

Figure 2: $\quad$ OUR tests for cells immobilized in each polymer matrix. Data is normalized to a planktonic control with equal cell density by dividing the observed rate within the gels by the average rate observed in the controls at $\mathrm{t}=0$. Photopolymers show near zero oxygen uptake, while thermal and alginate matrices show extended viability. The alginate deteriorated within a week, so further testing with that matrix was impossible. 


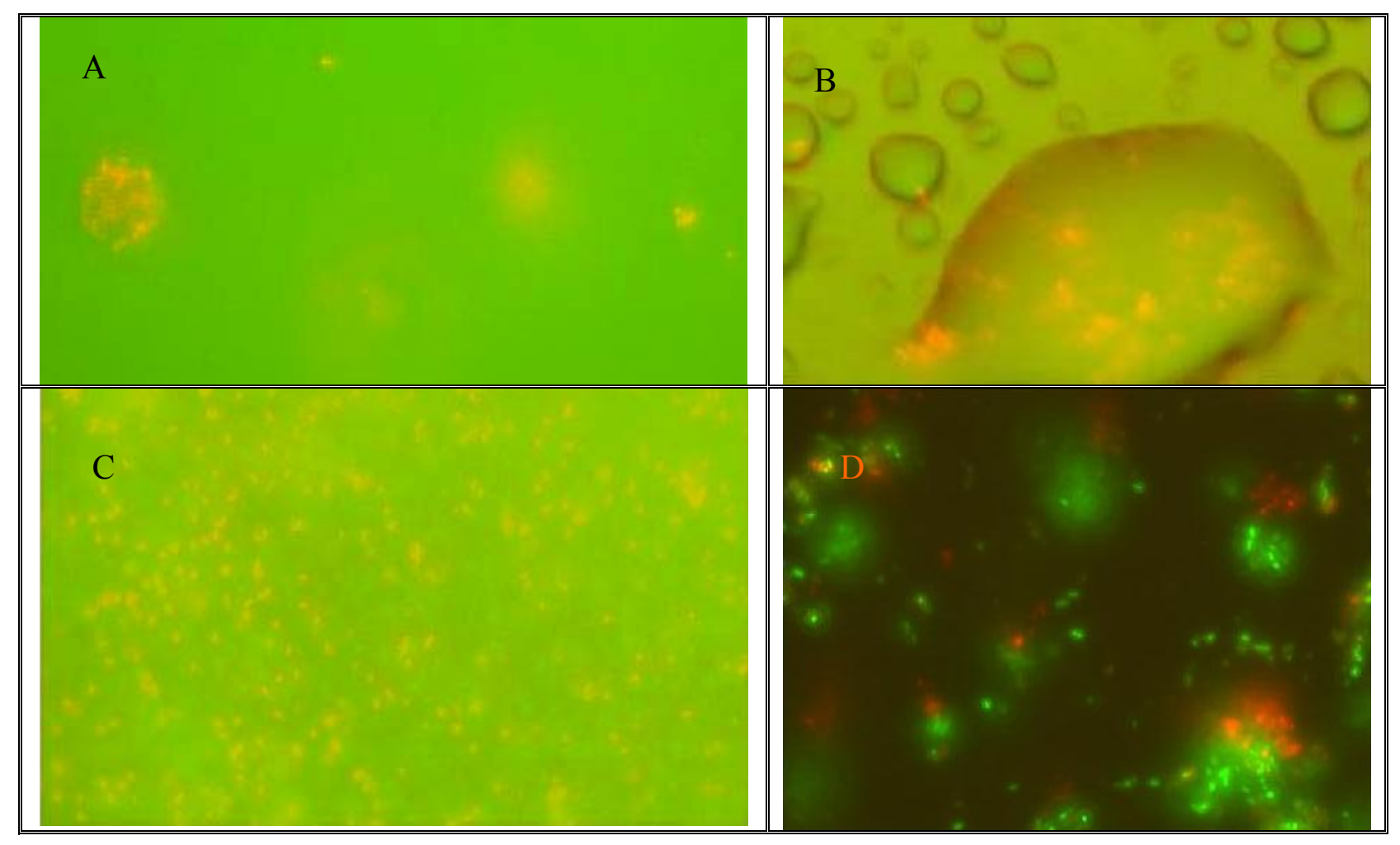

Figure 3: Representative LIVE/DEAD ${ }^{\circledR}$ stains of immobilized cells in photopolymer Photo 1 (A and B), alginate (C), and thermal polymer (D). Cells were dropped on the surface of the polymer before polymerization in Image B, while in A cells were completely mixed with the polymer before polymerization. Photopolymer and alginate images were taken immediately after polymerization, while Image $\mathrm{D}$ shows the thermal polymer 10 days after immobilization. 


\title{
Evaluating strategies for integrating bacterial cells into a biosensor designed to detect electrophilic toxins Part B: potassium efflux
}

\author{
K. Linares*, D. Fleming**, Y. Xu***, N. Love*, B. Love**, K. Meehan*** \\ Departments of *Civil \& Environmental Engineering, **Materials Science and Engineering, \\ and *** Electrical and Computer Engineering, Virginia Tech, Blacksburg, VA 24061 \\ Planned for submission to Sensors and Actuators B
}

\begin{abstract}
The biological element of a biosensor to detect electrophilic compounds by harnessing the glutathione-gated potassium efflux (GGKE) stress response system through the detection of effluxed potassium is characterized. The potassium efflux caused by a model electrophile is elucidated in planktonic cultures of Psuedomonas aeruginosa and Escherichia coli. P. aeruginosa was selected for further study because it is an environmentally relevant strain and effluxed comparable potassium per cell to E. coli. The bacterial culture was immobilized in two hydrogel polymers: a calcium alginate and a thermally-reversible gel. The potassium efflux from immobilized cells caused by N-ethyl maleimide, a model electrophile, was elucidated. The efflux from the alginate and thermal polymers was strong initially, but deteriorated with time, probably due to potassium limitation in the media.
\end{abstract}

\section{Introduction}

Real-time monitoring of toxicity in environmental samples is primarily performed through biosensors or bioassays, because laboratory analytical techniques take more time and require knowledge of the compound of interest in the sample. A number of whole-cell biosensors have been developed using genetically modified bacterial strains that respond to particular compounds, such as phenol (Philp et al., 2003; Gu and Choi, 2002), polycyclic aromatic hydrocarbons (PAHs) (Reid et al., 1998), and heavy metals (Taurianinen et al., 1998). One drawback with most whole cell biosensors is that they employ genetically modified bacteria as the reporter, the use of which is prohibited in many locations. One notable exception is the commercial Microtox ${ }^{\circledR}$ assay, which uses naturally luminescent Vibrio fischerii bacteria. Non-engineered cells do not mandate strict controls on release whereas those that have genetic modifications are heavily regulated. Additionally, the use of indigenous wild type cells more accurately reflects the conditions under observation than do 
engineered lab strains. With wild-type cells the intrinsic cellular physiology must be harnessed to detect the presence of compounds of interest or to determine if the cells are inhibited or stressed.

Electrophiles are a class of compounds that have been shown to trigger measurable stress responses in bacterial cells (Bott and Love, 2002). Industrially relevant electrophilic (oxidative) toxins include a range of chemicals, such as heavy metals and organic compounds containing chloro- and imide- constituents. This class of toxins, commonly found in industrial wastewater, is believed to impair biomass function in biological treatment plants when present at shock loads, and can result in process upset (Bott and Love, 2002). The most common modes of process upset are ineffective biological oxygen demand (BOD) removal, ineffective nitrification, deflocculation, and sludge bulking (Love and Bott, 2000). Although there is substantial speculation about the origin of these upsets, operators generally have insufficient information to identify the source of the problem. However, when asked, operators suggested that heavy metals and toxic organic compounds (which include electrophilic chemicals) are among the most common sources of these upsets (Love and Bott, 2000).

It is speculated that electrophilic chemicals cause process upset by triggering stress response mechanisms in the biomass. Activated sludge deflocculation, one common component of process upset, has been linked to bacterial activation of a stress response called the glutathione-gated potassium efflux (GGKE) response (Bott and Love, 2002). This mechanism is initiated when an electrophile enters the cell and the reaction between the electrophile and glutathione (N-(N-L- $\gamma$-glutamy-L-cysteinyl)glycine) activates potassium efflux pumps located in the cell membrane (Apontoweil and Berends, $1975 \mathrm{a}$ and $\mathrm{b}$ ) (shown 
in Figure 1). GGKE transports potassium ions out of the cell in exchange for hydrogen ions transported into the cell, which acidify the cytoplasm and cause activation of secondary stress responses that protect cells from oxidative damage (Ferguson et al., 2000).

In biomass, the GGKE response results in an increase in extracellular potassium, adding additional monovalent cations in the floc matrix, and increasing the intrafloc monovalent to divalent cation ratio (Bott and Love, 2002). This ratio is an important predictor of floc strength (Higgins and Novak, $1997 \mathrm{a}$ and b). Disrupting that ratio makes flocs unstable and results in loss of biomass from the system (Murthy et al., 1998). This type of upset encompasses the modes of upsets observed with electrophilic shock, namely, ineffective BOD removal, deflocculation, and sludge bulking. The development of sensors around this GGKE response to detect electrophilic compounds entering sewers or wastewater treatment plants would improve process operation and effluent quality by predicting the process effect linked to such upset events, and thus allow the adjustment of process operations to accommodate and minimize the process impact.

The goal of this project was to develop a biosensor based on the GGKE stress response system. By monitoring bulk potassium as an indicator of the stress experienced by the cells, the biosensor will monitor for electrophilic compounds that have been shown to cause deflocculation in the activated sludge process. The microscale biosensor under development includes a whole cell biological element, potassium detection membranes, and microfluidic componentry that compose a lab-on-a-chip device.

Within the biological element, bacterial cells will be immobilized in a polymer matrix. Immobilization of the bacterial cells is important because it as compared to a biofilm, it keeps the cell concentration more constant by maintaining the viability of the 
immobilized cells while reducing cell division. Additionally, immobilized cells cannot slough off as a biofilm layer could and clog the microfluidic channels in the device.

The focus of this work was on the design and characterization of the biological element of the biosensor, with the specific goal of quantifying the impact of immobilization on the rate and degree of potassium efflux in response to a model electrophile. In the current work, two polymers were investigated for use as the immobilization matrix: a calcium alginate and a thermally-reversible gel. In the completed sensor, the concentration of potassium will be monitored as an indicator of bacterial stress. By utilizing the intrinsic response of wild type cells and monitoring the change in potassium ion efflux from them, the device is devoid of genetically modified cells and its eventual use and commercialization are simplified greatly.

\section{Materials and Methods}

\subsection{Bacterial culturing}

\subsubsection{Growth conditions}

Pseudomonas aeruginosa was isolated previously from a local wastewater treatment plant and was grown in a mineral salt medium denoted PA M9. This medium consisted of $\mathrm{NaH}_{2} \mathrm{PO}_{4}, 3.0 \mathrm{~g} ; \mathrm{Na}_{2} \mathrm{HPO}_{4} * 7 \mathrm{H}_{2} \mathrm{O}, 6.0 \mathrm{~g} ; \mathrm{NH}_{4} \mathrm{Cl}, 1.0 \mathrm{~g} ; \mathrm{NaCl}, 0.50 \mathrm{~g} ; \mathrm{MgSO}_{4}{ }^{2-*} 7 \mathrm{H}_{2} \mathrm{O}, 0.246$ $\mathrm{g} ; \mathrm{CaCl}_{2}, 0.0147 \mathrm{~g} ; \mathrm{FeSO}_{4} * 7 \mathrm{H}_{2} \mathrm{O}, 2.5 \mathrm{mg} ; \mathrm{ZnCl}_{2}, 0.25 \mathrm{mg} ; \mathrm{MnSO}_{4} * \mathrm{H} 2 \mathrm{O}, 0.185 \mathrm{mg} ; \mathrm{CuSO}_{4}$, $0.030 \mathrm{mg} ; \mathrm{NaMoO}_{4} * 2 \mathrm{H}_{2} \mathrm{O}, 0.006 \mathrm{mg} ; \mathrm{CoCl}_{2} * 6 \mathrm{H}_{2} \mathrm{O}, 0.001 \mathrm{mg} ; \mathrm{H}_{3} \mathrm{BO}_{3}, 0.03 \mathrm{mg}$; glacial acetic acid, $0.89 \mathrm{~mL}$ per liter solution. A second medium denoted PA BT was used to improve alginate stability when it was the immobilizing hydrogel. The PA BT media consisted of: $\mathrm{NaH}_{2} \mathrm{PO}_{4}, 0.3 \mathrm{~g} ; \mathrm{Na}_{2} \mathrm{HPO}_{4} * 7 \mathrm{H}_{2} \mathrm{O}, 0.6 \mathrm{~g} ; \mathrm{NH}_{4} \mathrm{Cl}, 0.1 \mathrm{~g} ; \mathrm{NaCl}, 0.05 \mathrm{~g}$; Bis Tris, $1.0 \mathrm{~g} ; \mathrm{MgSO}_{4}{ }^{2-*} 7 \mathrm{H}_{2} \mathrm{O}, 0.246 \mathrm{~g} ; \mathrm{CaCl}_{2}, 0.0147 \mathrm{~g} ; \mathrm{FeSO}_{4} * 7 \mathrm{H}_{2} \mathrm{O}, 2.5 \mathrm{mg} ; \mathrm{ZnCl}_{2}, 0.25 \mathrm{mg}$; 
$\mathrm{MnSO}_{4} * \mathrm{H} 2 \mathrm{O}, 0.185 \mathrm{mg} ; \mathrm{CuSO}_{4}, 0.030 \mathrm{mg} ; \mathrm{NaMoO}_{4} * 2 \mathrm{H}_{2} \mathrm{O}, 0.006 \mathrm{mg} ; \mathrm{CoCl}_{2} * 6 \mathrm{H}_{2} \mathrm{O}$, $0.001 \mathrm{mg} ; \mathrm{H}_{3} \mathrm{BO}_{3}, 0.03 \mathrm{mg}$; and glacial acetic acid, $0.89 \mathrm{~mL}$ per liter solution. After preparing media but before autoclaving, the $\mathrm{pH}$ was adjusted to 7.0 using $50 \% \mathrm{w} / \mathrm{v} \mathrm{NaOH}$ (approximately $3 \mathrm{~mL}$ per liter PA M9 media, and about $4.5 \mathrm{~mL}$ per liter PA BT media).

Escherichia coli strain K-12, ATCC 29947, was grown on mineral salt medium M9. This media consisted of $\mathrm{NaH}_{2} \mathrm{PO}_{4}, 3.0 \mathrm{~g} ; \mathrm{Na}_{2} \mathrm{HPO}_{4} * 7 \mathrm{H}_{2} \mathrm{O}, 6.0 \mathrm{~g} ; \mathrm{NH}_{4} \mathrm{Cl}, 1.0 \mathrm{~g} ; \mathrm{NaCl}, 0.50 \mathrm{~g}$; $\mathrm{MgSO}_{4}{ }^{2-*} 7 \mathrm{H}_{2} \mathrm{O}, 0.246 \mathrm{~g} ; \mathrm{CaCl}_{2}, 0.0147 \mathrm{~g}$; Thiamine $\mathrm{HCl}, 1.0 \mathrm{mg}$; and D-glucose, $2.0 \mathrm{~g}$ per liter solution. No $\mathrm{pH}$ adjustment was required for this media. All media components were obtained from Fisher Scientific (Pittsburgh, PA).

Potassium stock was eliminated from the culture media to reduce the dilution required for the potassium efflux experiments. Potassium contamination from the sodium phosphate buffers, sodium chloride, and sodium hydroxide appeared to be adequate for growth requirements, and resulted in media concentration of about $2 \mathrm{mg} / \mathrm{L}$.

Cultures were maintained in $250 \mathrm{~mL}$ Erlenmeyer flasks using a gyratory water bath shaker (Model G76, New Brunswick Scientific, Edison, NJ) set at $37^{\circ} \mathrm{C}$ and were transferred to fresh media every two days using a 1:100 dilution factor. To expand the volume of culture, cells were transferred at the appropriate dilution to a five liter jug that was aerated using an aquarium pump and diffuser with magnetic stirring placed in an incubator at $37^{\circ} \mathrm{C}$. Monthly, cultures were restarted from frozen stock by streaking frozen culture on LuriaBertani (LB) agar plates consisting of: $\mathrm{NaCl}, 10 \mathrm{~g}$; tryptone/peptone, $10 \mathrm{~g}$; yeast extract, $5 \mathrm{~g}$; and Bacto agar, $10 \mathrm{~g}$ per liter solution. The streaked plate was incubated overnight at $37^{\circ} \mathrm{C}$. Then, a single colony was placed aseptically into fresh sterile media. 


\subsubsection{Growth Curve Preparation}

A growth curve was determined for each strain using sidearm flasks containing 100 $\mathrm{mL}$ growth media incubated in a rotary water bath shaker maintained at $37^{\circ} \mathrm{C}$. Transmittance through the media was measured at $590 \mathrm{~nm}$ on a spectrophotometer (Spectronic 20, Bausch and Lomb, Philadelphia, PA). Separate growth curves were determined spectrophotometrically for cultures grown in five liter batches.

\subsection{Immobilization polymer preparations}

\subsubsection{Alginate immobilization}

The calcium alginate hydrogel matrix, a copolymer of $\beta$-D-mannuronate (M-residue) and $\alpha$-L-guluronate (G-residue) (reviewed in Rehm, 1998), was used as the preliminary immobilization matrix for the cells because this matrix has been used extensively by others (for example, Elasri et al., 2000; Kohler, 2000; Polyak et al., 1997, 2001; Webb et al., 1997). To form alginate beads, five liters $P$. aeruginosa were grown overnight to mid-log growth state. The cells were concentrated by centrifugation in multiple bottles for 20 minutes at $4420 \mathrm{x} \mathrm{g}$ and the supernatant was discarded. The cells were resuspended in about $20 \mathrm{~mL}$ of fresh media and divided into aliquots of equal cell number for the immobilization. The resuspended bacterial concentrate was added to a $2 \%$ solution (w/v) of sodium alginate (Protanal LF10/60, FMC BioPolymer, Philadelphia, PA, USA) in water using approximately a 10:1 (v/v) ratio of alginate to cell solution. The solution was well mixed and slowly dropped by a 21 -gauge syringe into a $10 \%$ solution $(\mathrm{w} / \mathrm{v})$ of calcium chloride in water to form spheres. The beads were rinsed with nanopure water and placed in PA BT media.

PA BT media was used for alginate bead experiments because the beads were found to be unstable in the PA M9 media. The central modification for the BT media was the 
substantial reduction in sodium concentration. Because the alginate polymerizes by substitution of calcium for sodium within the polymer matrix, it was thought that ion exchange could compromise alginate stability and return the beads to a liquid state, which occurred within an hour in the PA M9 media.

The number of cells per batch was determined by dividing the cell concentration by the number of beads per batch. Cell concentration was determined by plating triplicate serial dilutions in sterile nanopure water of the resuspended culture on Luria-Bertani (LB) agar. The plates were incubated overnight at $37^{\circ} \mathrm{C}$, and the cell count was determined by counting the number of colonies per plate and correcting for the dilution factor.

\subsubsection{Thermal polymer immobilization}

A thermal polymer was also tested. As with the photopolymer, small beads were difficult to generate. To form the thermal polymer immobilization gel, the cells were concentrated into about $20 \mathrm{~mL}$ of media as described in Section 2.2.1. The concentrated cell solution was mixed at room temperature in a scintillation vial with a $15 \%(\mathrm{w} / \mathrm{v})$ solution of liquid thermal polymer, N-isopropylacrylamide-co-acrylic acid (NIPA-co-Aac), a copolymer with 98 mole percent NIPA and 2 mole percent AAc, to result in a $10 \%(\mathrm{w} / \mathrm{v})$ polymer solution. The vial was equilibrated in a water bath at $40^{\circ} \mathrm{C}$ for about five minutes until the mixture solidified into a white gel-like sphere about $1.5 \mathrm{~cm}$ in diameter. The somewhat spherical gel was removed from the vial and wrapped in single mesh fabric (21 holes per inch) to facilitate handling. The gel was then placed in the gyratory water bath shaker in PA M9 media at $40^{\circ} \mathrm{C}$ to maintain the polymer in the gelled state. The cell concentration in the matrix was determined by cell counts, as described in Section 2.2.1. 


\subsection{Potassium Efflux Experiments}

Potassium efflux experiments at various time points on the growth curve with planktonic cultures were carried out by growing five liters P. aeruginosa or E. coli overnight to the desired growth state in the appropriate growth medium. The cells were concentrated by centrifugation in multiple bottles for 20 minutes at $4420 \mathrm{x}$ g and the supernatant was discarded. The cells were resuspended in fresh media, combined, and the volume was adjusted to $700 \mathrm{~mL}$ with fresh media. Samples were taken from the well mixed flask for soluble potassium and plate counts. The resuspended culture was divided evenly among six flasks with $100 \mathrm{~mL}$ per flask. The flasks were placed on a multiple position stir plate and aerated using an aquarium pump to ensure oxygenation during the experiment. One milliliter automatic pipetter tips were placed on the end of the air tubing in each flask to reduce bubble size and to prevent contamination of the tubing. Each of three flasks was shocked with $1 \mathrm{~mL}$ of a $5 \mathrm{mg} / \mathrm{mL}$ N-ethyl malemide (NEM) stock, resulting in a dose of $50 \mathrm{mg} / \mathrm{L}$ of NEM. Three control flasks remained undosed with NEM. Samples for potassium measurement were taken over a one-hour time period by filtering the media through $0.2 \mu \mathrm{m}$ nitrocellulose MCE filters (25 mm diameter, Fisher Scientific, Pittsburgh, PA). Samples were acidified with concentrated nitric acid for preservation, and then diluted 1:10 with nanopure water. One milliliter of diluted sample was removed and replaced with $1 \mathrm{~mL}$ of $12.7 \mathrm{~g} / \mathrm{L}$ cesium chloride stock solution (Alfa Aesar, Ward Hill, MA) to minimize interference from sodium. Potassium standards were prepared using a potassium reference solution (Fisher Scientific, Fairlawn, NJ) and the same concentration of cesium chloride was added to standards. The samples were analyzed on an Atomic Absorption Spectrometer (AA) (5100 PC Atomic Absorption Spectrometer, Perkin Elmer, Norwalk, CT). All glassware used in the potassium 
measurements was prepared by acid washing in $10 \%$ nitric acid, followed by triple rinsing with nanopure water. Error for potassium efflux potential was calculated from the standard deviation of averages for analysis from three flasks and included standard deviation from the cell counts. Cell counts were determined by plating serial dilutions in sterile nanopure water of the resuspended culture on Luria-Bertani (LB) agar. The plates were incubated overnight at $37^{\circ} \mathrm{C}$, and the cell count was determined by counting the number of colonies per plate and correcting for the dilution factor.

Potassium efflux experiments with immobilized cultures (procedure shown in Figure 2) were carried out by growing $5 \mathrm{~L}$ culture overnight to mid-log growth state (absorbance of the media was between 0.10 and 0.20 at $590 \mathrm{~nm}$ ) in PA BT media. The polymer immobilization was carried out as described in Section 2.2. Once complete, the immobilized cells were equally divided among six flasks containing $100 \mathrm{~mL}$ media each. The experiment on the potassium concentration effluxed per cell after a shock with NEM proceeded in the same manner as described for the planktonic samples, but the experiment time was extended to two hours.

\subsection{Alginate bead material stability testing}

The material stability of the alginate beads after exposure to equivalent concentrations of potassium to that observed during efflux was determined using a texture analyzer (TA-XT2i Texture Analyzer, Texture Technologies Corporation, Scarsdale, NY). The instrument was operated to measure force in compression, with a test speed of $0.1 \mathrm{~mm} / \mathrm{s}$ using the $5 \mathrm{~kg}$ load cell. Rupture was deemed as the peak of the force curve before reaching the stage. 
To determine the effect of potassium on the bead stability, alginate beads without immobilized cells were incubated for two weeks in deionized water containing potassium at a range bracketing the values that would be observed per bead from cell efflux. The maximum efflux per cell was scaled down based on the cell loading per bead to determine the potassium dose per bead. Ten beads were used for each concentration, and the concentrations selected were 0.3 and $0.6 \mathrm{mg}$ potassium per $1.1 \mathrm{~mL}$ of liquid to bracket the possible range of efflux potential. The control consisted of 10 beads in $1.1 \mathrm{~mL}$ deionized water with no added potassium.

\section{Results and Discussion}

\subsection{Planktonic efflux experiments show no difference between bacterial strains}

A series of potassium efflux experiments were conducted on planktonic cultures of $P$. aeruginosa and E. coli across their growth curves to determine which strain effluxed the most potassium per cell, and to determine which growth state elicits the strongest efflux response. A typical result from a batch efflux experiment is shown in Figure 3. Figure 4 shows the series of batch experiments that were performed to compare the potassium efflux potential of the two strains at various growth states on media containing comparable potassium concentration. The average $\mathrm{K}^{+}$efflux in planktonic cultures grown to mid log state was $(4.50 \pm 0.4) \times 10^{-10} \mathrm{mg} \mathrm{K}^{+}$per cell for P. aeruginosa and $(5.54 \pm 0.8) \times 10^{-10} \mathrm{mg} \mathrm{K}^{+}$ per cell for $E$. coli, while cells in late log phase averaged a potassium efflux of $(3.07 \pm 0.4) \mathrm{x}$ $10^{-10} \mathrm{mg} \mathrm{K}^{+}$per cell for P. aeruginosa and $(4.15 \pm 0.3) \times 10^{-10} \mathrm{mg} \mathrm{K}^{+}$per cell for E. coli. Although it appears that late $\log$ phase $(0.20-0.25$ and $0.25-0.30$ absorbance units measured at $590 \mathrm{~nm}$ for E. coli and P. aeruginosa, respectively) experiments produced somewhat lower efflux potential than mid log phase cells (0.025-0.20 and 0.025-0.25 absorbance units 
measured at $590 \mathrm{~nm}$ for $E$. coli and $P$. aeruginosa, respectively) no difference exists in the average efflux potentials based on a statistical t-test between mid and late log phase experiments with either culture. Further, no difference exists between the average efflux potentials between the cultures at either growth state. Since the activated sludge $P$. aeruginosa isolate used in these experiments effluxes comparable $\mathrm{K}^{+}$on average per cell, we continued to use $P$. aeruginosa in further experiments because it may more accurately represent conditions at wastewater plants than the laboratory E. coli strain.

\subsection{Material failure in alginate beads cannot be attributed to $\mathrm{K}^{+}$efflux}

Because the alginate matrix degraded after only five days of polymerization, experiments were conducted to determine if the potassium efflux from the cells caused the breakdown of the polymer structure. The alginate polymerizes by substitution of calcium for sodium within the matrix, and matrix stability was hypothesized to be affected by reequilibration in sodium. Because of the similarity in the properties of sodium and potassium, it was thought that the potassium effluxed from the cells interacts with the matrix and aids in its degradation. However, the concentration of potassium that would be effluxed into the bulk liquid had no effect on the bead stability as measured by a texture analyzer to measure force in compression, as shown in Figure 5.

\subsection{Potassium efflux from alginate-immobilized cells is reduced as compared to} planktonic cultures, but nearly equal for thermal polymer-immobilized cells

Experiments to determine the amount of potassium effluxed per cell while immobilized were carried out with $P$. aeruginosa at mid-log growth state in calcium alginate beads. Sample results from initial efflux experiments conducted with alginate-immobilized cells are shown in Figure 6. A t-test showed that the potassium concentration at point four 
was statistically different from the initial value, indicating that efflux occurred. The efflux potential with the immobilized culture was $(1.3 \pm 0.1) \times 10^{-10} \mathrm{mg} \mathrm{K}^{+}$per cell, as shown in Table 1, which is much lower than the efflux from planktonic cultures. However, efflux was significantly reduced in experiments conducted on the same immobilized cells after five days (shown in Figure 7), probably because the maintenance media had a very low potassium concentration, and the cells were unable to replenish their internal potassium stocks. The large variability and the reduced initial efflux potential observed in the data from the alginate immobilized cells is likely due to electrophilic diffusion limitations into the beads and $\mathrm{K}^{+}$out of the beads, although these limitations were not explored or quantified.

On the other hand, the efflux potential from the thermal polymer-immobilized cells was higher than that from the alginate and comparable to the results for planktonic culture, as shown in Table 1. The efflux observed one day after immobilization was $(4.6 \pm 0.8) \times 10^{-10}$ $\mathrm{mg} \mathrm{K}^{+} /$cell, four times greater than that of the alginate-immobilized cells (Figure 8). As in the alginate, the efflux potential decreased with time. Figure 9 shows the efflux results from cells immobilized for five days. The figure shows no clear efflux trend, although the control seems to be uptaking potassium. Again, it is thought that the reduced efflux potential with time is attributed to the low-potassium maintenance media.

Table 1: The efflux potential from immobilized P. aeruginosa in two polymer matrices on day one as compared to the average of four planktonic experiments

\begin{tabular}{|c|c|c|}
\hline Matrix & Efflux Potential (mg K ${ }^{+} /$cell) & $\mathbf{n}$ \\
\hline None (Planktonic) & $(4.50 \pm 0.4) \times 10^{-10}$ & 4 \\
\hline Alginate & $(1.3 \pm 0.1) \times 10^{-10}$ & 1 \\
\hline Thermal & $(4.6+0.8) \times 10^{-10}$ & 1 \\
\hline
\end{tabular}




\section{Conclusions}

A series of experiments were conducted in this work to select an appropriate polymer matrix for bacterial cell immobilization within the biosensor under development. The ideal matrix will be physically and chemically stable over several weeks, will be non-toxic to the cells, and will not limit the diffusion of oxygen, compounds necessary for cell growth, or the electrophiles which would trigger a stress response. Two matrices were examined here: a calcium alginate and a thermal polymer.

Both polymers showed stable initial efflux results, but later efflux experiments on the polymers resulted in unstable and reduced efflux, perhaps because the potassium concentration in the matrix was limited, thus preventing the cells from replenishing their potassium stocks. The sodium alginate matrix was materially unstable and unable to contain the bacterial cells after five days, but the cause could not be attributed to the potassium effluxed from the cells. Efflux from the alginate beads was four times lower than that from the thermal or the planktonic cells, and the variability was much higher. The thermal polymer was non-toxic, stable, and the initial efflux potential from thermal polymerimmobilized cells was nearly equal to that from planktonic cells. The only limitation on the incorporation of the thermal polymer within the microfluidic sensor is the need to maintain a higher-than-ambient temperature in the cell chamber. On the whole, the thermal polymer shows great potential for incorporation in the biosensor.

\section{Acknowledgements}

The project was supported by the Paul L. Busch Award and the EPA Midwest Hazardous Substances Research Center. KAL acknowledges the support of the Charles E. Via, Jr. Department of Civil and Environmental Engineering Endowment. The authors 
would like to thank Julie Petruska, Jody Smiley, and Phil Wunderly for analytical and laboratory support. 


\section{References}

Apontoweil, P., Berends, W. (1975a). Glutathione biosythesis in Escherichia coli K-12: properties of the enzymes and regulation. Biochimica et Biophysica Acta, 399 (1), 1-9.

Apontoweil, P., Berends, W. (1975b). Isolation and initial characterization of glutathionedeficient mutants of Escherichia coli K-12. Biochimica et Biophysica Acta. 399(1), 10-22.

Bott, C. B. and Love, N. G. (2002) Investigating a mechanistic cause for activated sludge deflocculation in response to shock loads of toxic electrophilic chemicals. Water Environment Research. 74, 306-315.

Bott, Charles B. (2001) Elucidating the role of toxin-induced microbial stress responses in biological wastewater treament process upset. Diss. Virginia Polytechnic Insitute and State University.

Elasri, Mohamed O., Tricia Reid, Steven Hutchens, Robert V. Miller. (2000) Response of a Pseudomonas aeruginosa biofilm community to DNA-damaging chemical agents. FEMS Microbiology Ecology 33, 21-25

Erickson, David, and Dongqing Li. (2004) Integrated microfluidic devices. Analytica Chimica Acta 507, 11-26

Ferguson, G., McLaggan P. D., Booth, I.R. (1995). Potassium channel activation by glutathione-S-conjugates in Escherichia coli. Molecular Microbiology. 17(6), 1025-1033.

Gu, Man Bock, and Sue Hyung Choi. (2002) A portable toxicity biosensor using freezedried recombinant bioluminescent bacteria. Biosensor and Bioelectronics. 17, 433-440

Higgins, M.J. and Novak, J.T. (1997a) Dewatering and settling of activated sludges: The case for using cation analysis. Water Environment Research 69 (2), 225-232

Higgins, M.J. and Novak, J.T. (1997b) The effect of cations on the settling and dewatering of activated sludges: Laboratory results. Water Environment Research 69 (2), 215-224

Love, N. G., Bott, C.B. (2000). WERF Project 99-WWF-2 Report: A review of and needs survey of upset early warning devices. Water Environment Research Foundation.

Kohler, Sabine, Till T. Bachmann, Jutta Schmitt, Shimshon Belkin, Rolf D. Schmid. (2000) Detection of 4-chlorobenzoate using immobilized recombinant Escherichia coli reporter strains. Sensors and Actuators B 70, 139-144

Murthy, SN, JT Novak, RD De Haas. (1998) Monitoring cations to predict and improve activated sludge settling and dewatering properties of industrial wastewaters. Water Science and Technology. 38 (3), 119-126 
Philp, Jim C., Severine Balmand, Eva Hajto, Mark J. Bailey, Siouxsi Wiles, Andrew S. Whiteley, Andrew K. Lilley, Janos Hajto, and Sandra A. Dunbar. (2003). Whole cell immobilized biosensor for toxicity assessment of a wastewater treatment plant treating phenolics-containing waste. Analytica Chimica Acta 487(1) 61-74

Polyak, B., E. Bassis, A. Novodvorets, S. Belkin, and R.S. Marks. (1997) Optical fiber bioluminescent whole-cell microbial biosensors to genotoxicants. Water Science and Technology. 42 (12), 305-311

Polyak, Boris S., Efim Bassis, Alex Novodvorets, Shimshon Belkin, Robert S. Marks. Bioluminescent whole cell optical fiber sensor to genotoxicants: system optimization. (2001) Sensors and Actuators B 74, 18-26

Rehm, Bernd H.A. (1998) Alginate lyase from Pseudomonas aeruginosa CF1/M1 prefers the hexameric oligomannuronate as substrate. FEMS Microbiology Letters 165, 175-180

Reid, Brian J., Kirk T. Semple, Christopher J. Macleod, Jedda J. Weitz, Graeme I. Paton. (1998) Feasibility of using prokaryote biosensors to assess acute toxicity of polycyclic aromatic hydrocarbons. FEMS Microbiology Letters 169, 227-233

Taurianinen, Sisko, Matti Karp, Wei Chang, and Marko Virta. (1998) Luminescent bacterial sensor for cadmium and lead. Biosensor and Bioelectronics 13, 931-938

Webb O. F., P.R. Beinkowski, U. Matrubutham, F.A. Evans, A. Heitzer, G.S. Sayler. (1997) Kineticis and response of a Pseudomonas fluorescens HK44 biosensor. Biotechnology and Bioengineering. 54 (5), 491-502 


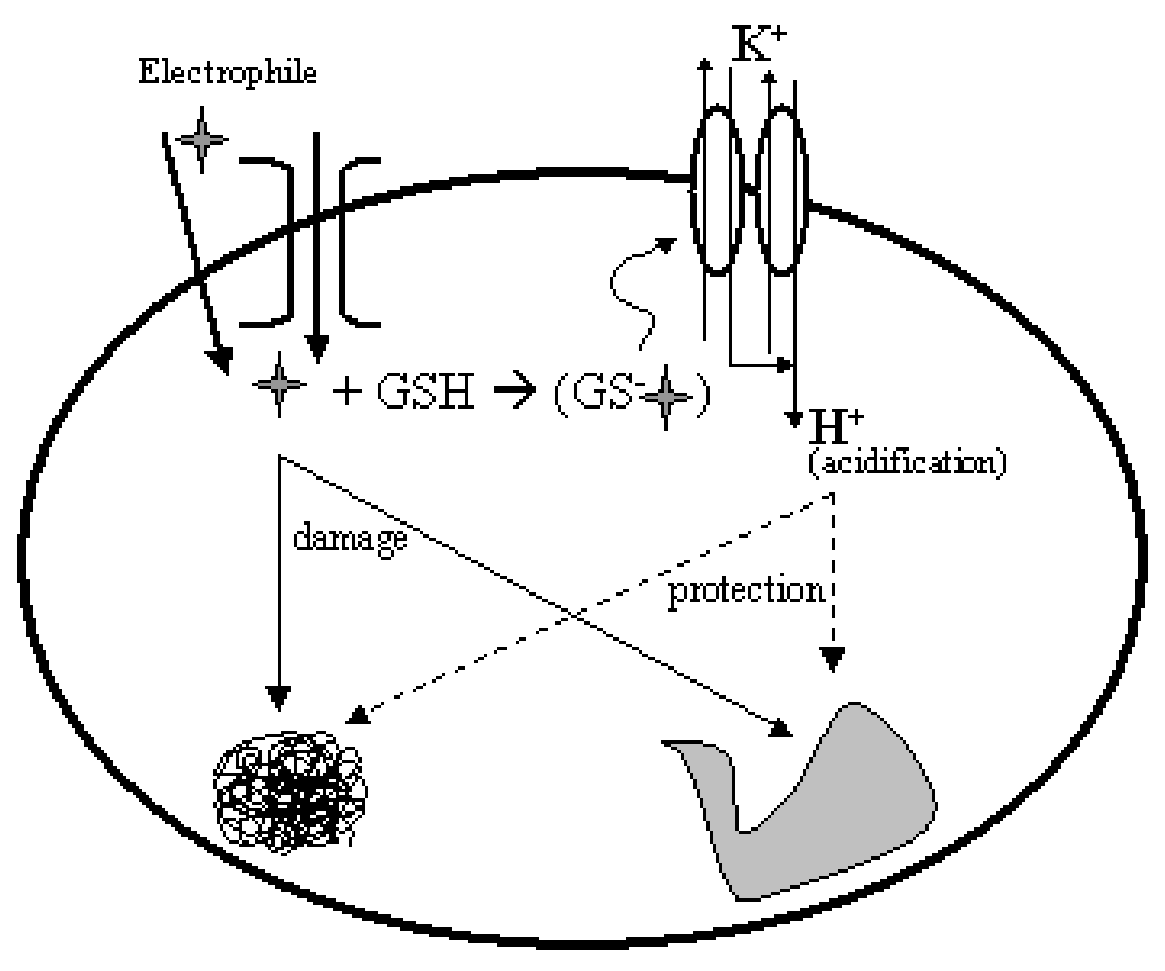

Figure 1: The glutathione-gated potassium efflux (GGKE) system. When an electrophile enters a cell, it can damage DNA and proteins by oxidation. Cells have developed the GGKE stress response to reduce this type of damage. Reduced glutathione, GSH, reacts with the electrophile to create a glutathione-electrophile conjugate. The presence of this conjugate within the cells triggers efflux channels that efflux potassium outside the cell while concurrently importing hydrogen ions. These hydrogen ions acidify the cytoplasm, and the $\mathrm{pH}$ drop affords protection from the electrophile for the DNA and proteins within the cell. Overall, the GGKE stress response system is characterized by potassium efflux in response to an electrophilic challenge. (After Dr. Charles Bott, 2001) 


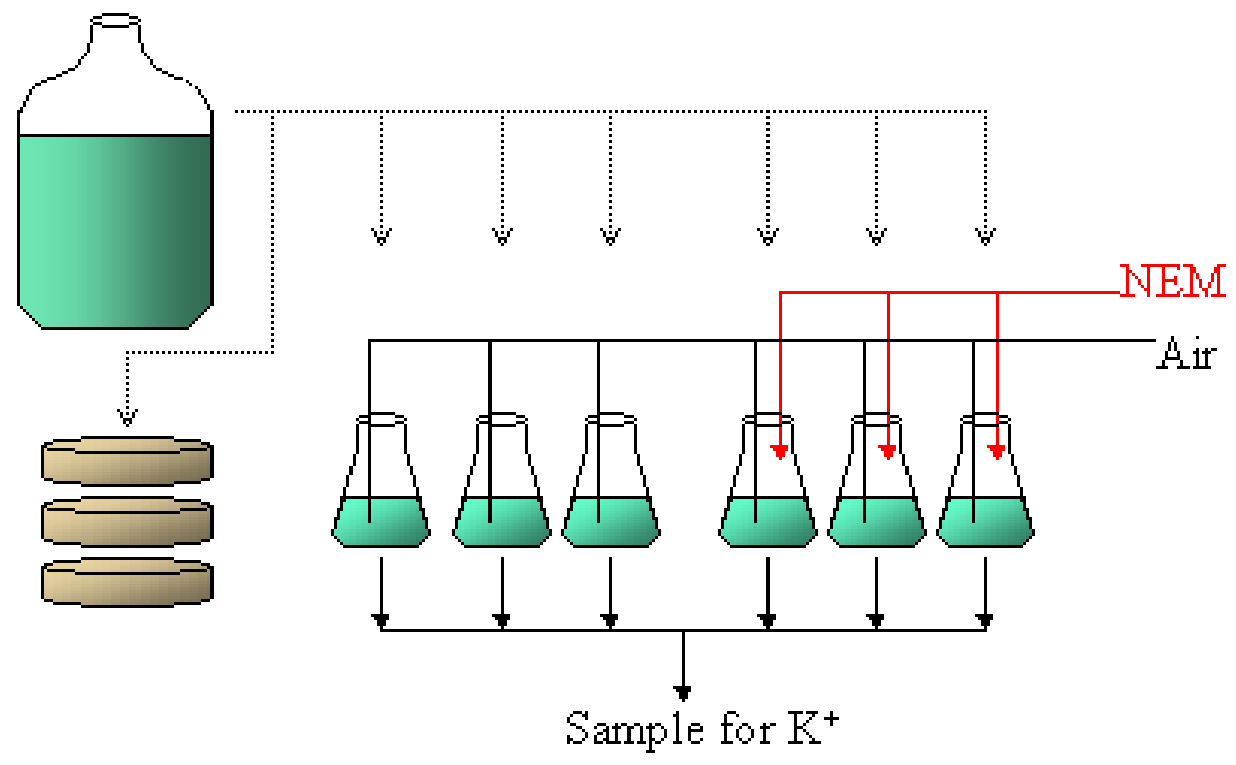

Figure 2: The experimental setup for potassium efflux experiments. Culture was grown to the appropriate growth state in a $5 \mathrm{~L} \mathrm{jug}$, then concentrated by centrifugation and resuspended. An aliquot for plate counts was removed. The concentrated culture was divided among six flasks, which were aerated and, at time $=0$, dosed with NEM. Samples for potassium were taken over time to determine the increase in potassium concentration due to cell efflux. 


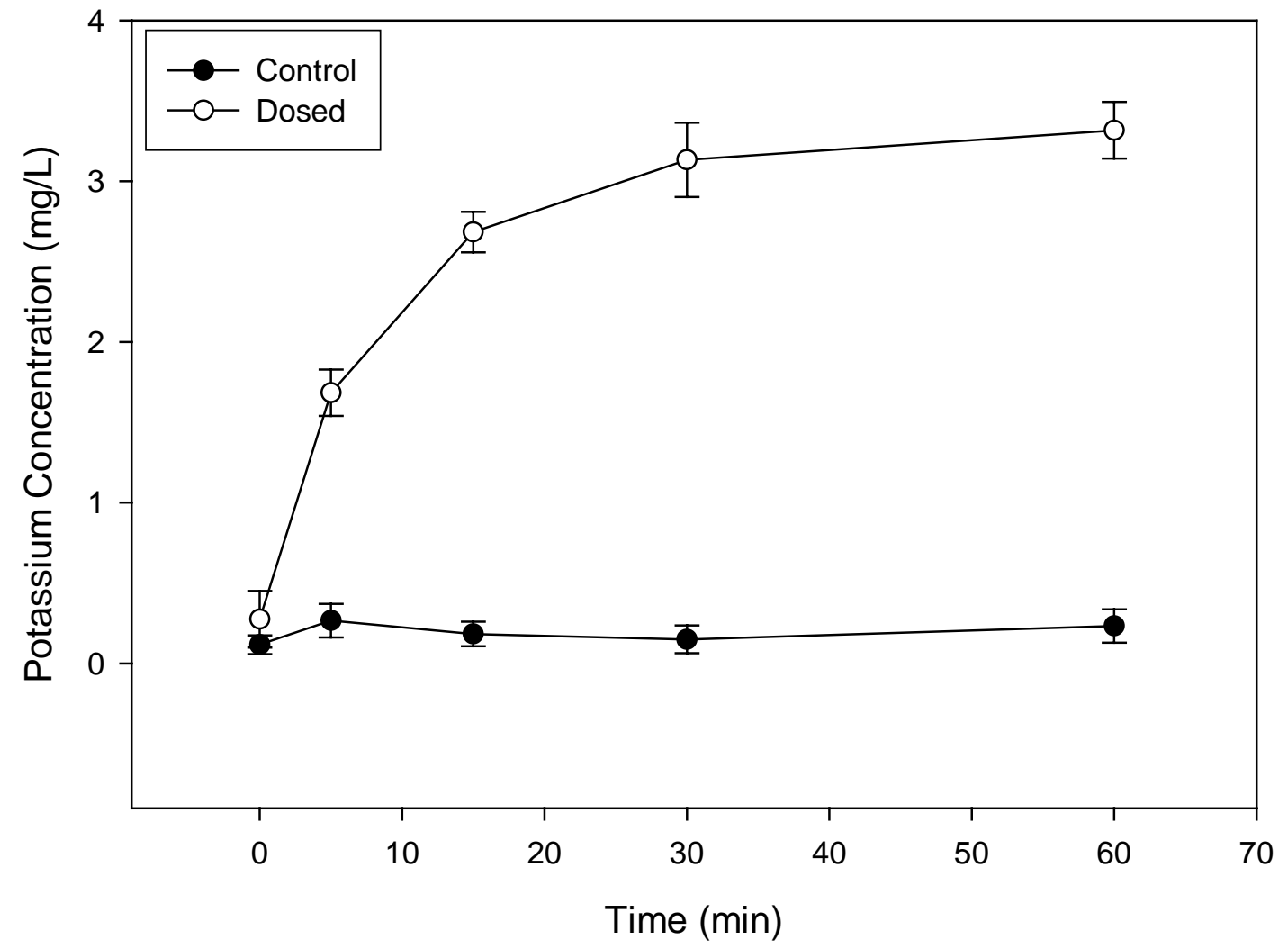

Figure 3. Batch $\mathrm{K}^{+}$efflux experiment with planktonic $P$. aeruginosa at an absorbance (measured at $590 \mathrm{~nm}$ ) of 0.215 after exposure to $50 \mathrm{mg} / \mathrm{L} \mathrm{N}$-ethylmaleimide (NEM) versus an unshocked control. Error bars represent the standard deviation of the averages for three flasks. 


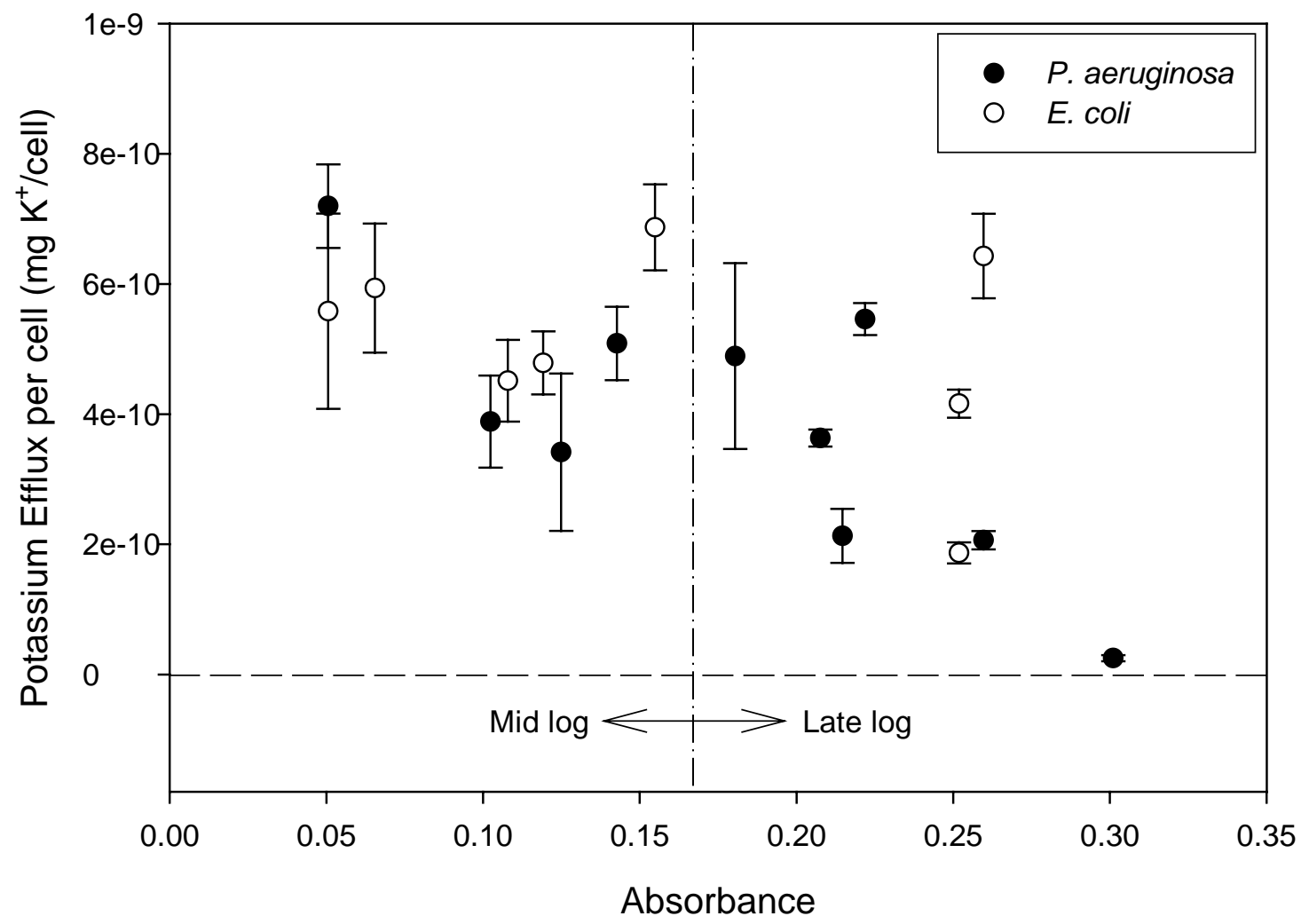

Figure 4. $\quad \mathrm{K}^{+}$efflux potentials ( $\mathrm{mg} \mathrm{K}^{+}$effluxed per cell) versus planktonic culture density, measured as absorbance (at $590 \mathrm{~nm}$ ), for P. aeruginosa and E. coli. 


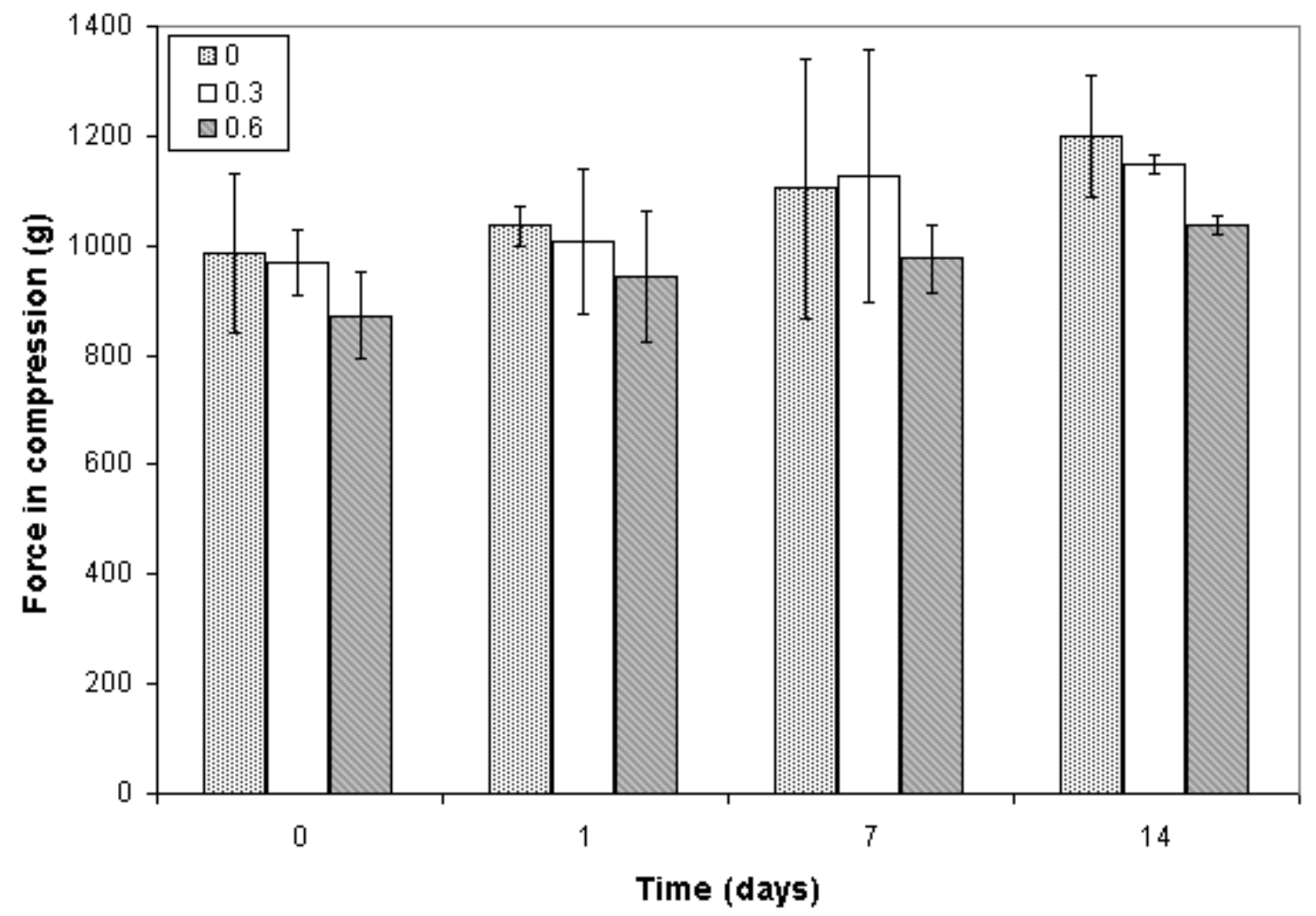

Figure 5: $\quad$ No significant difference is observed in the force required to rupture for alginate beads incubated over time with potassium concentrations comparable to that effluxed from immobilized cells. 


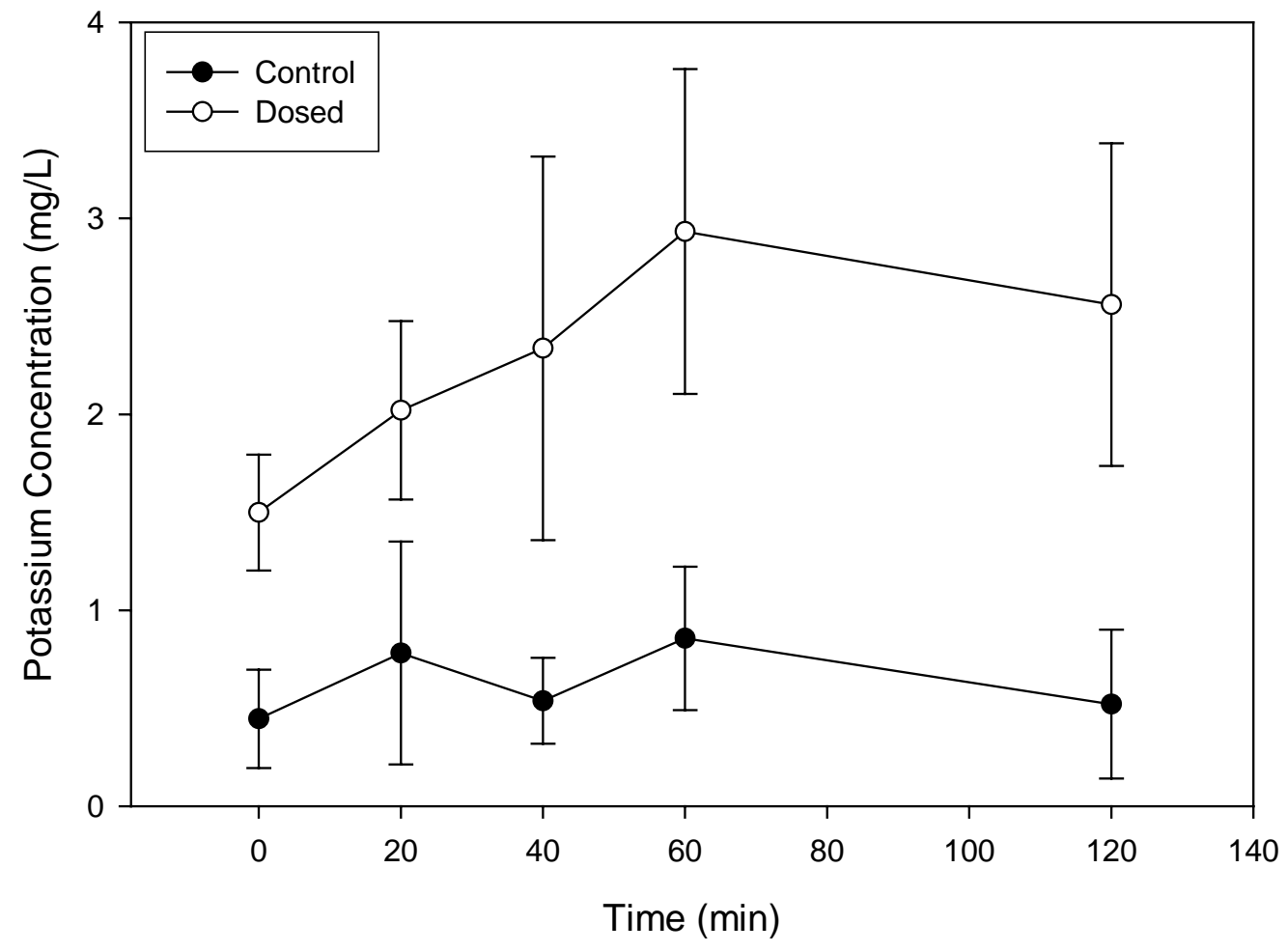

Figure 6. $\quad \mathrm{K}^{+}$efflux $\left((1.3 \pm 0.1) \times 10^{-10} \mathrm{mg} \mathrm{K}^{+}\right.$per cell $)$at $\mathrm{t}=1$ day from P. aeruginosa immobilized in calcium alginate beads after exposure to $50 \mathrm{mg} / \mathrm{L}$ NEM versus an unstressed, immobilized control. 


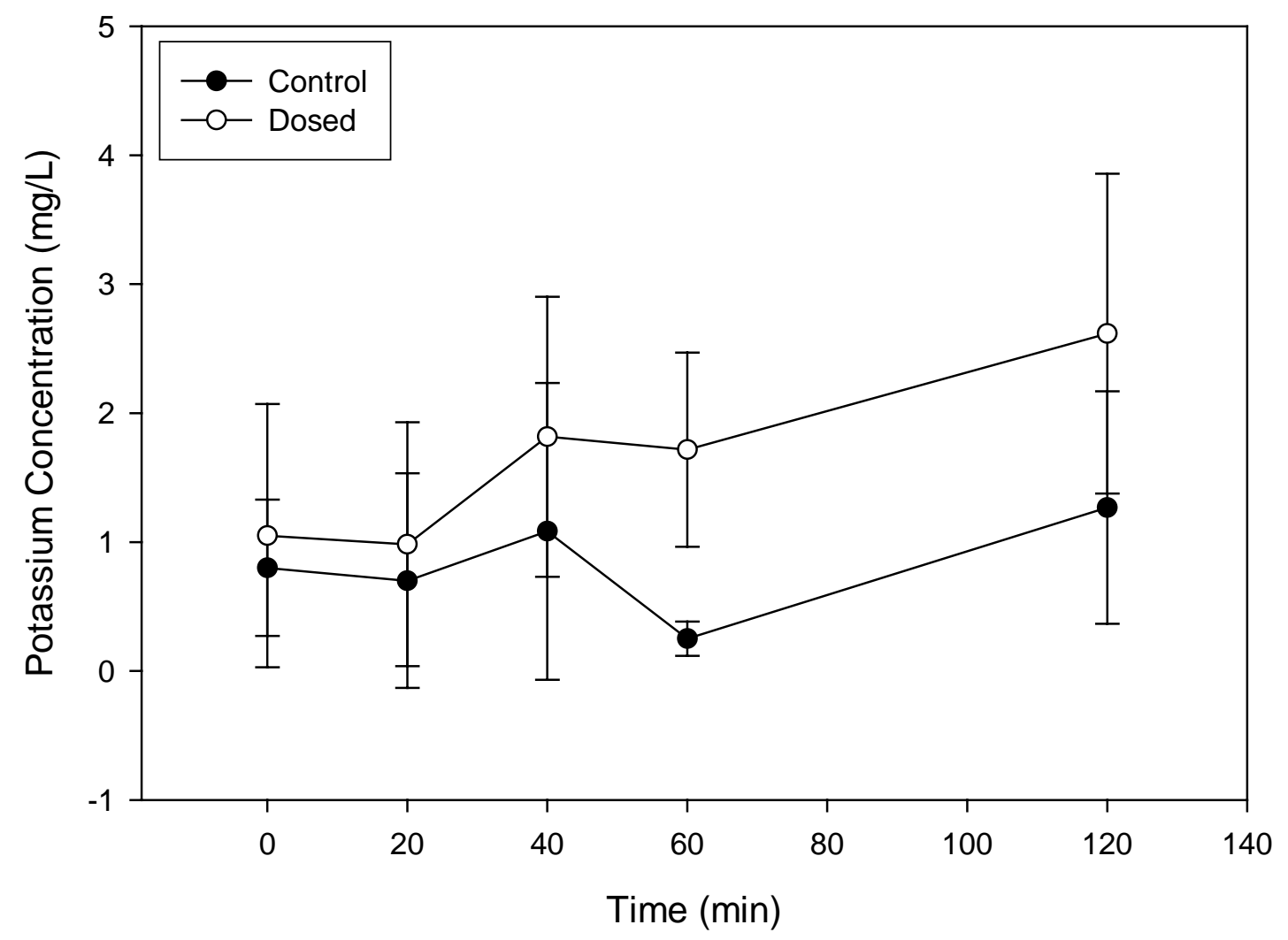

Figure 7: $\quad \mathrm{K}^{+}$efflux $\left((1.3 \pm 0.1) \times 10^{-10} \mathrm{mg} \mathrm{K}^{+}\right.$per cell $)$at $\mathrm{t}=5$ days from $P$. aeruginosa immobilized in calcium alginate beads after exposure to $50 \mathrm{mg} / \mathrm{L}$ NEM versus an unstressed, immobilized control. 


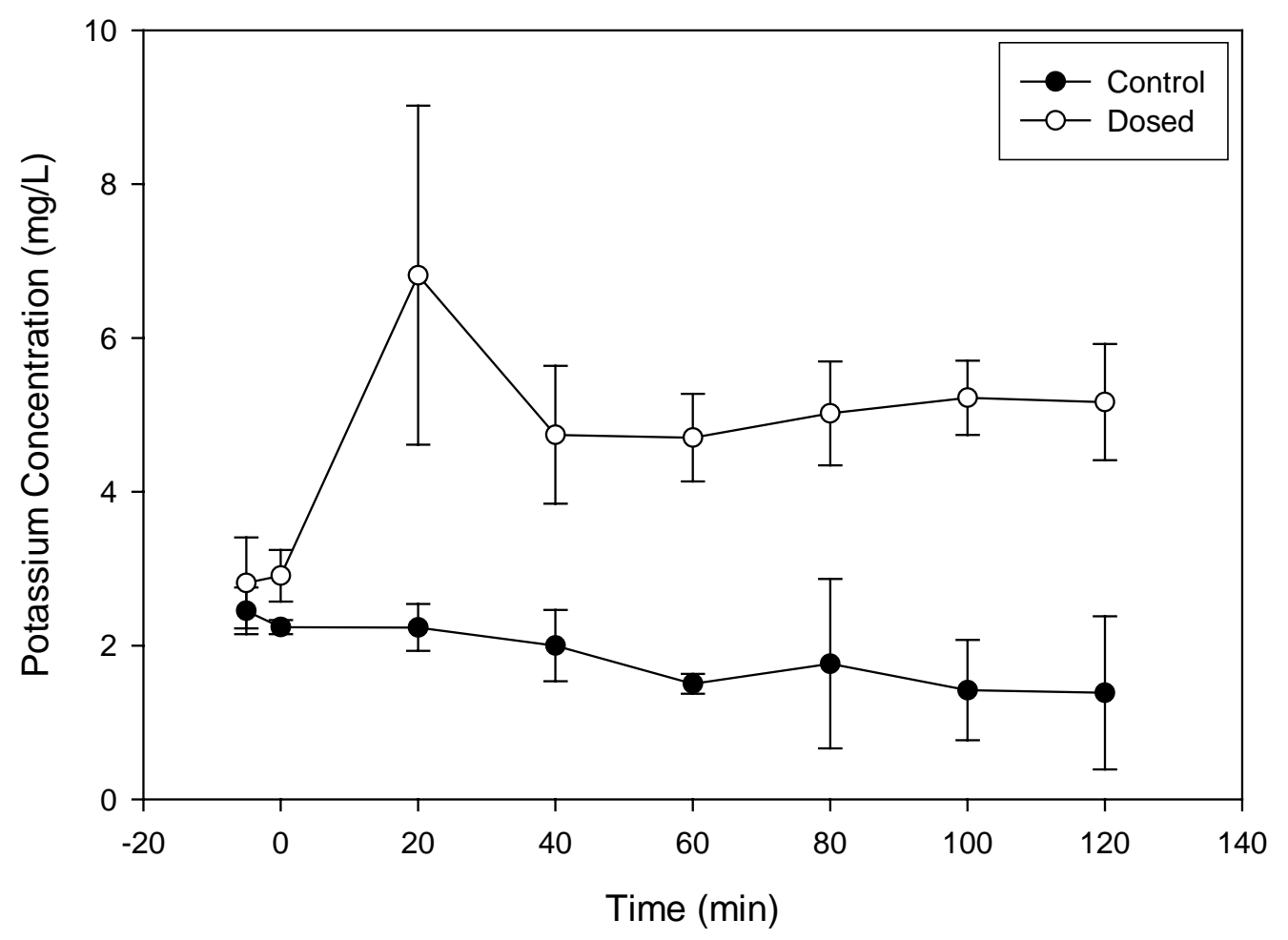

Figure 8. $\quad \mathrm{K}^{+}$efflux $\left((4.6 \pm 0.8) \times 10^{-10} \mathrm{mg} \mathrm{K}^{+} / \mathrm{cell}\right)$ at $\mathrm{t}=1$ day from $P$. aeruginosa immobilized in thermal polymer gels after exposure to $50 \mathrm{mg} / \mathrm{L}$ NEM versus an unstressed, immobilized control. 


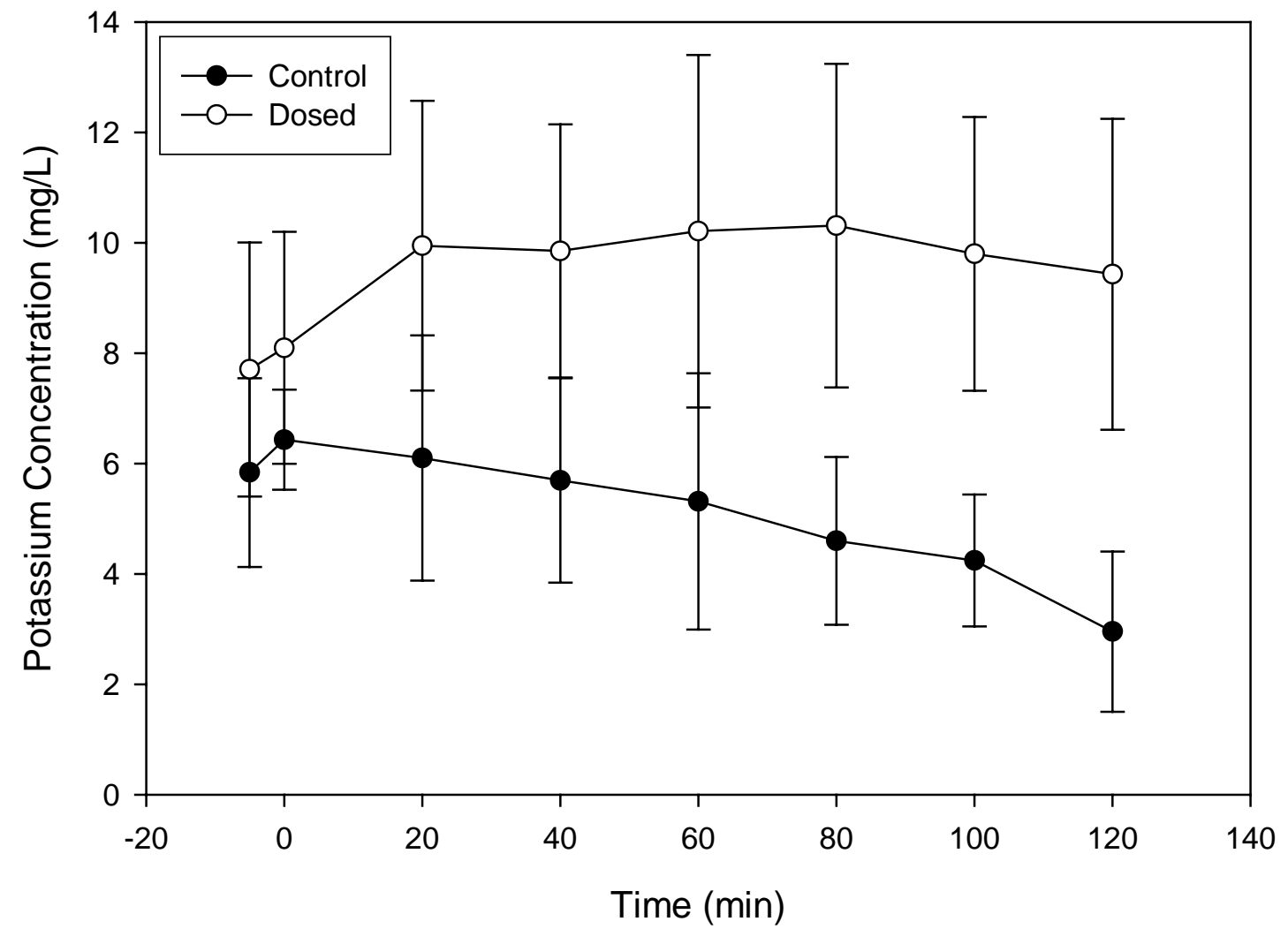

Figure 9: $\quad \mathrm{K}^{+}$efflux $\left((4.6 \pm 0.8) \times 10^{-10} \mathrm{mg} \mathrm{K}^{+} /\right.$cell $)$at $\mathrm{t}=5$ days from $P$. aeruginosa immobilized in thermal polymer gels after exposure to $50 \mathrm{mg} / \mathrm{L}$ NEM versus an unstressed, immobilized control. 


\section{Chapter 4: Engineering Significance}

\section{Engineering Significance}

Properly functioning wastewater treatment plants are vital to human health and water quality. However, even the most efficient plant may have instances of process upset, characterized by deflocculation and poor nutrient and BOD removal, that result in the failure of the treatment train. During such an event, operators typically are unaware that upset has begun until the event is well underway and the damage to the biological treatment step has been done. Providing operators with advanced warning when an upset is about to occur would allow them to initiate protective measures to ensure the continued functioning of the treatment process. Such advance warning would be possible with the biosensor under development here.

This biosensor will be the first to harness the GGKE stress response mechanism to link the efflux of potassium from immobilized cells with the presence of an electrophile in the sample. The change in potassium concentration across the sensor caused by potassium efflux from immobilized cells will be monitored; and, at a certain threshold increase, activation of the GGKE system will be inferred. Because the system is activated by electrophiles, the sensor will not be useful for upset events caused by other classes of compounds, such as oil and grease. Since many upsets can be linked to electrophilic shock and potassium efflux and, thus, to deflocculation, the sensor will serve a vital role in improving the functionality of wastewater treatment plants under the influence of toxic chemical shocks.

Incorporating this sensor in the real-time analyses of plant influent will inform operators of potential upset due to electrophilic shock. However, it will not tell the whole 
story of the potential for upset events because it is only useful for predicting electrophilic shock upset. Combining this sensor with other real-time sensors, such as sensors measuring the influent's effect on oxygen uptake rates within the bioreactor, would provide a more complete picture of the upset potential of the influent. Adding sensors for other effects on the biomass to create a sensor network that reponds to plant influent in real time would significantly improve the operator's control over process operations by providing information on the types of effects the influent may cause in the biomass. Although such a sensor would provide limited information on the cause of the effect, the early warning allows operators time to reroute the suspect influent or initiate treatment steps to mitigate the toxic effects of the influent.

In addition to using an array of biosensors to monitor the plant influent, such sensors might be applied to test the effluent from industries that discharge to the sewer system. This testing could be conducted as a prerequisite for discharge to the sewer, to ensure the safety of the large quantities of wastewater generated from industrial activities. Alternately, daily samples of industrial wastewater could be collected and the testing could be performed on the stored samples after an upset event, or after the upset warning sensors at the plant were triggered, in an attempt to find the cause of the upset. Such a system would work well in an area containing a few high volume industrial contributions where the testing of stored samples would take minimal time. As the number of industries increases, the time to determine the source of the cause increases, as does the age of the sample tested, reducing the reliability of the results. Clearly, for such attempts to link the causative industry to an upset event, the results of the biosensor must be proven and reliable. Extensive tests to determine the response of the sensor against background shifts in $\mathrm{pH}$ and temperature must be 
performed to rule out the possibility of false positive results. On the whole, an array of biosensors to monitor for process upset by electrophilic shock and by other modes of upset would improve the state of wastewater treatment by allowing operators time to respond to the threat, and by potentially enabling them to link the each upset with its cause. 


\section{Appendix A: Data for Chapter 2}

\section{A.1 Data for oxygen uptake rate experiments}

Data averaged from Probe A and B

Presented in Chapter 2, Figure 2

A.1.1 Photopolymerizable polymer: Photo 3, 4-21-04, Book 2, Page 87
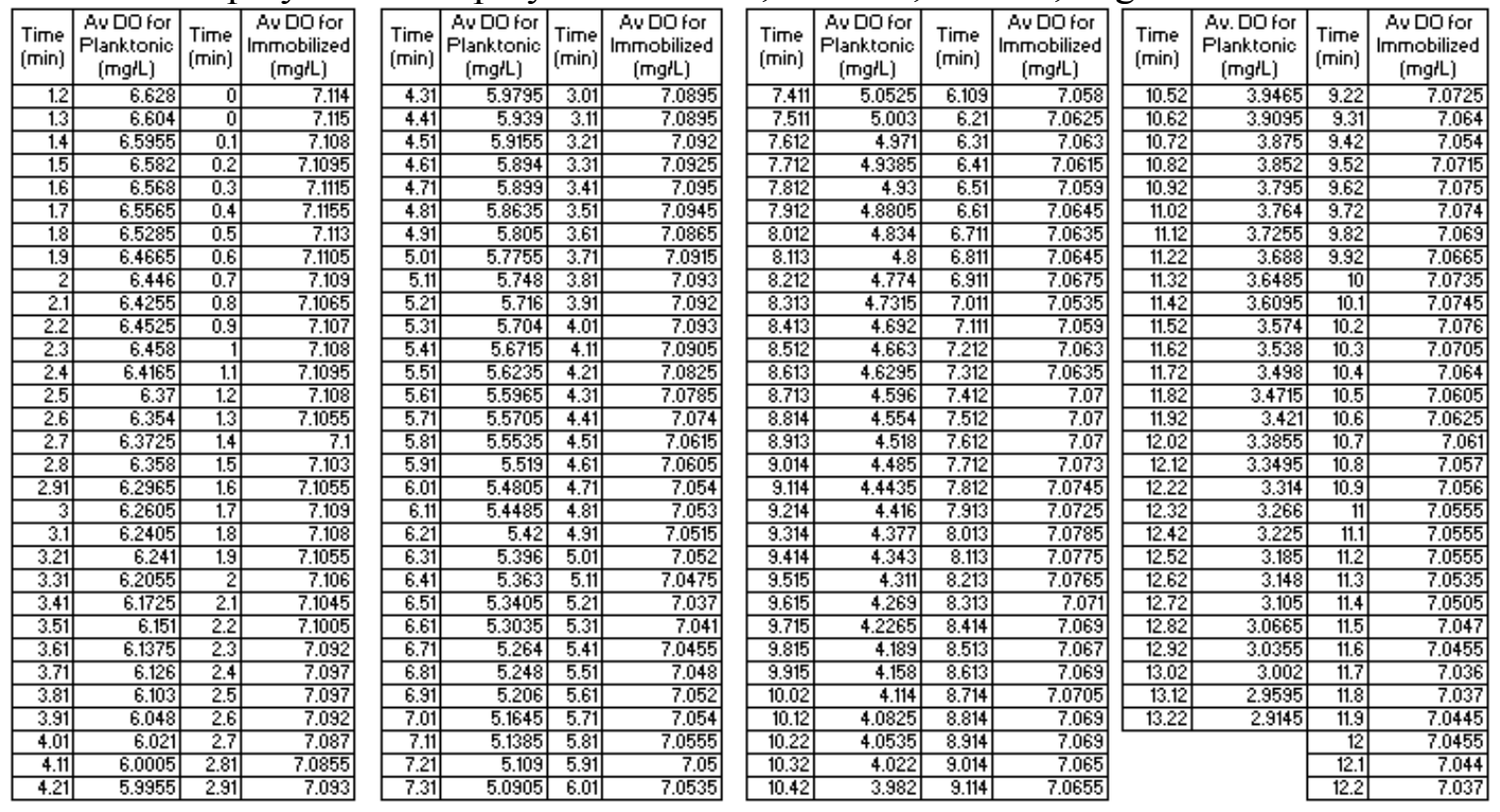

\begin{tabular}{|r|r|}
\hline $\begin{array}{r}\text { Time } \\
\text { (min) }\end{array}$ & $\begin{array}{c}\text { Av DO for } \\
\text { Immobilized } \\
\text { (mgIL) }\end{array}$ \\
\hline 12.32 & \multicolumn{1}{|c|}{7.037} \\
\hline 12.42 & 7.0325 \\
\hline 12.52 & 7.0385 \\
\hline 12.62 & 7.0385 \\
\hline 12.72 & 7.037 \\
\hline 12.82 & 7.041 \\
\hline 12.92 & 7.036 \\
\hline 13.02 & 7.0405 \\
\hline 13.12 & 7.042 \\
\hline 13.22 & 7.038 \\
\hline 13.32 & 7.038 \\
\hline 13.42 & 7.0385 \\
\hline 13.52 & 7.0355 \\
\hline 13.62 & 7.033 \\
\hline 13.72 & 7.031 \\
\hline 13.82 & 7.032 \\
\hline 13.92 & 7.033 \\
\hline 14.02 & 7.029 \\
\hline 14.12 & 7.029 \\
\hline 14.22 & 7.0295 \\
\hline 14.32 & 7.02 \\
\hline 14.42 & 7.016 \\
\hline 14.52 & 7.011 \\
\hline 14.62 & 7.0115 \\
\hline 14.72 & 7.011 \\
\hline 14.82 & 7.0125 \\
\hline 14.92 & 7.0205 \\
\hline 15.02 & 7.0095 \\
\hline 15.12 & 7.0085 \\
\hline 15.22 & 7.0055 \\
\hline 15.32 & 7.006 \\
\hline & \\
\hline
\end{tabular}

\begin{tabular}{|r|r|}
\hline $\begin{array}{r}\text { Time } \\
\text { (min) }\end{array}$ & $\begin{array}{c}\text { Av DO for } \\
\text { Immobilized } \\
\text { (mgr) })\end{array}$ \\
\hline 15.42 & 7.0055 \\
\hline 15.52 & 7.003 \\
\hline 15.62 & 7.004 \\
\hline 15.72 & 7.0035 \\
\hline 15.83 & 7.0035 \\
\hline 15.93 & 7.0025 \\
\hline 16.02 & 7.003 \\
\hline 16.13 & 7.004 \\
\hline 16.23 & 7.0015 \\
\hline 16.33 & 6.9995 \\
\hline 16.43 & 6.998 \\
\hline 16.53 & 7.005 \\
\hline 16.63 & 7.0035 \\
\hline 16.73 & 6.996 \\
\hline 16.83 & 7 \\
\hline 16.93 & 7.0025 \\
\hline 17.03 & 7.0025 \\
\hline 17.13 & 7.005 \\
\hline 17.23 & 6.9935 \\
\hline 17.33 & 7.0005 \\
\hline 17.43 & 7.0005 \\
\hline 17.53 & 7.0015 \\
\hline 17.63 & 7.003 \\
\hline 17.73 & 7.0035 \\
\hline 17.83 & 7.0005 \\
\hline 17.93 & 6.9975 \\
\hline 18.03 & 6.993 \\
\hline 18.13 & 6.998 \\
\hline 18.23 & 6.998 \\
\hline 18.33 & 6.9975 \\
\hline 18.43 & 6.995 \\
\hline & \\
\hline
\end{tabular}

\begin{tabular}{|r|r|}
\hline $\begin{array}{r}\text { Time } \\
\text { (min) }\end{array}$ & $\begin{array}{c}\text { Average DO for } \\
\text { Immobilized } \\
\text { (mgrt) }\end{array}$ \\
\hline 18.53 & 6.988 \\
\hline 18.63 & 6.988 \\
\hline 18.73 & 6.9835 \\
\hline 18.83 & 6.9845 \\
\hline 18.93 & 6.9835 \\
\hline 19.03 & 6.988 \\
\hline 19.13 & 6.988 \\
\hline 19.23 & 6.9865 \\
\hline 19.33 & 6.994 \\
\hline 19.43 & 6.994 \\
\hline 19.53 & 6.994 \\
\hline 19.63 & 6.9965 \\
\hline 19.73 & 6.996 \\
\hline 19.83 & 6.9895 \\
\hline 19.93 & 6.9955 \\
\hline 20.03 & 6.9925 \\
\hline 20.13 & 6.987 \\
\hline 20.23 & 6.9855 \\
\hline 20.33 & 6.9845 \\
\hline 20.43 & 6.982 \\
\hline 20.53 & 6.983 \\
\hline 20.63 & 6.983 \\
\hline 20.73 & 6.985 \\
\hline 20.83 & 6.9715 \\
\hline 20.93 & 6.9815 \\
\hline 21.03 & 6.9855 \\
\hline 21.13 & 6.9845 \\
\hline 21.23 & 6.981 \\
\hline 21.33 & 6.975 \\
\hline 21.43 & 6.979 \\
\hline 21.53 & 6.9765 \\
\hline & \\
\hline
\end{tabular}

\begin{tabular}{|r|r|}
\hline $\begin{array}{r}\text { Time } \\
\text { (min) }\end{array}$ & $\begin{array}{r}\text { Av DO for } \\
\text { Immobilized } \\
\text { (mgl') }\end{array}$ \\
\hline 21.63 & \multicolumn{1}{|c|}{6.977} \\
\hline 21.73 & 6.972 \\
\hline 21.83 & 6.9725 \\
\hline 21.93 & 6.973 \\
\hline 22.03 & 6.971 \\
\hline 22.13 & 6.968 \\
\hline 22.23 & 6.9635 \\
\hline 22.33 & 6.9615 \\
\hline 22.43 & 6.966 \\
\hline 22.54 & 6.9655 \\
\hline 22.64 & 6.9655 \\
\hline 22.74 & 6.96 \\
\hline 22.84 & 6.9635 \\
\hline 22.94 & 6.966 \\
\hline 23.04 & 6.962 \\
\hline 23.14 & 6.9635 \\
\hline 23.24 & 6.9645 \\
\hline 23.34 & 6.966 \\
\hline 23.44 & 6.965 \\
\hline 23.54 & 6.966 \\
\hline 23.64 & 6.964 \\
\hline 23.74 & 6.9575 \\
\hline 23.84 & 6.956 \\
\hline 23.94 & 6.961 \\
\hline 24.04 & 6.9425 \\
\hline 24.14 & 6.934 \\
\hline 24.24 & 6.9505 \\
\hline 24.34 & 6.955 \\
\hline 24.44 & 6.955 \\
\hline 24.54 & 6.952 \\
\hline 24.64 & 6.94 \\
\hline & \\
\hline
\end{tabular}

\begin{tabular}{|r|r|}
\hline $\begin{array}{r}\text { Time } \\
\text { (min) }\end{array}$ & $\begin{array}{r}\text { Av DO for } \\
\text { Immobilized } \\
\text { (mgll) }\end{array}$ \\
\hline 24.7 & 6.9365 \\
\hline 24.8 & 6.944 \\
\hline 24.9 & 6.9465 \\
\hline 25 & 6.946 \\
\hline 25.1 & 6.9455 \\
\hline 25.2 & 6.9475 \\
\hline 25.3 & 6.944 \\
\hline 25.4 & 6.944 \\
\hline 25.5 & 6.9415 \\
\hline 25.6 & 6.942 \\
\hline 25.7 & 6.9385 \\
\hline 25.8 & 6.9295 \\
\hline 25.9 & 6.9305 \\
\hline 26 & 6.9365 \\
\hline 26.1 & 6.9365 \\
\hline 26.2 & 6.934 \\
\hline 26.3 & 6.932 \\
\hline 26.4 & 6.9355 \\
\hline 26.5 & 6.9345 \\
\hline 26.6 & 6.9335 \\
\hline 26.7 & 6.935 \\
\hline 26.8 & 6.9315 \\
\hline 26.9 & 6.9305 \\
\hline 27 & 6.9265 \\
\hline 27.1 & 6.927 \\
\hline 27.2 & 6.921 \\
\hline 27.3 & 6.9255 \\
\hline 27.4 & 6.9265 \\
\hline 27.5 & 6.9235 \\
\hline 27.6 & 6.918 \\
\hline 27.7 & 6.923 \\
\hline & \\
\hline
\end{tabular}




\section{Oxygen Uptake Rates for Photopolymer Gel with New Initiator (Photo 3): 4-21-04}

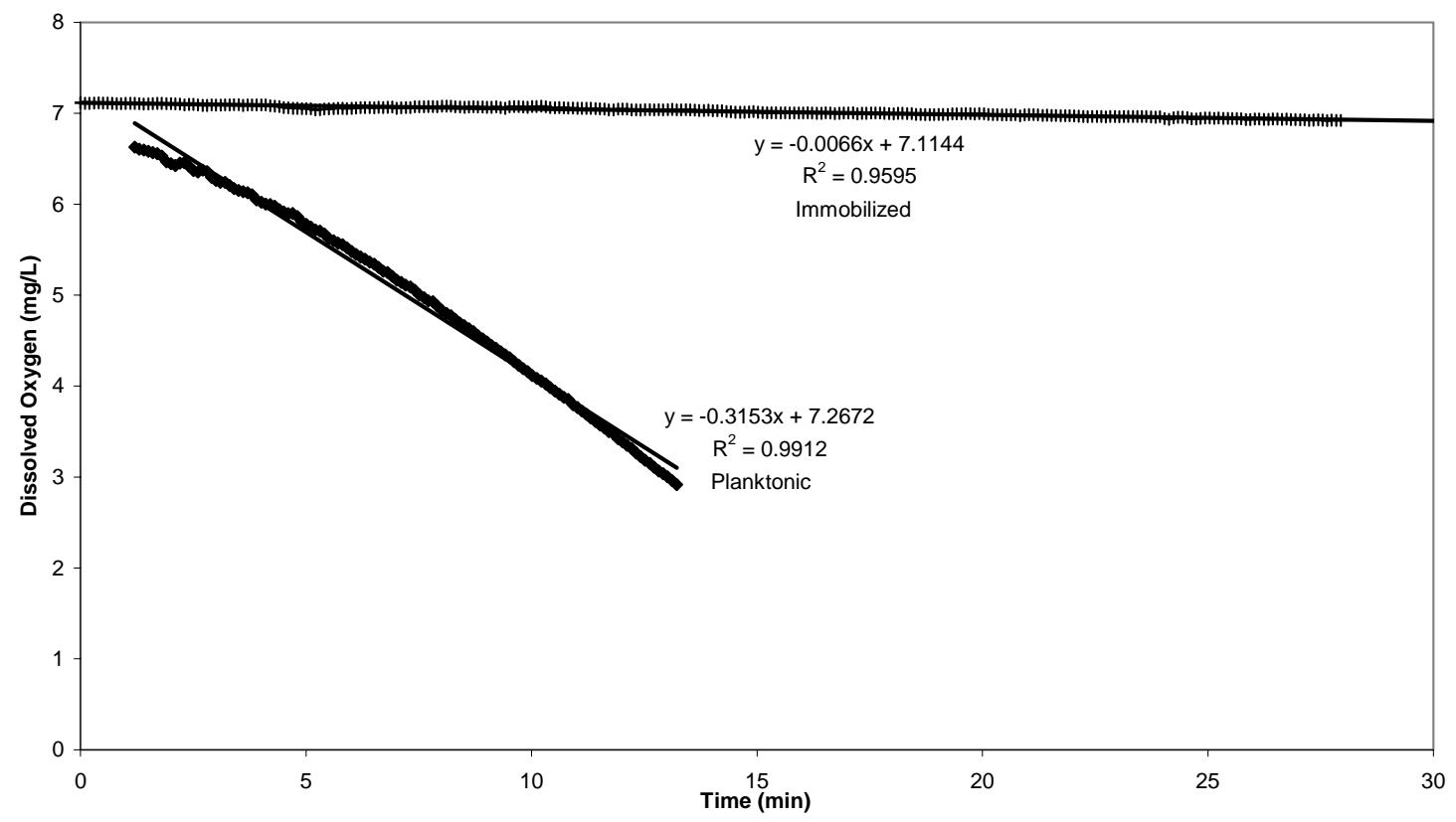

A.1.2 Photopolymerizable polymer: Photo 2, 3-18-04, Book 2, Page 77

\begin{tabular}{|c|c|c|c|}
\hline $\begin{array}{l}\text { Time } \\
\text { (min) }\end{array}$ & $\begin{array}{c}\text { AvDO for } \\
\text { Planktonic } \\
\text { [mglt) }\end{array}$ & $\begin{array}{l}\text { Time } \\
\text { (min) }\end{array}$ & $\begin{array}{c}\text { Av DO for } \\
\text { Immobilized } \\
\text { (mglL) }\end{array}$ \\
\hline 1.102 & 7.1025 & 1.2 & 7.3925 \\
\hline 1.202 & 7.097 & 1.3 & 7.3895 \\
\hline 1.302 & 7.0895 & 1.4 & 7.409 \\
\hline 1.402 & 7.091 & 1.5 & 7.3795 \\
\hline 1.502 & 7.096 & 1.6 & 7.431 \\
\hline 1.602 & 7.1025 & 1.7 & 7.4345 \\
\hline 1.703 & 7.0955 & 1.8 & 7.4195 \\
\hline 1.803 & 7.1035 & 1.9 & 7.4075 \\
\hline 1.903 & 7.0935 & 2 & 7.405 \\
\hline 2.003 & 7.0925 & 2.1 & 7.394 \\
\hline 2.103 & 7.102 & 2.2 & 7.3765 \\
\hline 2.203 & 7.0795 & 2.3 & 7.4045 \\
\hline 2.303 & 7.083 & 2.4 & 7.3965 \\
\hline 2.404 & 7.0915 & 2.5 & 7.4 \\
\hline 2.504 & 7.073 & 2.6 & 7.3915 \\
\hline$\frac{2.003}{2.603}$ & 7.0675 & 2.7 & 7.399 \\
\hline 2.704 & 7.025 & 2.8 & 7.374 \\
\hline 2.804 & 7.0385 & 2.91 & 7.356 \\
\hline 2.905 & 7.026 & 3 & 7.3985 \\
\hline 3.004 & 7.034 & 3.11 & 7.397 \\
\hline 3.104 & 7,0355 & 3.21 & 7.376 \\
\hline 3.205 & 7.0285 & 3.31 & 7.3585 \\
\hline 3.305 & 7.0095 & 3.41 & 7.343 \\
\hline 3.405 & 6.974 & 3.51 & 7.3275 \\
\hline 3.505 & 6.9695 & 3.61 & 7.35 \\
\hline 3.605 & 6.9575 & 3.71 & 7.3685 \\
\hline 3.706 & 6.9435 & 3.81 & 7.3595 \\
\hline 3.805 & 6.9375 & 3.91 & 7.355 \\
\hline 3.905 & 6.954 & 4.01 & 7.3705 \\
\hline 4.006 & 6.93 & 4.11 & 7.406 \\
\hline 4.106 & 6.9255 & 4.21 & 7.407 \\
\hline
\end{tabular}
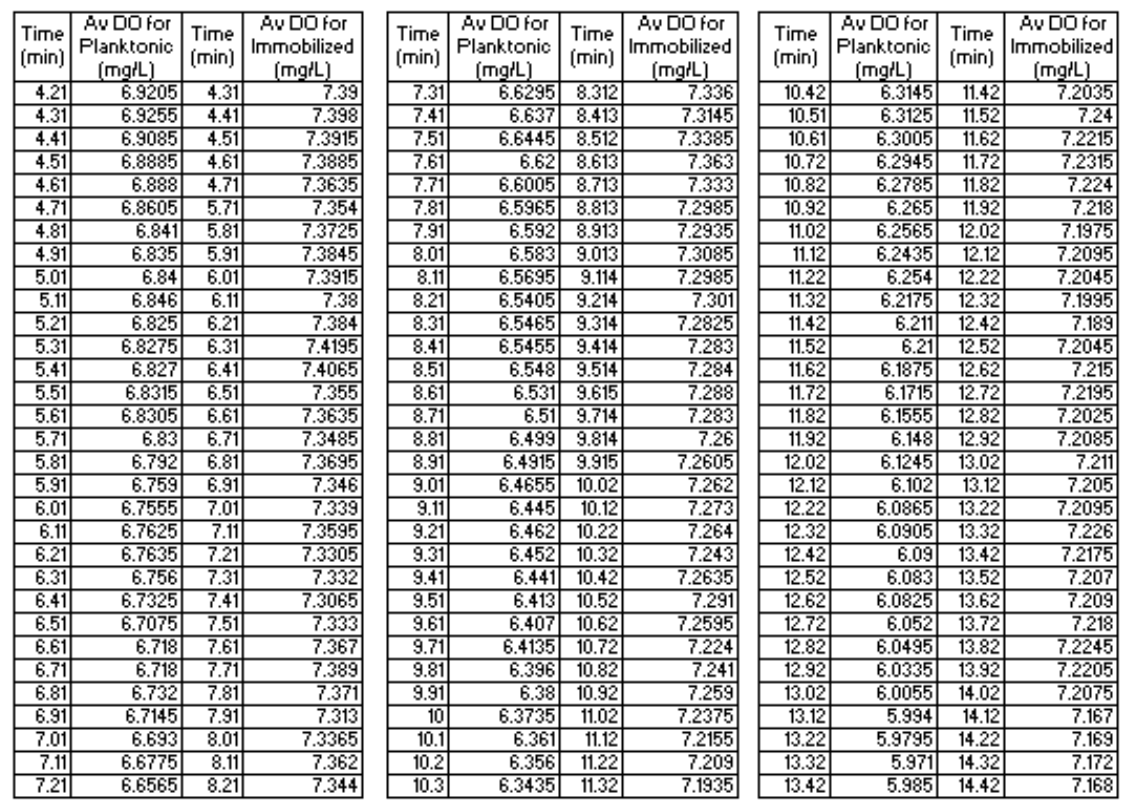


\begin{tabular}{|c|c|c|c|}
\hline $\begin{array}{l}\text { Time } \\
\text { (min) }\end{array}$ & $\begin{array}{c}\text { Av DO for } \\
\text { Planktonic } \\
\text { [mglt) }\end{array}$ & $\begin{array}{l}\text { Time } \\
\text { (min) }\end{array}$ & $\begin{array}{l}\text { Av DO for } \\
\text { Immobilized } \\
\text { [mgrl] }\end{array}$ \\
\hline 13.52 & 5.973 & 14.52 & 7.168 \\
\hline 13.62 & 5.942 & 4.62 & 7.174 \\
\hline 13.72 & 5.9185 & 14.72 & 7.162 \\
\hline 13.82 & 5.909 & 14.82 & 7.191 \\
\hline 13.92 & 5.8925 & 14.92 & 7.186 \\
\hline 14.02 & 5.8865 & 15.02 & 7.191 \\
\hline 14.12 & 5.9075 & 15.12 & 7.179 \\
\hline 14.22 & 5.898 & 15.22 & 7.215 \\
\hline 14.32 & 5.8475 & 15.32 & 7.228 \\
\hline 14.42 & 5.845 & 15.42 & 7.1965 \\
\hline 14.52 & 5.821 & 15.52 & 7.168 \\
\hline 14.62 & 5.829 & 15.62 & 7.1815 \\
\hline 14.72 & 5.817 & 18.03 & 7.236 \\
\hline 14.82 & 5.7975 & 18.13 & 7.274 \\
\hline 14.92 & 5.7685 & 18.23 & 7.249 \\
\hline 15.02 & 5.7545 & 18.33 & 7.241 \\
\hline 15.12 & 5.752 & 18.43 & 7.257 \\
\hline 15.22 & 5.7505 & 18.53 & 7.275 \\
\hline 15.32 & 5.731 & 18.63 & 7.2595 \\
\hline 15.42 & 5.715 & 18.73 & 7.2605 \\
\hline 15.52 & 5.698 & 18.83 & 7.278 \\
\hline 15.62 & 5.6965 & 18.93 & 7.2765 \\
\hline 15.72 & 5.683 & 19.03 & 7.273 \\
\hline 15.82 & 5.6785 & 19.13 & 7.248 \\
\hline 15.92 & 5.676 & 19.23 & 7.251 \\
\hline 16.02 & 5.6615 & 19.33 & 7.2555 \\
\hline 16.12 & 5.6335 & 19.43 & 7.258 \\
\hline 16.22 & 5.624 & 19.53 & 7.257 \\
\hline 16.32 & 5.61 & 19.63 & 7.255 \\
\hline 16.42 & 5.604 & 19.73 & 7.248 \\
\hline 16.52 & 5.574 & 19.83 & 7.2645 \\
\hline
\end{tabular}

\begin{tabular}{|c|c|c|c|}
\hline $\begin{array}{l}\text { Time } \\
\text { (min) }\end{array}$ & $\begin{array}{c}\text { Á DD for } \\
\text { Planktonic } \\
\text { [mgrll] }\end{array}$ & $\begin{array}{l}\text { Time } \\
\text { (min) }\end{array}$ & $\begin{array}{c}\text { Av DQ for } \\
\text { Immobilized } \\
\text { (mgll) }\end{array}$ \\
\hline 16.6 & 5.5645 & 19.93 & 7.2635 \\
\hline 16.7 & 5.565 & 20.03 & 7.262 \\
\hline 16.8 & 5.553 & 20.13 & 7.245 \\
\hline 16.9 & 5.5525 & 20.23 & 7.249 \\
\hline 17 & 5.5295 & 20.33 & 7.2445 \\
\hline 17.1 & 5.516 & 20.43 & 7.2395 \\
\hline 17.2 & 5.506 & 20.53 & 7.242 \\
\hline 17.3 & 5.4955 & 20.63 & 7.2525 \\
\hline 17.4 & 5.4765 & 20.73 & 7.236 \\
\hline 17.5 & 5.4695 & 20.83 & 7.224 \\
\hline 17.6 & 5.4565 & 20.93 & 7.232 \\
\hline 17.7 & 5.452 & 21.03 & 7.236 \\
\hline 17.8 & 5.4165 & 21.13 & 7.23 \\
\hline 17.9 & 5.4055 & 21.23 & 7.225 \\
\hline 18 & 5.406 & 21.33 & 7.243 \\
\hline 18.1 & 5.393 & 21.43 & 7.2255 \\
\hline 18.2 & 5.3745 & 21.53 & 7.1925 \\
\hline 18.3 & 5.3615 & 21.63 & 7.183 \\
\hline 18.4 & 5.35 & 21.73 & 7.1735 \\
\hline 18.5 & 5.341 & 21.83 & 7.1785 \\
\hline 18.6 & 5.33 & 21.93 & 7.174 \\
\hline 18.7 & 5.337 & 22.03 & 7.167 \\
\hline 18.8 & 5.316 & 22.13 & 7.1655 \\
\hline 18.9 & 5.2905 & 22.23 & 7.1725 \\
\hline 19 & 5.273 & 22.33 & 7.181 \\
\hline 19.1 & 5.2475 & 22.43 & 7.1775 \\
\hline 19.2 & 5.244 & 22.53 & 7.1895 \\
\hline 19.3 & 5.249 & 22.63 & 7.1895 \\
\hline 19.4 & 5.226 & 22.73 & 7.1935 \\
\hline 19.5 & 5.2245 & 22.83 & 7.177 \\
\hline 19.6 & 5.21 & 22.93 & 7.1925 \\
\hline
\end{tabular}

\begin{tabular}{|c|c|c|c|}
\hline $\begin{array}{l}\text { Time } \\
\text { (min) }\end{array}$ & $\begin{array}{l}\text { AuDO for } \\
\text { Planktonic } \\
\text { (mglt) }\end{array}$ & $\begin{array}{l}\text { Time } \\
\text { (min) }\end{array}$ & $\begin{array}{l}\text { Av DO for } \\
\text { Immobilized } \\
\text { (mgll) }\end{array}$ \\
\hline 19.73 & 5.2015 & 23 & 7.1795 \\
\hline 19.83 & 5.1875 & 23.1 & 7.187 \\
\hline 19.93 & 5.184 & 23.2 & 7.187 \\
\hline 20.03 & 5.157 & 23.3 & 7.1895 \\
\hline 20.13 & 5.1425 & 23.4 & 7.1735 \\
\hline 20.23 & 5.135 & 23.5 & 7.159 \\
\hline 20.33 & 5.1045 & 23.6 & 7.181 \\
\hline 20.43 & 5.103 & 23.7 & 7.1845 \\
\hline 20.53 & 5.0895 & 23.8 & 7.1835 \\
\hline 20.63 & 5.075 & 23.9 & 7.1775 \\
\hline 20.73 & 5.073 & 24 & 7.176 \\
\hline 20.83 & 5.0445 & 24.1 & 7.1895 \\
\hline 20.93 & 5.0325 & 24.2 & 7.1865 \\
\hline 21.03 & 5.031 & 24.3 & 7.164 \\
\hline 21.13 & 5.0205 & 24.4 & 7.1625 \\
\hline 21.23 & 5.0225 & 24.5 & 7.174 \\
\hline 21.33 & 4.982 & 24.6 & 7.179 \\
\hline 21.43 & 4.9685 & 24.7 & 7.181 \\
\hline 21.53 & 4.971 & 24.8 & 7.191 \\
\hline 21.63 & 4.9525 & 24.9 & 7.167 \\
\hline 21.73 & 4.939 & 25 & 7.174 \\
\hline 21.83 & 4.9265 & 25.1 & 7.17 \\
\hline 21.93 & 4.9165 & 25.2 & 7.1425 \\
\hline 22.03 & 4.906 & 25.3 & 7.165 \\
\hline 22.13 & 4.8865 & 25.4 & 7.16 \\
\hline 22.23 & 4.878 & 25.5 & 7.151 \\
\hline 22.33 & 4.855 & 25.6 & 7.15 \\
\hline 22.43 & 4.8215 & 25.7 & 7.1545 \\
\hline 22.53 & 4.812 & 25.8 & 7.1325 \\
\hline 22.63 & 4.8085 & 25.9 & 7.1375 \\
\hline 22.73 & 4.807 & 26 & 7.1375 \\
\hline
\end{tabular}

Oxygen Uptake Rates for Photopolymer Gel, Photo 2, 3-18-04

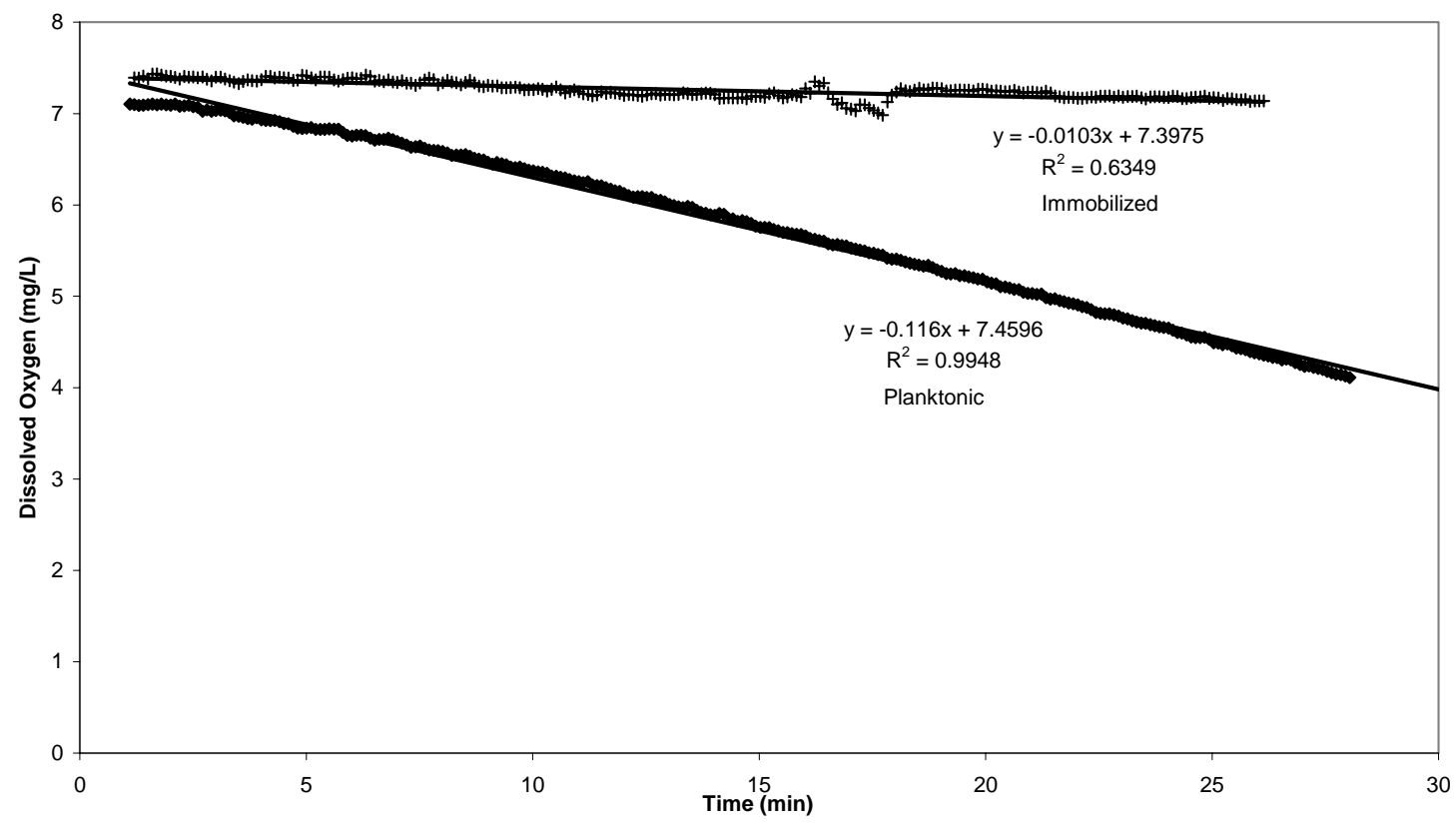


A.1.3 Photopolymerizable polymer: Photo 1, 2-26-04, Book 2, Page 72

\begin{tabular}{|r|r|r|r|}
\hline $\begin{array}{r}\text { Time } \\
\text { (min) }\end{array}$ & $\begin{array}{r}\text { Av DD for } \\
\text { Planktonic } \\
\text { [mgrl) }\end{array}$ & $\begin{array}{r}\text { Time } \\
\text { (min) }\end{array}$ & $\begin{array}{c}\text { Av DO for } \\
\text { Immobilized } \\
\text { (mglL) }\end{array}$ \\
\hline 2.1 & 6.531 & 2.104 & 6.9035 \\
\hline 2.2 & 6.52 & 2.203 & 6.911 \\
\hline 2.3 & 6.498 & 2.304 & 6.927 \\
\hline 2.4 & 6.48 & 2.404 & 6.9295 \\
\hline 2.5 & 6.449 & 2.504 & 6.902 \\
\hline 2.6 & 6.422 & 2.604 & 6.9045 \\
\hline 2.7 & 6.395 & 2.704 & 6.922 \\
\hline 2.81 & 6.367 & 2.804 & 6.9225 \\
\hline 2.91 & 6.338 & 2.905 & 6.8935 \\
\hline 3 & 6.316 & 3.004 & 6.898 \\
\hline 3.11 & 6.285 & 3.105 & 6.89 \\
\hline 3.21 & 6.255 & 3.205 & 6.9 \\
\hline 3.31 & 6.23 & 3.305 & 6.898 \\
\hline 3.41 & 6.198 & 3.405 & 6.886 \\
\hline 3.51 & 6.177 & 3.505 & 6.913 \\
\hline 3.61 & 6.149 & 3.606 & 6.9195 \\
\hline 3.71 & 6.14 & 3.706 & 6.912 \\
\hline 3.81 & 6.081 & 3.805 & 6.9055 \\
\hline 3.91 & 6.049 & 3.906 & 6.917 \\
\hline 4.01 & 6.023 & 4.006 & 6.923 \\
\hline 4.11 & 5.995 & 4.106 & 6.9035 \\
\hline 4.21 & 5.988 & 4.206 & 6.907 \\
\hline 4.31 & 5.932 & 4.306 & 6.9045 \\
\hline 4.41 & 5.9 & 4.407 & 6.902 \\
\hline 4.51 & 5.885 & 4.506 & 6.933 \\
\hline 4.61 & 5.851 & 4.606 & 6.9055 \\
\hline 4.71 & 5.824 & 4.707 & 6.9155 \\
\hline 4.81 & 5.797 & 4.807 & 6.8965 \\
\hline 4.91 & 5.775 & 4.907 & 6.9115 \\
\hline 5.01 & 5.746 & 5.007 & 6.9055 \\
\hline 5.11 & 5.702 & 5.107 & 6.9185 \\
\hline & & & \\
\hline
\end{tabular}

\begin{tabular}{|r|r|r|r|}
\hline $\begin{array}{r}\text { Time } \\
\text { (min) }\end{array}$ & $\begin{array}{c}\text { Av DO for } \\
\text { Planktonic } \\
\text { [mgrl) }\end{array}$ & $\begin{array}{r}\text { Time } \\
\text { (min) }\end{array}$ & $\begin{array}{c}\text { Av DO for } \\
\text { Immobilized } \\
\text { (mgll) }\end{array}$ \\
\hline 5.208 & 5.67 & 5.208 & 6.918 \\
\hline 5.307 & 5.64 & 5.307 & 6.9265 \\
\hline 5.408 & 5.603 & 5.407 & 6.9045 \\
\hline 5.508 & 5.572 & 5.508 & 6.9075 \\
\hline 5.609 & 5.533 & 5.608 & 6.916 \\
\hline 5.708 & 5.496 & 5.708 & 6.929 \\
\hline 5.808 & 5.472 & 5.808 & 6.934 \\
\hline 5.909 & 5.428 & 5.908 & 6.946 \\
\hline 6.009 & 5.398 & 6.009 & 6.923 \\
\hline 6.109 & 5.376 & 6.109 & 6.924 \\
\hline 6.209 & 5.332 & 6.209 & 6.9175 \\
\hline 6.309 & 5.317 & 6.309 & 6.9305 \\
\hline 6.41 & 5.28 & 6.409 & 6.9425 \\
\hline 6.51 & 5.259 & 6.51 & 6.9155 \\
\hline 6.609 & 5.212 & 6.609 & 6.9155 \\
\hline 6.71 & 5.165 & 6.71 & 6.921 \\
\hline 6.81 & 5.15 & 6.81 & 6.9295 \\
\hline 6.911 & 5.119 & 6.91 & 6.921 \\
\hline 7.01 & 5.06 & 7.01 & 6.904 \\
\hline 7.11 & 5.035 & 7.11 & 6.9245 \\
\hline 7.211 & 4.999 & 7.211 & 6.9465 \\
\hline 7.311 & 4.96 & 7.311 & 6.9415 \\
\hline 7.41 & 4.915 & 7.41 & 6.9295 \\
\hline 7.511 & 4.888 & 7.511 & 6.9145 \\
\hline 7.611 & 4.861 & 7.611 & 6.91 \\
\hline 7.712 & 4.823 & 7.712 & 6.909 \\
\hline 7.811 & 4.812 & 7.811 & 6.873 \\
\hline 7.911 & 4.747 & 7.911 & 6.8935 \\
\hline 8.012 & 4.713 & 8.012 & 6.895 \\
\hline 8.111 & 4.686 & 8.111 & 6.9 \\
\hline 8.212 & 4.641 & 8.212 & 6.9025 \\
\hline & & & \\
\hline
\end{tabular}

\begin{tabular}{|r|r|r|r|}
\hline $\begin{array}{r}\text { Time } \\
\text { (min) }\end{array}$ & $\begin{array}{c}\text { Av DO for } \\
\text { Planktonic } \\
\text { [mgil) }\end{array}$ & $\begin{array}{r}\text { Time } \\
\text { (min) }\end{array}$ & $\begin{array}{c}\text { Av DO for } \\
\text { Immobilized } \\
\text { [mgll) }\end{array}$ \\
\hline 8.312 & 4.612 & 8.312 & 6.875 \\
\hline 8.412 & 4.561 & 8.412 & 6.873 \\
\hline 8.512 & 4.524 & 8.512 & 6.8525 \\
\hline 8.612 & 4.497 & 8.612 & 6.845 \\
\hline 8.713 & 4.45 & 8.713 & 6.829 \\
\hline 8.813 & 4.404 & 8.813 & 6.822 \\
\hline 8.913 & 4.372 & 8.913 & 6.8315 \\
\hline 9.013 & 4.331 & 9.013 & 6.8465 \\
\hline 9.113 & 4.299 & 9.113 & 6.861 \\
\hline 9.214 & 4.259 & 9.213 & 6.851 \\
\hline 9.314 & 4.21 & 9.314 & 6.8655 \\
\hline 9.413 & 4.183 & 9.413 & 6.88 \\
\hline 9.514 & 4.144 & 9.514 & 6.873 \\
\hline 9.614 & 4.102 & 9.614 & 6.8835 \\
\hline 9.715 & 4.058 & 9.714 & 6.89 \\
\hline 9.814 & 4.02 & 9.814 & 6.894 \\
\hline 9.914 & 3.99 & 9.914 & 6.8915 \\
\hline 10.02 & 3.956 & 10.02 & 6.9055 \\
\hline 10.12 & 3.926 & 10.12 & 6.901 \\
\hline 10.22 & 3.882 & 10.21 & 6.873 \\
\hline 10.32 & 3.831 & 10.32 & 6.868 \\
\hline 10.42 & 3.799 & 10.42 & 6.869 \\
\hline 10.52 & 3.748 & 10.52 & 6.8685 \\
\hline 10.62 & 3.704 & 10.62 & 6.855 \\
\hline 10.72 & 3.676 & 10.72 & 6.8565 \\
\hline 10.82 & 3.622 & 10.82 & 6.846 \\
\hline 10.92 & 3.589 & 10.92 & 6.858 \\
\hline 11.02 & 3.545 & 11.02 & 6.8635 \\
\hline 11.12 & 3.51 & 11.12 & 6.868 \\
\hline 11.22 & 3.48 & 11.22 & 6.869 \\
\hline 11.32 & 3.439 & 11.32 & 6.884 \\
\hline
\end{tabular}

\begin{tabular}{|r|r|r|r|}
\hline $\begin{array}{r}\text { Time } \\
\text { (min) }\end{array}$ & $\begin{array}{c}\text { AvDO for } \\
\text { Planktonic } \\
\text { (mglL) }\end{array}$ & $\begin{array}{r}\text { Time } \\
\text { (min) }\end{array}$ & $\begin{array}{c}\text { Av DO for } \\
\text { Immobilized } \\
\text { (mg'll) }\end{array}$ \\
\hline 11.42 & 3.402 & 11.42 & 6.8875 \\
\hline 11.52 & 3.356 & 11.52 & 6.9045 \\
\hline 11.62 & 3.312 & 11.62 & 6.89 \\
\hline 11.72 & 3.28 & 11.72 & 6.8745 \\
\hline 11.82 & 3.24 & 11.82 & 6.8555 \\
\hline 11.92 & 3.201 & 11.92 & 6.8545 \\
\hline 12.02 & 3.158 & 12.02 & 6.829 \\
\hline
\end{tabular}




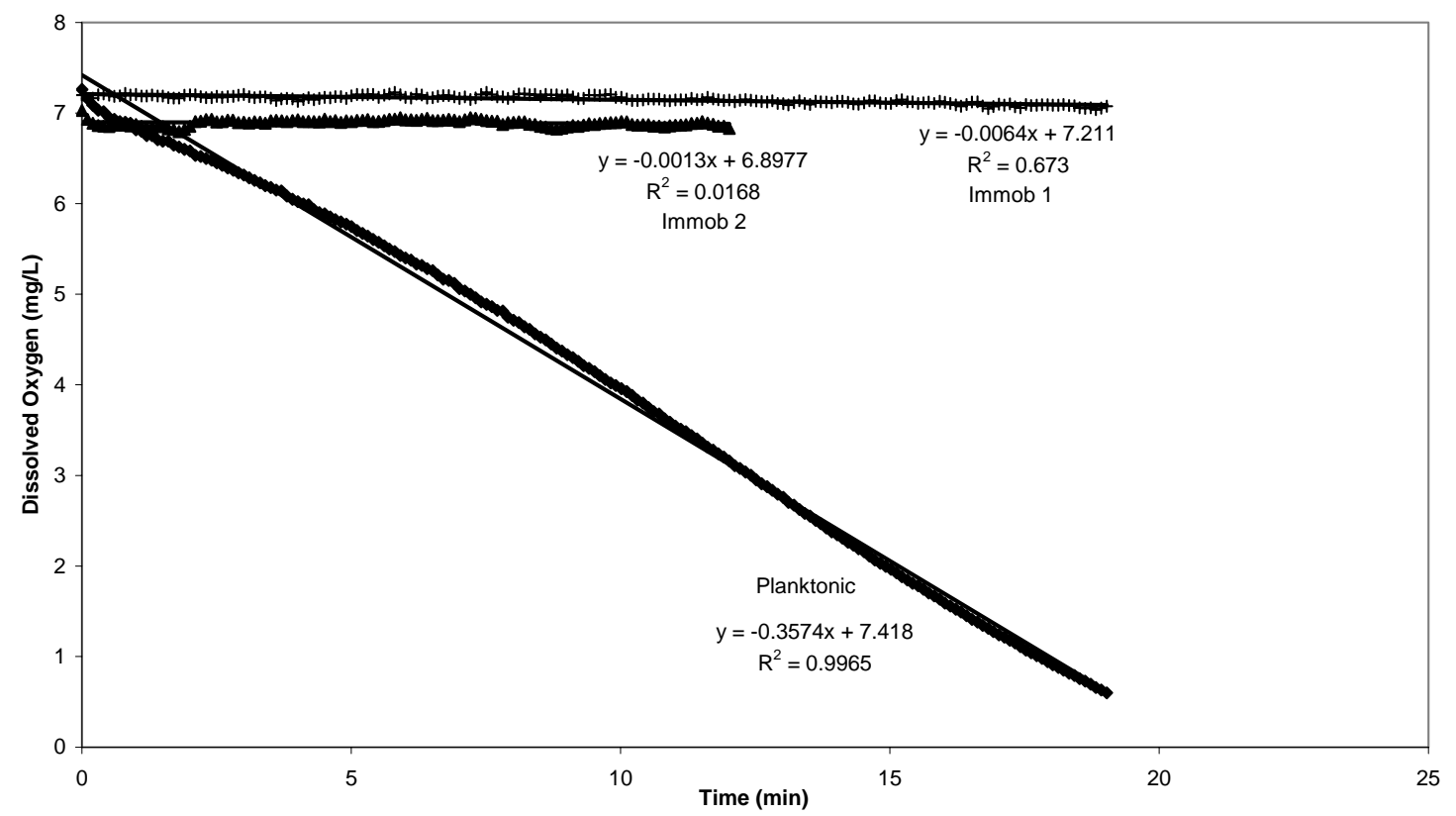

A.1.4 Alginate oxygen uptake rates

Alginate polymer: day zero, 4-18-04, Book 2, Page 84

\begin{tabular}{|c|c|c|c|}
\hline $\begin{array}{l}\text { Time } \\
\text { (min) }\end{array}$ & $\begin{array}{c}\text { AvDO for } \\
\text { Planktonic } \\
\text { (mglt)] }\end{array}$ & $\begin{array}{l}\text { Time } \\
\text { (min) }\end{array}$ & $\begin{array}{c}\text { AvDO for } \\
\text { Immobilized } \\
\text { (mglt) }\end{array}$ \\
\hline 1.203 & 7.8395 & 1.202 & 7.417 \\
\hline 1.303 & 7.8295 & 1.303 & 7.4145 \\
\hline 1.403 & 7.7675 & 1.402 & 7.416 \\
\hline 1.503 & 7.756 & 1.502 & 7.388 \\
\hline 1.603 & 7.714 & 1.603 & 7.417 \\
\hline 1.704 & 7.693 & 1.703 & 7.407 \\
\hline 1.803 & 7.684 & 1.803 & 7.397 \\
\hline 1.903 & 7.7265 & 1.903 & 7.4195 \\
\hline 2.004 & 7.688 & 2.003 & 7.373 \\
\hline 2.104 & 7.623 & 2.104 & 7.3795 \\
\hline 2.204 & 7.7085 & 2.203 & 7.3805 \\
\hline 2.304 & 7.7565 & 2.304 & 7.382 \\
\hline 2.405 & 7.6905 & 2.404 & 7.3855 \\
\hline 2.505 & 7.679 & 2.504 & 7.3695 \\
\hline 2.604 & 7.687 & 2.604 & 7.3475 \\
\hline 2.705 & 7.66 & 2.704 & 7.342 \\
\hline 2.805 & 7.6205 & 2.805 & 7.334 \\
\hline 2.905 & 7.601 & 2.905 & 7.3425 \\
\hline 3.005 & 7.574 & 3.004 & 7.3335 \\
\hline 3.105 & 7.5825 & 3.105 & 7.3255 \\
\hline 3.206 & 7.5815 & 3.205 & 7.337 \\
\hline 3.306 & 7.59 & 3.306 & 7.3205 \\
\hline 3.406 & 7.554 & 3.405 & 7.313 \\
\hline 3.506 & 7.562 & 3.505 & 7.285 \\
\hline 3.606 & 7.5555 & 3.606 & 7.2595 \\
\hline 3.707 & 7.5545 & 3.705 & 7.2825 \\
\hline 3.806 & 7.5545 & 3.806 & 7.3015 \\
\hline 3.907 & 7.5265 & 3.906 & 7.2715 \\
\hline 4.007 & 7.48 & 4.007 & 7.2475 \\
\hline 4.107 & 7.4575 & 4.107 & 7.2595 \\
\hline 4.207 & 7.439 & 4.206 & 7.2605 \\
\hline
\end{tabular}

\begin{tabular}{|r|r|r|r|}
\hline $\begin{array}{r}\text { Time } \\
\text { (min) }\end{array}$ & $\begin{array}{r}\text { AvDO for } \\
\text { Planktonic } \\
\text { (mglL) }\end{array}$ & $\begin{array}{r}\text { Time } \\
\text { (min) }\end{array}$ & $\begin{array}{c}\text { Av DO for } \\
\text { Immobilized } \\
\text { [mgrl }]\end{array}$ \\
\hline 4.307 & 7.4315 & 4.307 & 7.252 \\
\hline 4.408 & 7.398 & 4.407 & 7.2225 \\
\hline 4.508 & 7.418 & 4.508 & 7.2235 \\
\hline 4.607 & 7.445 & 4.607 & 7.226 \\
\hline 4.708 & 7.487 & 4.707 & 7.2285 \\
\hline 4.808 & 7.4765 & 4.808 & 7.222 \\
\hline 4.909 & 7.477 & 4.907 & 7.226 \\
\hline 5.008 & 7.4725 & 5.008 & 7.208 \\
\hline 5.109 & 7.461 & 5.108 & 7.1965 \\
\hline 5.209 & 7.4595 & 5.208 & 7.1935 \\
\hline 5.308 & 7.4565 & 5.308 & 7.1835 \\
\hline 5.409 & 7.4555 & 5.408 & 7.188 \\
\hline 5.509 & 7.4355 & 5.509 & 7.169 \\
\hline 5.61 & 7.457 & 5.609 & 7.156 \\
\hline 5.709 & 7.404 & 5.708 & 7.154 \\
\hline 5.809 & 7.437 & 5.809 & 7.1515 \\
\hline 5.91 & 7.418 & 5.909 & 7.144 \\
\hline 6.01 & 7.378 & 6.01 & 7.149 \\
\hline 6.11 & 7.3805 & 6.109 & 7.1295 \\
\hline 6.21 & 7.4035 & 6.209 & 7.1125 \\
\hline 6.31 & 7.3765 & 6.31 & 7.1065 \\
\hline 6.411 & 7.3655 & 6.41 & 7.104 \\
\hline 6.51 & 7.357 & 6.51 & 7.1025 \\
\hline 6.611 & 7.3345 & 6.61 & 7.0885 \\
\hline 6.711 & 7.3415 & 6.71 & 7.0785 \\
\hline 6.811 & 7.378 & 6.811 & 7.0635 \\
\hline 6.911 & 7.3565 & 6.911 & 7.055 \\
\hline 7.011 & 7.3195 & 7.011 & 7.061 \\
\hline 7.112 & 7.3125 & 7.111 & 7.0485 \\
\hline 7.212 & 7.2875 & 7.212 & 7.0335 \\
\hline 7.312 & 7.297 & 7.312 & 7.022 \\
\hline & & & \\
\hline
\end{tabular}

\begin{tabular}{|r|r|r|r|}
\hline $\begin{array}{r}\text { Time } \\
\text { (min) }\end{array}$ & $\begin{array}{r}\text { AvDO for } \\
\text { Planktonic } \\
\text { (mglL) }\end{array}$ & $\begin{array}{r}\text { Time } \\
\text { (min) }\end{array}$ & $\begin{array}{c}\text { Av DO for } \\
\text { Immobilized } \\
\text { (mglt) }\end{array}$ \\
\hline 7.412 & 7.284 & 7.411 & 7.02 \\
\hline 7.512 & 7.297 & 7.512 & 7.0165 \\
\hline 7.613 & 7.2915 & 7.612 & 7.017 \\
\hline 7.713 & 7.2785 & 7.712 & 6.9965 \\
\hline 7.812 & 7.2815 & 7.812 & 6.993 \\
\hline 7.913 & 7.2695 & 7.912 & 6.9765 \\
\hline 8.013 & 7.262 & 8.013 & 6.9745 \\
\hline 8.113 & 7.246 & 8.113 & 6.982 \\
\hline 8.213 & 7.2385 & 8.213 & 6.977 \\
\hline 8.314 & 7.239 & 8.313 & 6.957 \\
\hline 8.414 & 7.2165 & 8.413 & 6.942 \\
\hline 8.514 & 7.193 & 8.513 & 6.944 \\
\hline 8.614 & 7.1855 & 8.613 & 6.9415 \\
\hline 8.714 & 7.173 & 8.714 & 6.9195 \\
\hline 8.815 & 7.1955 & 8.814 & 6.863 \\
\hline 8.915 & 7.157 & 8.913 & 6.7805 \\
\hline 9.014 & 7.1455 & 9.014 & 6.7545 \\
\hline 9.115 & 7.141 & 9.114 & 6.796 \\
\hline 9.215 & 7.091 & 9.215 & 6.784 \\
\hline 9.315 & 7.1235 & 9.314 & 6.7915 \\
\hline 9.415 & 7.127 & 9.414 & 6.773 \\
\hline 9.515 & 7.095 & 9.515 & 6.7595 \\
\hline 9.616 & 7.0815 & 9.615 & 6.762 \\
\hline 9.715 & 7.0825 & 9.715 & 6.7485 \\
\hline 9.816 & 7.0805 & 9.815 & 6.745 \\
\hline 9.916 & 7.084 & 9.915 & 6.7535 \\
\hline 10.02 & 7.0795 & 10.02 & 6.729 \\
\hline 10.12 & 7.0665 & 10.12 & 6.7265 \\
\hline 10.22 & 7.063 & 10.22 & 6.744 \\
\hline 10.32 & 7.0345 & 10.32 & 6.7305 \\
\hline 10.42 & 7.0215 & 10.42 & 6.712 \\
\hline & & & \\
\hline
\end{tabular}




\begin{tabular}{|c|c|c|c|}
\hline $\begin{array}{l}\text { Time } \\
\text { (min) }\end{array}$ & $\begin{array}{l}\text { AuDO for } \\
\text { Planktonic } \\
\text { [mglt) }\end{array}$ & $\begin{array}{l}\text { Time } \\
\text { (min) }\end{array}$ & $\begin{array}{l}\text { Av DD for } \\
\text { Immobilized } \\
\text { [mgll] }\end{array}$ \\
\hline 10.5 & 6.995 & 10.52 & 6.6945 \\
\hline 10.6 & 6.995 & 10.62 & 6.689 \\
\hline 10.7 & 7.001 & 10.72 & 6.69 \\
\hline 10.8 & 6.976 & 10.82 & 6.6675 \\
\hline 10.9 & 6.9835 & 10.92 & 6.664 \\
\hline 11 & 6.9595 & 11.02 & 6.6835 \\
\hline 11.1 & 6.944 & 11.12 & 6.719 \\
\hline 11.2 & 6.948 & 11.22 & 6.6835 \\
\hline 11.3 & 6.924 & 11.32 & 6.6435 \\
\hline 11.4 & 6.945 & 11.42 & 6.653 \\
\hline 11.5 & 6.909 & 11.52 & 6.664 \\
\hline 11.6 & 6.891 & 11.62 & 6.6445 \\
\hline 11.7 & 6.906 & 11.72 & 6.643 \\
\hline 11.8 & 6.918 & 11.82 & 6.648 \\
\hline 11.9 & 6.895 & 11.92 & 6.658 \\
\hline 12 & 6.874 & 12.02 & 6.646 \\
\hline 12.1 & 6.8755 & 12.12 & 6.63 \\
\hline 12.2 & 6.8525 & 12.22 & 6.6505 \\
\hline 12.3 & 6.8235 & 12.32 & 6.655 \\
\hline 12.4 & 6.799 & 12.42 & 6.6415 \\
\hline 12.5 & 6.807 & 12.52 & 6.602 \\
\hline 12.6 & 6.808 & 12.62 & 6.592 \\
\hline 12.7 & 6.804 & 12.72 & 6.6 \\
\hline 12.8 & 6.78 & 12.82 & 6.5995 \\
\hline 12.9 & 6.762 & 12.92 & 6.614 \\
\hline 13 & 6.784 & 13.02 & 6.6395 \\
\hline 13.1 & 6.7685 & 13.12 & 6.6665 \\
\hline 13.2 & 6.7485 & 13.22 & 6.669 \\
\hline 13.3 & 6.7475 & 13.32 & 6.668 \\
\hline 13.4 & 6.7325 & 13.42 & 6.641 \\
\hline 13.5 & 6.7205 & 13.52 & 6.629 \\
\hline
\end{tabular}

\begin{tabular}{|r|r|r|r|}
\hline $\begin{array}{r}\text { Time } \\
\text { (min) }\end{array}$ & $\begin{array}{c}\text { AvDO for } \\
\text { Planktonic } \\
\text { (mgrl) }\end{array}$ & $\begin{array}{r}\text { Time } \\
\text { (min) }\end{array}$ & $\begin{array}{c}\text { Av DO for } \\
\text { Immobilized } \\
\text { (mgll) }\end{array}$ \\
\hline 13.62 & 6.6995 & 13.62 & 6.5985 \\
\hline 13.72 & 6.6815 & 13.72 & 6.593 \\
\hline 13.82 & 6.6775 & 13.82 & 6.5775 \\
\hline 13.92 & 6.6945 & 13.92 & 6.5655 \\
\hline 14.02 & 6.67 & 14.02 & 6.557 \\
\hline 14.12 & 6.647 & 14.12 & 6.554 \\
\hline 14.22 & 6.6605 & 14.22 & 6.543 \\
\hline 14.32 & 6.6595 & 14.32 & 6.5355 \\
\hline 14.42 & 6.64 & 14.42 & 6.514 \\
\hline 14.52 & 6.603 & 14.52 & 6.5025 \\
\hline 14.62 & 6.6185 & 14.62 & 6.5005 \\
\hline 14.72 & 6.6125 & 14.72 & 6.491 \\
\hline 14.82 & 6.5955 & 14.82 & 6.4775 \\
\hline 14.92 & 6.6115 & 14.92 & 6.463 \\
\hline 15.02 & 6.6025 & 15.02 & 6.465 \\
\hline 15.12 & 6.586 & 15.12 & 6.455 \\
\hline 15.22 & 6.565 & 15.22 & 6.445 \\
\hline 15.32 & 6.5395 & 15.32 & 6.426 \\
\hline 15.42 & 6.527 & 15.42 & 6.4155 \\
\hline 15.53 & 6.511 & 15.52 & 6.415 \\
\hline 15.63 & 6.502 & 15.62 & 6.4065 \\
\hline 15.73 & 6.4855 & 15.72 & 6.3775 \\
\hline 15.83 & 6.4955 & 15.82 & 6.3905 \\
\hline 15.93 & 6.4955 & 15.93 & 6.3775 \\
\hline 16.03 & 6.494 & 16.02 & 6.379 \\
\hline 16.13 & 6.4805 & 16.13 & 6.364 \\
\hline 16.23 & 6.452 & 16.23 & 6.3435 \\
\hline 16.33 & 6.4315 & 16.33 & 6.3485 \\
\hline 16.43 & 6.434 & 16.43 & 6.3465 \\
\hline 16.53 & 6.4205 & 16.53 & 6.3205 \\
\hline 16.63 & 6.4085 & 16.63 & 6.324 \\
\hline & & & \\
\hline
\end{tabular}

\begin{tabular}{|c|c|c|c|}
\hline $\begin{array}{l}\text { Time } \\
\text { (min) }\end{array}$ & $\begin{array}{c}\text { Av DO for } \\
\text { Planktonic } \\
\text { (mgrl) }\end{array}$ & $\begin{array}{l}\text { Time } \\
\text { (min) }\end{array}$ & $\begin{array}{l}\text { Av DO for } \\
\text { Immobilized } \\
\text { (mgll) }\end{array}$ \\
\hline 16.7 & 6.4025 & 16.73 & 6.326 \\
\hline 16.8 & 6.3665 & 16.83 & 6.3075 \\
\hline 16.9 & 6.363 & 16.93 & 6.294 \\
\hline 17 & 6.362 & 17.03 & 6.288 \\
\hline 17.1 & 6.352 & 17.13 & 6.2725 \\
\hline 17.2 & 6.367 & 17.23 & 6.2665 \\
\hline 17.3 & 6.3435 & 17.33 & 6.259 \\
\hline 17.4 & 6.3445 & 17.43 & 6.2475 \\
\hline 17.5 & 6.323 & 17.53 & 6.2495 \\
\hline 17.6 & 6.3225 & 17.63 & 6.23 \\
\hline 17.7 & 6.309 & 17.73 & 6.2295 \\
\hline 17.8 & 6.274 & 17.83 & 6.22 \\
\hline 17.9 & 6.2745 & 17.93 & 6.2215 \\
\hline 18 & 6.26 & 18.03 & 6.206 \\
\hline 18.1 & 6.264 & 18.13 & 6.198 \\
\hline 18.2 & 6.2365 & 18.23 & 6.188 \\
\hline 18.3 & 6.2355 & 18.33 & 6.1765 \\
\hline 18.4 & 6.217 & 18.43 & 6.1765 \\
\hline 18.5 & 6.196 & 18.53 & 6.172 \\
\hline 18.6 & 6.1825 & 18.63 & 6.1535 \\
\hline 18.7 & 6.165 & 18.73 & 6.151 \\
\hline 18.8 & 6.174 & 18.83 & 6.141 \\
\hline 18.9 & 6.166 & 18.93 & 6.141 \\
\hline 19 & 6.1585 & 19.03 & 6.1365 \\
\hline 19.1 & 6.13 & 19.13 & 6.1155 \\
\hline 19.2 & 6.112 & 19.23 & 6.1075 \\
\hline 19.3 & 6.085 & 19.33 & 6.1085 \\
\hline 19.4 & 6.1145 & 19.43 & 6.0955 \\
\hline 19.5 & 6.1015 & 19.53 & 6.082 \\
\hline 19.6 & 6.114 & 19.63 & 6.062 \\
\hline 19.7 & 6.0785 & 19.73 & 6.056 \\
\hline
\end{tabular}

\begin{tabular}{|c|c|c|c|}
\hline $\begin{array}{l}\text { Time } \\
\text { (min) }\end{array}$ & $\begin{array}{c}\text { Av DO for } \\
\text { Planktonic } \\
\text { [mgrl] }\end{array}$ & $\begin{array}{l}\text { Time } \\
\text { (min) }\end{array}$ & $\begin{array}{l}\text { Av DO for } \\
\text { Immobilized } \\
\text { (mgrl) }\end{array}$ \\
\hline 19.8 & 6.057 & 19.83 & 6.057 \\
\hline 19.9 & 6.0715 & 19.93 & 6.064 \\
\hline 20 & 6.065 & 20.03 & 6.051 \\
\hline 20.1 & 6.067 & 20.13 & 6.042 \\
\hline 20.2 & 6.035 & 20.23 & 6.037 \\
\hline 20.3 & 6.0015 & 20.33 & 6.0105 \\
\hline 20.4 & 5.988 & 20.43 & 6.015 \\
\hline 20.5 & 5.98 & 20.53 & 6.0125 \\
\hline 20.6 & 5.9715 & 20.63 & 5.993 \\
\hline 20.7 & 5.9735 & 20.73 & 5.979 \\
\hline 20.8 & 5.9675 & 20.83 & 5.976 \\
\hline 20.9 & 5.9625 & 20.93 & 5.9795 \\
\hline 21 & 5.9575 & 21.03 & 5.953 \\
\hline 21.1 & 5.9265 & 21.13 & 5.921 \\
\hline 21.2 & 5.91 & 21.23 & 5.944 \\
\hline 21.3 & 5.9135 & 21.33 & 5.941 \\
\hline 21.4 & 5.891 & 21.43 & 5.895 \\
\hline 21.5 & 5.89 & 21.53 & 5.91 \\
\hline 21.6 & 5.8795 & 21.63 & 5.905 \\
\hline 21.7 & 5.851 & 21.73 & 5.916 \\
\hline 21.8 & 5.8665 & 21.83 & 5.906 \\
\hline 21.9 & 5.856 & 21.93 & 5.8975 \\
\hline 22 & 5.8495 & 22.03 & 5.881 \\
\hline 22.1 & 5.8265 & 22.13 & 5.884 \\
\hline 22.2 & 5.818 & 22.23 & 5.872 \\
\hline 22.3 & 5.7965 & 22.33 & 5.846 \\
\hline 22.4 & 5.802 & 22.43 & 5.831 \\
\hline 22.5 & 5.791 & 22.54 & 5.8435 \\
\hline 22.6 & 5.781 & 22.64 & 5.8395 \\
\hline 22.7 & 5.759 & 22.74 & 5.8365 \\
\hline 22.8 & 5.744 & 22.84 & 5.829 \\
\hline
\end{tabular}

\begin{tabular}{|r|r|}
\hline $\begin{array}{r}\text { Time } \\
\text { (min) }\end{array}$ & $\begin{array}{c}\text { Av DO for } \\
\text { Immobilized } \\
\text { (mgll) }\end{array}$ \\
\hline 23 & 5.812 \\
\hline 23.1 & 5.805 \\
\hline 23.2 & 5.785 \\
\hline 23.3 & 5.79 \\
\hline 23.4 & 5.779 \\
\hline 23.5 & 5.7765 \\
\hline 23.6 & 5.7715 \\
\hline 23.7 & 5.757 \\
\hline 23.8 & 5.741 \\
\hline 23.9 & 5.7385 \\
\hline 24 & 5.718 \\
\hline 24.1 & 5.7065 \\
\hline 24.2 & 5.713 \\
\hline 24.3 & 5.675 \\
\hline 24.4 & 5.613 \\
\hline 24.5 & 5.6215 \\
\hline 24.6 & 5.668 \\
\hline 24.7 & 5.675 \\
\hline 24.8 & 5.671 \\
\hline 24.9 & 5.6655 \\
\hline 25 & 5.6525 \\
\hline 25.1 & 5.6395 \\
\hline 25.2 & 5.612 \\
\hline 25.3 & 5.6045 \\
\hline 25.4 & 5.605 \\
\hline 25.5 & 5.5965 \\
\hline 25.6 & 5.587 \\
\hline 25.7 & 5.5255 \\
\hline 25.8 & 5.4855 \\
\hline 25.9 & 5.5295 \\
\hline 26 & 5.55 \\
\hline
\end{tabular}

\begin{tabular}{|r|r|}
\hline $\begin{array}{r}\text { Time } \\
\text { (min) }\end{array}$ & $\begin{array}{c}\text { Av DO for } \\
\text { Immobilized } \\
\text { (mglt) }\end{array}$ \\
\hline 26.14 & 5.554 \\
\hline 26.24 & 5.5345 \\
\hline 26.34 & 5.5355 \\
\hline 26.44 & 5.5265 \\
\hline 26.54 & 5.5195 \\
\hline 26.64 & 5.5065 \\
\hline 26.74 & 5.4975 \\
\hline 26.84 & 5.483 \\
\hline 26.94 & 5.4695 \\
\hline 27.04 & 5.4355 \\
\hline 27.14 & 5.3965 \\
\hline 27.24 & 5.3825 \\
\hline 27.34 & 5.3655 \\
\hline 27.44 & 5.349 \\
\hline 27.54 & 5.3235 \\
\hline 27.64 & 5.297 \\
\hline 27.74 & 5.338 \\
\hline 27.84 & 5.349 \\
\hline 27.94 & 5.3195 \\
\hline 28.04 & 5.2995 \\
\hline
\end{tabular}


Alginate polymer: days 1,3 , and 5
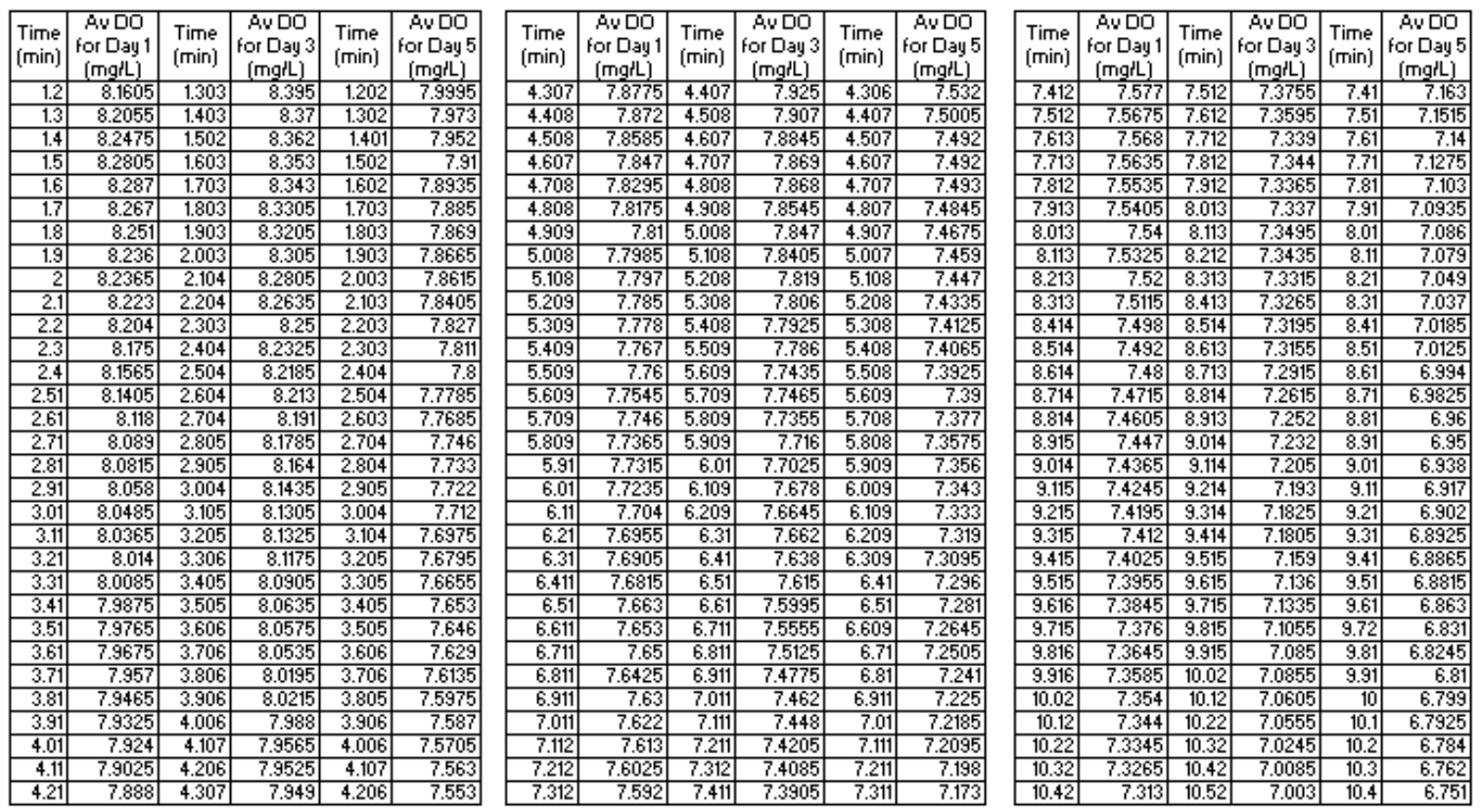

\begin{tabular}{|r|r|r|r|r|r|}
\hline $\begin{array}{r}\text { Time } \\
\text { (min) }\end{array}$ & $\begin{array}{r}\text { AvDO } \\
\text { for Day 1 } \\
\text { (mgl') }\end{array}$ & $\begin{array}{r}\text { Time } \\
\text { (min) }\end{array}$ & $\begin{array}{c}\text { AvDO } \\
\text { ror Day 3 } \\
\text { (mglL) }\end{array}$ & $\begin{array}{r}\text { Time } \\
\text { (min) }\end{array}$ & $\begin{array}{r}\text { AvDO } \\
\text { for Day 5 } \\
\text { (mglL) }\end{array}$ \\
\hline 10.5 & 7.3075 & 10.62 & 6.999 & 10.52 & 6.73 \\
\hline 10.6 & 7.3005 & 10.72 & 6.9805 & 10.62 & 6.717 \\
\hline 10.7 & 7.291 & 10.82 & 6.965 & 10.72 & 6.6995 \\
\hline 10.8 & 7.2805 & 10.92 & 6.957 & 10.82 & 6.679 \\
\hline 10.9 & 7.2705 & 11.02 & 6.95 & 10.92 & 6.653 \\
\hline 11 & 7.2655 & 11.12 & 6.922 & 11.02 & 6.644 \\
\hline 11.1 & 7.2445 & 11.22 & 6.893 & 11.12 & 6.6235 \\
\hline 11.2 & 7.2385 & 11.32 & 6.883 & 11.22 & 6.6055 \\
\hline 11.3 & 7.2335 & 11.42 & 6.8565 & 11.32 & 6.591 \\
\hline 11.4 & 7.219 & 11.52 & 6.8535 & 11.42 & 6.572 \\
\hline 11.5 & 7.2085 & 11.62 & 6.844 & 11.52 & 6.5665 \\
\hline 11.6 & 7.2055 & 11.72 & 6.8225 & 11.62 & 6.5695 \\
\hline 11.7 & 7.1995 & 11.82 & 6.8 & 11.72 & 6.562 \\
\hline 11.8 & 7.1905 & 11.92 & 6.7915 & 11.82 & 6.5515 \\
\hline 11.9 & 7.1805 & 12.02 & 6.78 & 11.92 & 6.5295 \\
\hline 12 & 7.1715 & 12.12 & 6.756 & 12.02 & 6.5115 \\
\hline 12.1 & 7.164 & 12.22 & 6.751 & 12.12 & 6.4895 \\
\hline 12.2 & 7.1555 & 12.32 & 6.727 & 12.22 & 6.4835 \\
\hline 12.3 & 7.1465 & 12.42 & 6.7105 & 12.32 & 6.4695 \\
\hline 12.4 & 7.131 & 12.52 & 6.68 & 12.42 & 6.455 \\
\hline 12.5 & 7.1105 & 12.62 & 6.675 & 12.52 & 6.443 \\
\hline 12.6 & 7.099 & 12.72 & 6.669 & 12.62 & 6.4235 \\
\hline 12.7 & 7.0975 & 12.82 & 6.6605 & 12.72 & 6.413 \\
\hline 12.8 & 7.0935 & 12.92 & 6.6335 & 12.82 & 6.3955 \\
\hline 12.9 & 7.089 & 13.02 & 6.6215 & 12.92 & 6.3775 \\
\hline 13 & 7.073 & 13.12 & 6.6175 & 13.02 & 6.3655 \\
\hline 13.1 & 7.0635 & 13.22 & 6.607 & 13.12 & 6.338 \\
\hline 13.2 & 7.056 & 13.32 & 6.575 & 13.22 & 6.3175 \\
\hline 13.3 & 7.0365 & 13.42 & 6.5685 & 13.32 & 6.3115 \\
\hline 13.4 & 7.028 & 13.52 & 6.55 & 13.42 & 6.292 \\
\hline 13.5 & 7.021 & 13.62 & 6.5345 & 13.52 & 6.283 \\
\hline & & & & & \\
\hline
\end{tabular}

\begin{tabular}{|c|c|c|c|c|c|}
\hline $\begin{array}{l}\text { Time } \\
\text { (min) }\end{array}$ & $\begin{array}{c}\text { Av DO } \\
\text { for Day } 1 \\
\text { (mgrl) }\end{array}$ & $\begin{array}{l}\text { Time } \\
\text { (min) }\end{array}$ & $\begin{array}{c}\text { AvDO } \\
\text { for Day } 3 \\
\text { (mglt) }\end{array}$ & $\begin{array}{l}\text { Time } \\
\text { (min) }\end{array}$ & $\begin{array}{c}\text { AvDO } \\
\text { for Day } 5 \\
\text { (mglt) }\end{array}$ \\
\hline 13.62 & \begin{tabular}{|l|}
7.0125 \\
\end{tabular} & 13.72 & 6.527 & 13.6 & 6.2805 \\
\hline 13.72 & 6.9955 & 13.82 & 6.5125 & 13.7 & 6.265 \\
\hline 13.82 & 6.976 & 13.92 & 6.5015 & 13.8 & 6.248 \\
\hline 13.92 & 6.9625 & 14.02 & 6.495 & 13.9 & 6.223 \\
\hline 14.02 & 6.9595 & 14.12 & 6.4715 & 14 & 6.199 \\
\hline 14.12 & 6.9515 & 14.22 & 6.451 & 14.1 & 6.183 \\
\hline 14.22 & 6.938 & 14.32 & 6.4475 & 14.2 & 6.178 \\
\hline 14.32 & 6.927 & 14.42 & 6.4325 & 14.3 & 6.177 \\
\hline 14.42 & 6.916 & 14.52 & 6.4255 & 14.4 & 6.1685 \\
\hline 14.52 & 6.901 & 14.62 & 6.416 & 14.5 & 6.147 \\
\hline 14.62 & 6.895 & 14.72 & 6.4 & 14.6 & 6.135 \\
\hline 14.72 & 6.8875 & 14.82 & 6.3855 & 14.7 & 6.116 \\
\hline 14.82 & 6.872 & 14.92 & 6.363 & 14.8 & 6.0905 \\
\hline 14.92 & 6.8605 & 15.02 & 6.336 & 14.9 & 6.072 \\
\hline 15.02 & 6.851 & 15.12 & 6.3155 & 15 & 6.057 \\
\hline 15.12 & 6.842 & 15.22 & 6.3065 & 15.1 & 6.0435 \\
\hline 15.22 & 6.826 & 15.32 & 6.3055 & 15.2 & 6.02 \\
\hline 15.32 & 6.8145 & 15.42 & 6.292 & 15.3 & 6.006 \\
\hline 15.42 & 6.807 & 15.52 & 6.275 & 15.4 & 6.00 \\
\hline 15.53 & 6.7915 & 15.62 & 6.2565 & 15.5 & 5.9945 \\
\hline 15.63 & 6.77 & 15.72 & 6.228 & 15.6 & 5.97 \\
\hline 15.72 & 6.769 & 15.82 & 6.2115 & 15.7 & 5.95 \\
\hline 15.83 & 6.7735 & 15.93 & 6.1835 & 15.8 & 5.938 \\
\hline 15.93 & 6.7745 & 16.02 & 6.1855 & 15.9 & 5.920 \\
\hline 16.03 & 6.77 & 16.12 & 6.171 & 16 & 5. \\
\hline 16.13 & 6.7575 & 16.23 & 6.159 & 16.1 & 5.88 \\
\hline 16.23 & 6.745 & 16.33 & 6.144 & 16.2 & 5.86 \\
\hline 16.33 & 6.7325 & 16.43 & 6.142 & 16.3 & 5.8575 \\
\hline 16.43 & 6.713 & 16.53 & 6.097 & 16.4 & 5.84 \\
\hline 16.53 & 6.7045 & 16.63 & 6.0955 & 16.5 & 5.83 \\
\hline 16.63 & 6.6865 & 16.73 & 6.0935 & 16.6 & 5.80 \\
\hline
\end{tabular}

\begin{tabular}{|r|r|r|r|r|r|}
\hline $\begin{array}{r}\text { Time } \\
\text { (min) }\end{array}$ & $\begin{array}{r}\text { AvDO } \\
\text { for Day 1 } \\
\text { (mgl) }\end{array}$ & $\begin{array}{r}\text { Time } \\
\text { (min) }\end{array}$ & $\begin{array}{c}\text { AvDO } \\
\text { for Day 3 } \\
\text { (mgl') }\end{array}$ & $\begin{array}{r}\text { Time } \\
\text { (min) }\end{array}$ & $\begin{array}{c}\text { AvDO } \\
\text { for Day 5 } \\
\text { (mglL) }\end{array}$ \\
\hline 16.73 & 6.676 & 16.83 & 6.085 & 16.73 & 5.7935 \\
\hline 16.83 & 6.6725 & 16.93 & 6.047 & 16.82 & 5.7815 \\
\hline 16.93 & 6.6655 & 17.03 & 6.0395 & 16.93 & 5.767 \\
\hline 17.03 & 6.646 & 17.13 & 6.008 & 17.03 & 5.7535 \\
\hline 17.13 & 6.6285 & 17.23 & 6.016 & 17.13 & 5.739 \\
\hline 17.23 & 6.628 & 17.33 & 6.0025 & 17.23 & 5.7105 \\
\hline 17.33 & 6.6115 & 17.43 & 5.9905 & 17.33 & 5.6975 \\
\hline 17.43 & 6.6 & 17.53 & 5.9425 & 17.43 & 5.6825 \\
\hline 17.53 & 6.5925 & 17.63 & 5.9415 & 17.53 & 5.671 \\
\hline 17.63 & 6.5895 & 17.73 & 5.9285 & 17.63 & 5.643 \\
\hline 17.73 & 6.578 & 17.83 & 5.9255 & 17.73 & 5.6245 \\
\hline 17.83 & 6.5535 & 17.93 & 5.92 & 17.83 & 5.6155 \\
\hline 17.93 & 6.55 & 18.03 & 5.9035 & 17.93 & 5.6015 \\
\hline 18.03 & 6.538 & 18.13 & 5.887 & 18.03 & 5.5905 \\
\hline 18.13 & 6.5255 & 18.23 & 5.872 & 18.13 & 5.5635 \\
\hline 18.23 & 6.5125 & 18.33 & 5.856 & 18.23 & 5.5355 \\
\hline 18.33 & 6.5045 & 18.43 & 5.8415 & 18.33 & 5.519 \\
\hline 18.43 & 6.49 & 18.53 & 5.8305 & 18.43 & 5.513 \\
\hline 18.53 & 6.4745 & 18.63 & 5.8135 & 18.53 & 5.4835 \\
\hline 18.63 & 6.4705 & 18.73 & 5.7905 & 18.63 & 5.469 \\
\hline 18.73 & 6.454 & 18.83 & 5.7605 & 18.73 & 5.468 \\
\hline 18.83 & 6.4375 & 18.93 & 5.7505 & 18.83 & 5.461 \\
\hline 18.93 & 6.424 & 19.03 & 5.746 & 18.93 & 5.447 \\
\hline 19.03 & 6.4105 & 19.13 & 5.7345 & 19.03 & 5.433 \\
\hline 19.13 & 6.398 & 19.23 & 5.718 & 19.13 & 5.4105 \\
\hline 19.23 & 6.3785 & 19.33 & 5.696 & 19.23 & 5.393 \\
\hline 19.33 & 6.3715 & 19.43 & 5.684 & 19.33 & 5.381 \\
\hline 19.43 & 6.3605 & 19.53 & 5.668 & 19.43 & 5.364 \\
\hline 19.53 & 6.3465 & 19.63 & 5.6465 & 19.53 & 5.3445 \\
\hline 19.63 & 6.3465 & 19.73 & 5.643 & 19.63 & 5.3295 \\
\hline 19.73 & 6.3405 & 19.83 & 5.625 & 19.73 & 5.325 \\
\hline & & & & & \\
\hline
\end{tabular}




\begin{tabular}{|r|r|r|r|r|r|}
\hline $\begin{array}{r}\text { Time } \\
\text { (min) }\end{array}$ & $\begin{array}{c}\text { Av DD } \\
\text { for Day 1 } \\
\text { (mgrl) }\end{array}$ & $\begin{array}{c}\text { Time } \\
\text { (min) }\end{array}$ & $\begin{array}{c}\text { Av DD } \\
\text { for Day 3 } 3 \\
\text { (mgrl) }\end{array}$ & $\begin{array}{r}\text { Time } \\
\text { (min) }\end{array}$ & $\begin{array}{c}\text { Av DD } \\
\text { for Day } 5 \\
\text { (mgrl) }\end{array}$ \\
\hline 19.83 & 6.33 & 19.93 & 5.6195 & 19.8 & 5.295 \\
\hline 19.93 & 6.319 & 20.03 & 5.61 & 19.9 & 5.2845 \\
\hline 20.03 & 6.3145 & 20.13 & 5.581 & 20 & 5.266 \\
\hline 20.13 & 6.3065 & 20.23 & 5.5655 & 20.1 & 5.2515 \\
\hline 20.23 & 6.29 & 20.33 & 5.5555 & 20.2 & 5.231 \\
\hline 20.33 & 6.277 & 20.43 & 5.544 & 20.3 & 5.1835 \\
\hline 20.43 & 6.2675 & 20.53 & 5.53 & 20.4 & 5.1245 \\
\hline 20.53 & 6.253 & 20.63 & 5.515 & 20.5 & 5.058 \\
\hline 20.63 & 6.2405 & 20.73 & 5.4945 & 20.6 & 5.06 \\
\hline 20.73 & 6.233 & 20.83 & 5.48 & 20.7 & 5.1035 \\
\hline 20.83 & 6.2315 & 20.93 & 5.476 & 20.8 & 5.095 \\
\hline 20.93 & 6.2205 & 21.03 & 5.4535 & 20.9 & 5.0505 \\
\hline 21.03 & 6.212 & 21.13 & 5.445 & 21 & 4.9845 \\
\hline 21.13 & 6.2085 & 21.23 & 5.4415 & 21.1 & 4.9415 \\
\hline 21.23 & 6.1955 & 21.33 & 5.4275 & 21.2 & 4.9695 \\
\hline 21.33 & 6.188 & 21.43 & 5.403 & 21.3 & 4.9455 \\
\hline 21.43 & 6.1735 & 21.53 & 5.3945 & 21.4 & 4.905 \\
\hline 21.53 & 6.1635 & 21.63 & 5.375 & 21.5 & 4.8645 \\
\hline 21.63 & 6.149 & 21.73 & 5.3655 & 21.6 & 4.8445 \\
\hline 21.73 & 6.133 & 21.83 & 5.345 & 21.7 & 4.902 \\
\hline 21.83 & 6.1235 & 21.93 & 5.3355 & 21.8 & 4.953 \\
\hline 21.93 & 6.1205 & 22.03 & 5.3185 & 21.9 & 4.9485 \\
\hline 22.03 & 6.105 & 22.13 & 5.297 & 22 & 4.9455 \\
\hline 22.13 & 6.0975 & 22.23 & 5.287 & 22.1 & 4.9355 \\
\hline 22.24 & 6.088 & 22.33 & 5.27 & 22.2 & 4.9165 \\
\hline 22.33 & 6.0805 & 22.43 & 5.2635 & 22.3 & 4.903 \\
\hline 22.44 & 6.071 & 22.53 & 5.2415 & 22.4 & 4.8885 \\
\hline 22.54 & 6.0705 & 22.63 & 5.235 & 22.5 & 4.8635 \\
\hline 22.64 & 6.069 & 22.74 & 5.1995 & 22.6 & 4.8475 \\
\hline 22.74 & 6.0465 & 22.83 & 5.1955 & 22.7 & 4.8305 \\
\hline 22.84 & 6.02 & 22.94 & 5.1925 & 22.8 & 4.81 \\
\hline
\end{tabular}

\begin{tabular}{|c|c|c|c|c|c|}
\hline $\begin{array}{l}\text { Time } \\
\text { (min) }\end{array}$ & $\begin{array}{c}\text { Av DO } \\
\text { for Day } 1 \\
\text { (mgll) }\end{array}$ & $\begin{array}{l}\text { Time } \\
\text { (min) }\end{array}$ & $\begin{array}{c}\text { Av DO } \\
\text { for Day } 3 \\
\text { [mgll) }\end{array}$ & $\begin{array}{l}\text { Time } \\
\text { (min) }\end{array}$ & $\begin{array}{c}\text { Av DO } \\
\text { for Day } 5 \\
\text { (mglt) }\end{array}$ \\
\hline 22.94 & 6.011 & 23.04 & 5.1735 & 22.93 & 4.799 \\
\hline 23.04 & 6.0115 & 23.14 & 5.1495 & 23.04 & 4.78 \\
\hline 23.14 & 5.9945 & 23.24 & 5.1435 & 23.14 & 4.7645 \\
\hline 23.24 & 5.975 & 23.34 & 5.1285 & 23.23 & 4.751 \\
\hline 23.34 & 5.96 & 23.44 & 5.112 & 23.34 & 4.7405 \\
\hline 23.44 & 5.9525 & 23.54 & 5.094 & 23.44 & 4.7175 \\
\hline 23.54 & 5.9335 & 23.64 & 5.072 & 23.54 & 4.6845 \\
\hline 23.64 & 5.922 & 23.74 & 5.0775 & 23.64 & 4.6725 \\
\hline 23.74 & 5.9195 & 23.84 & 5.0585 & 23.74 & 4.655 \\
\hline 23.84 & 5.8975 & 23.94 & 5.0395 & 23.84 & 4.653 \\
\hline 23.94 & 5.89 & 24.04 & 5.042 & 23.94 & 4.6255 \\
\hline 24.04 & 5.887 & 24.14 & 5.012 & 24.04 & 4.597 \\
\hline 24.14 & 5.877 & 24.24 & 5.01 & 24.14 & 4.5585 \\
\hline 24.24 & 5.865 & 24.34 & 4.9915 & 24.24 & 4.535 \\
\hline 24.34 & 5.8475 & 24.44 & 4.975 & 24.34 & 4.496 \\
\hline 24.44 & 5.8355 & 24.54 & 4.96 & 24.44 & 4.436 \\
\hline 24.54 & 5.8275 & 24.64 & 4.9475 & 24.54 & 4.3965 \\
\hline 24.64 & 5.83 & 24.74 & 4.913 & 24.64 & 4.3405 \\
\hline 24.74 & 5.8145 & 24.84 & 4.9035 & 24.74 & 4.293 \\
\hline \multirow[t]{6}{*}{24.84} & 5.799 & 24.94 & 4.898 & & \\
\hline & & 25.04 & 4.878 & & \\
\hline & & 25.14 & 4.859 & & \\
\hline & & 25.24 & 4.8495 & & \\
\hline & & 25.34 & 4.835 & & \\
\hline & & 25.44 & 4.8265 & & \\
\hline
\end{tabular}

Oxygen Uptake Rates for Alginate Gels: Experiment Begun 4-18-04

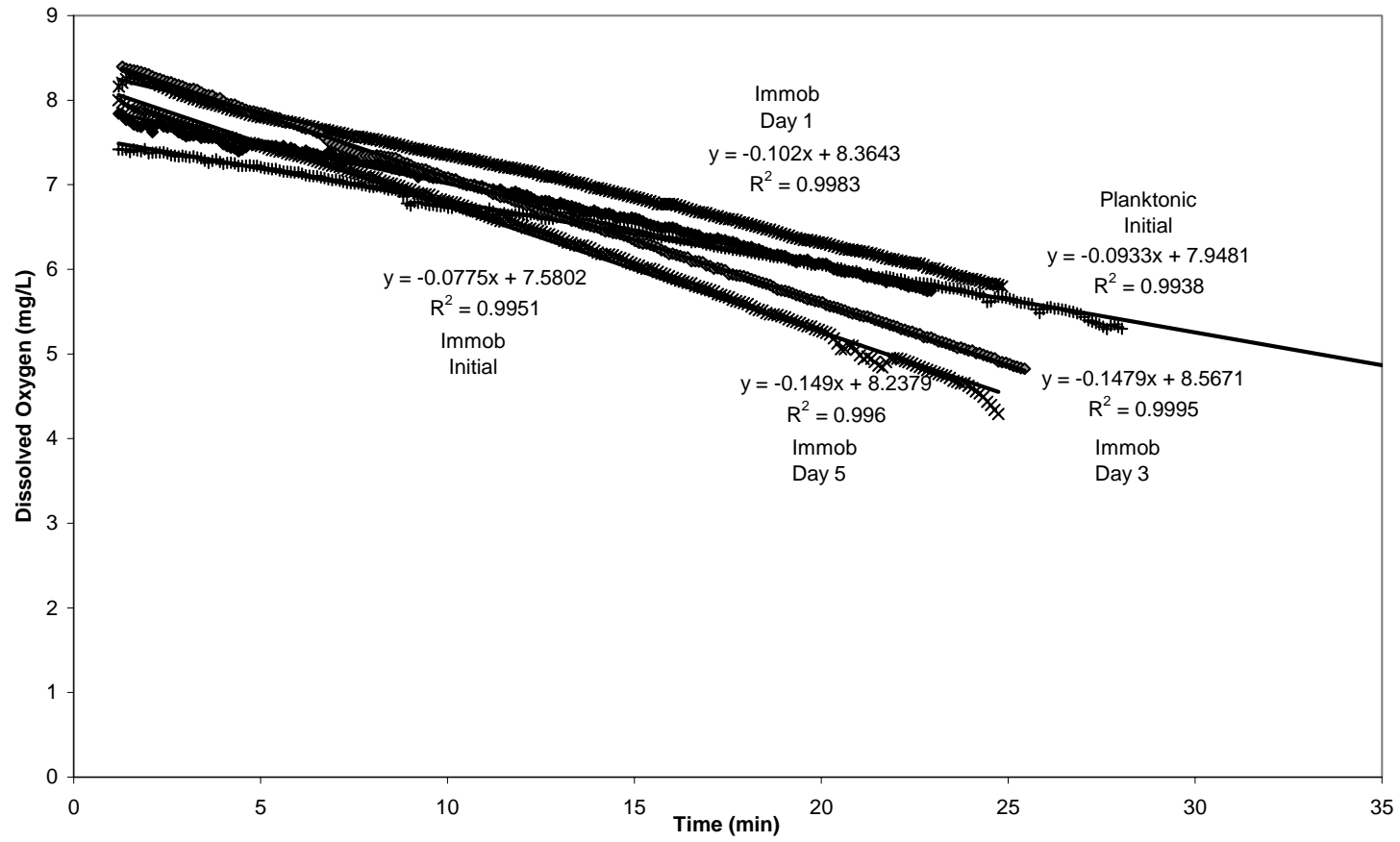




\begin{tabular}{|l|r|r|r|}
\hline Sample & Date & Gel Age (days) & DO Uptake Rate (mg/L/min) \\
\hline Plank Control & $4 / 18 / 04$ & 0 & 0.0933 \\
\hline Gel & $4 / 18 / 04$ & 0 & 0.0775 \\
\hline Gel & $4 / 19 / 04$ & 1 & 0.1020 \\
\hline Gel & $4 / 21 / 04$ & 3 & 0.1479 \\
\hline Gel & $4 / 23 / 04$ & 5 & 0.149 \\
\hline
\end{tabular}

A.1.5 Thermal polymer oxygen uptake rates

Thermal polymer: planktonic control, and polymer on days $0,1,5,8,10$, and 14

4-18-04, Book 2, Page 84

\begin{tabular}{|c|c|}
\hline cells counts & 4.00E+09 2.90E+09 3.80E+09 \\
\hline $\begin{array}{l}\text { ave } \\
\text { tot vol }\end{array}$ & $\begin{array}{c}3.57 \mathrm{E}+09 \text { cells per } \mathrm{mL} \\
12 \mathrm{~mL}\end{array}$ \\
\hline
\end{tabular}

cells per batch $7.13 \mathrm{E}+09$

\begin{tabular}{|c|c|c|c|c|c|c|c|c|c|c|c|c|c|}
\hline $\begin{array}{l}\text { Time } \\
\text { (min) }\end{array}$ & $\begin{array}{c}\text { Av DO for } \\
\text { Planktoni } \\
\text { c (mglt) }\end{array}$ & $\begin{array}{l}\text { Time } \\
\text { (min) }\end{array}$ & $\begin{array}{c}\text { Au DO } \\
\text { for Day 0 } \\
\text { (mgll) }\end{array}$ & $\begin{array}{l}\text { Time } \\
\text { (min) }\end{array}$ & \begin{tabular}{|c|} 
Av DO \\
for Day 1 \\
(mgrl)
\end{tabular} & $\begin{array}{l}\text { Time } \\
\text { (min) }\end{array}$ & \begin{tabular}{|c|} 
Av DO \\
for Day 3 \\
(mgrll)
\end{tabular} & $\begin{array}{l}\text { Time } \\
\text { (min) }\end{array}$ & $\begin{array}{c}\text { Av DO } \\
\text { for Day } 8 \\
\text { (mgll) }\end{array}$ & $\begin{array}{l}\text { Time } \\
\text { (min) }\end{array}$ & \begin{tabular}{|c|} 
Au DO \\
for Day \\
10 (mglt)
\end{tabular} & $\begin{array}{l}\text { Time } \\
\text { (min) }\end{array}$ & \begin{tabular}{|c|} 
Aw DO \\
for Day \\
14 (mglt)
\end{tabular} \\
\hline 2.303 & 6.3045 & 2.303 & 5.823 & 3.505 & 4.8945 & 2.504 & 2.6735 & 3.104 & 6.559 & 2.505 & 5.0645 & 2.504 & 4.8605 \\
\hline 2.404 & 6.2575 & 2.404 & 5.7615 & 3.605 & 4.874 & 2.603 & 2.633 & 3.204 & 6.5205 & 2.604 & 5.0725 & 2.604 & 4.799 \\
\hline 2.504 & 6.2195 & 2.504 & 5.8605 & 3.706 & 4.894 & 2.704 & 2.6765 & 3.305 & 6.642 & 2.704 & 5.085 & 2.704 & 4.833 \\
\hline 2.604 & 6.187 & 2.603 & 5.7265 & 3.805 & 4.886 & 2.804 & 2.651 & 3.405 & 6.645 & 2.805 & 5.0785 & 2.804 & 4.8 \\
\hline 2.704 & 6.1245 & 2.704 & 5.781 & 3.906 & 4.902 & 2.904 & 2.663 & 3.504 & 6.671 & 2.905 & 5.0395 & 2.905 & 4.8115 \\
\hline 804 & 6.0875 & 804 & 5.8545 & 006 & 4.917 & 004 & 2.641 & 605 & 6.705 & .005 & 5.0405 & 3.004 & 4.7955 \\
\hline 905 & 6.034 & 905 & 5.959 & 106 & 4.835 & 104 & 2.586 & 705 & 6.628 & 3.105 & 5.027 & 3.105 & 4.778 \\
\hline 3.004 & 5.9995 & 004 & 5.839 & 4.206 & 4.843 & 3.205 & 2.544 & 3.806 & 6.6005 & 3.205 & 5.085 & 3.205 & 4.8155 \\
\hline 3.104 & 5.9535 & 3.104 & 5.761 & .306 & 4.84 & 305 & 2.544 & 3.905 & 6.646 & 3.306 & 5.0605 & 3.306 & 4.791 \\
\hline 3.205 & 5.895 & 3.205 & 5.8145 & 4.407 & 4.846 & & 2.5545 & 4.005 & 6.685 & & 5.097 & 3.405 & 4.816 \\
\hline 3.305 & 5.835 & 3.305 & 5.8915 & 4.506 & 4.8055 & 3.505 & 2.509 & 4.106 & 6.689 & 3.506 & 5.038 & 3.505 & 4.7885 \\
\hline 3.405 & 5.7815 & 3.405 & 5.823 & 4.607 & 4.8 & 3.605 & 2.4655 & 4.206 & 6.651 & 3.606 & 5.035 & 3.606 & 4.768 \\
\hline 3.505 & 5.7395 & 3.505 & 5.7565 & 4.707 & 4.8345 & 3.706 & 2.477 & 4.306 & 6.67 & 3.706 & 5.0735 & 3.706 & 4.775 \\
\hline 3.605 & 5.6625 & 3.605 & 5.6575 & 4.807 & 4.751 & 3.805 & 2.433 & 4.406 & 6.5825 & 3.806 & 5.038 & 3.806 & 4.7685 \\
\hline 3.706 & 5.606 & 3.706 & 5.545 & 4.907 & 4.772 & 3.905 & 2.4245 & 4.506 & 6.666 & 3.906 & 5.0665 & 3.906 & 4.795 \\
\hline 3.805 & 5.554 & 3.805 & 5.61 & 5.007 & 4.81 & 4.006 & 2.4045 & 4.607 & 6.589 & 4.007 & 5.0345 & 4.006 & 4.7725 \\
\hline 3.906 & 5.523 & 3.905 & 5.68 & 5.107 & 4.764 & 4.106 & 2.373 & 4.706 & 6.6225 & 4.107 & 5.064 & 4.107 & 4.7575 \\
\hline 4.006 & 5.477 & 4.006 & 5.641 & 5.208 & 4.7445 & 4.206 & 2.3475 & 4.806 & 6.607 & 4.207 & 5.021 & 4.206 & 4.753 \\
\hline 4.106 & 5.414 & 4.106 & 5.5465 & 5.307 & 4.715 & 4.306 & 2.3245 & 4.907 & 6.6995 & 4.307 & 5.067 & 4.307 & 4.8105 \\
\hline 4.206 & 5.3455 & 4.206 & 5.5795 & 5.408 & 4.774 & 4.406 & 2.2895 & 5.006 & 6.695 & 4.407 & 5.033 & 4.407 & 4.753 \\
\hline 4.306 & 5.298 & 4.306 & 5.6695 & 5.508 & 4.7495 & 4.507 & 2.308 & 5.107 & 6.6495 & 4.508 & 5.066 & 4.508 & 4.7765 \\
\hline 4.407 & 5.2435 & 4.406 & 5.491 & 5.608 & 4.692 & 4.606 & 2.253 & 5.207 & 6.6605 & 4.607 & 4.957 & 4.607 & 4.7615 \\
\hline 4.507 & 5.1755 & 4.507 & 5.492 & 5.708 & 4.633 & 4.707 & 2.245 & 5.308 & 6.683 & 4.708 & 4.9805 & 4.707 & 4.7515 \\
\hline 4.606 & 5.1 & 4.606 & 5.5205 & 5.808 & 4.6255 & 4.807 & 2.2485 & 5.407 & 6.707 & 4.808 & 4.988 & 4.808 & 4.709 \\
\hline 4.707 & 5.047 & 707 & 5.413 & 5.909 & 6905 & 4.907 & 2.1955 & 507 & 6.6765 & & 4.968 & 4.907 & 4.6745 \\
\hline 4.807 & 5.0125 & 4.807 & 5.383 & 6.009 & 4.7555 & 5.007 & 2.1685 & 5.608 & 6.6095 & 5.008 & 4.9015 & 5.008 & 4.6965 \\
\hline 4.907 & 4.9525 & 4.907 & 5.443 & 6.109 & 4.624 & 5.107 & 2.1675 & 5.708 & 6.6295 & 5.108 & 4.82 & 5.108 & 4.674 \\
\hline 5.007 & 4.911 & 5.007 & 5.3545 & 6.209 & 4.655 & 5.208 & 2.15 & 5.807 & 6.712 & 5.209 & 4.81 & 5.208 & 4.6985 \\
\hline 5.107 & 4.8145 & 5.107 & 5.2985 & 6.309 & 4.6635 & 5.307 & 2.1215 & 5.908 & 6.6445 & 5.308 & 4.793 & 5.308 & 4.643 \\
\hline 5.208 & 4.756 & 5.208 & 5.315 & 6.41 & 4.5915 & 5.407 & 2.0635 & 6.008 & 6.6095 & 5.408 & 4.8205 & 5.408 & 4.6665 \\
\hline 5.308 & 4.7075 & 5.308 & 5.3785 & 6.51 & 4.651 & 5.508 & 2.073 & 6.109 & 6.6335 & 5.509 & 4.802 & 5.509 & 4.679 \\
\hline
\end{tabular}




\begin{tabular}{|c|c|c|c|c|c|c|c|c|c|c|c|c|c|}
\hline $\begin{array}{l}\text { Time } \\
\text { (min) }\end{array}$ & $\begin{array}{c}\text { AvDO } \\
\text { for } \\
\text { Plankto }\end{array}$ & $\begin{array}{l}\text { Time } \\
\text { (min) }\end{array}$ & \begin{tabular}{|c|} 
Av DO \\
for Day 0 \\
(mgrll]
\end{tabular} & $\begin{array}{l}\text { Time } \\
\text { (min) }\end{array}$ & $\begin{array}{c}\text { AvDO } \\
\text { for Day } 1 \\
\text { (mgrt) }\end{array}$ & $\begin{array}{l}\text { Time } \\
\text { (min) }\end{array}$ & \begin{tabular}{|c|} 
Aw DO \\
for Day 3 \\
(mglt)
\end{tabular} & $\begin{array}{l}\text { Time } \\
\text { (min) }\end{array}$ & \begin{tabular}{c|} 
Av DO \\
for Day 8 \\
[mgrt)
\end{tabular} & $\begin{array}{l}\text { Time } \\
\text { (min) }\end{array}$ & $\begin{array}{c}\text { Av DO } \\
\text { for Day } \\
10 \text { (mgrt) }\end{array}$ & $\begin{array}{l}\text { Time } \\
\text { (min) }\end{array}$ & $\begin{array}{c}\text { AvDO } \\
\text { for Day } \\
14 \text { (mgrll) }\end{array}$ \\
\hline 5.408 & 4.629 & 5.407 & 5.2425 & 6.609 & 4.6575 & 5.608 & 2.049 & 6.208 & 6.567 & 5.609 & $\begin{array}{r}4.822 \\
\end{array}$ & 5.609 & 4.662 \\
\hline 5.508 & 4.551 & 5.508 & 5.3435 & 6.71 & 4.617 & 5.708 & 1.9835 & 6.308 & 6.5895 & 5.709 & 4.8225 & 5.708 & 4.607 \\
\hline 5.608 & 4.4845 & 5.608 & 5.2595 & 6.81 & 4.5615 & 5.808 & 1.962 & 6.409 & 6.6405 & 5.809 & 4.777 & 5.809 & 4.5935 \\
\hline 5.708 & 4.4535 & 5.708 & 5.226 & 6.911 & 4.4995 & 5.908 & 1.92 & 6.509 & 6.6115 & 5.909 & 4.8145 & 5.909 & 4.571 \\
\hline 5.808 & 4.3745 & 5.808 & 5.2505 & 7.01 & 4.5055 & 6.009 & 1.937 & 6.609 & 6.4795 & 6.01 & 4.7745 & 6.01 & 4.568 \\
\hline 5.909 & 4.303 & 5.908 & 5.2455 & 7.11 & 4.525 & 6.109 & 1.9325 & 6.709 & 6.5255 & 6.109 & 4.7325 & 6.109 & 4.627 \\
\hline 6.009 & 4.24 & 6.009 & 5.1945 & 7.211 & 4.4885 & 6.209 & 1.882 & 6.809 & 6.5405 & 6.21 & 4.742 & 6.209 & 4.5925 \\
\hline 6.109 & 4.1705 & 6.109 & 5.237 & 7.311 & 4.55 & 6.309 & 1.8665 & 6.91 & 6.5235 & 6.31 & 4.711 & 6.31 & 4.602 \\
\hline 6.209 & 4.0935 & 6.208 & 5.1765 & 7.411 & 4.4615 & 6.41 & 1.834 & 7.01 & 6.5745 & 6.411 & 4.7465 & 6.41 & 4.612 \\
\hline 6.309 & 4.0115 & 6.309 & 5.081 & 7.511 & 4.4375 & 6.51 & 1.8085 & 7.11 & 6.5995 & 6.51 & 4.744 & 6.51 & 4.5395 \\
\hline 6.41 & 3.935 & 6.409 & 4.983 & 7.612 & 4.525 & 6.609 & 1.8145 & 7.21 & 6.651 & 6.61 & 4.735 & 6.61 & 4.5965 \\
\hline 6.51 & 3.8655 & 6.51 & 5.0075 & 7.712 & 4.409 & 6.71 & 1.7475 & 7.31 & 6.5315 & 6.711 & 4.7115 & 6.711 & 4.5535 \\
\hline 6.609 & 3.8105 & 6.609 & 5.0185 & 7.811 & 4.464 & 6.81 & 1.7315 & 7.41 & 6.6905 & 6.811 & 4.71 & 6.811 & 4.5815 \\
\hline 6.71 & 3.731 & 6.709 & 4.9545 & 7.912 & 4.3785 & 6.911 & 1.7205 & 7.51 & 6.6135 & 6.911 & 4.698 & 6.911 & 4.5775 \\
\hline 6.81 & 3.6645 & 6.81 & 5.0705 & 8.012 & 4.3735 & 7.01 & 1.6715 & 7.611 & 6.5645 & 7.011 & 4.6655 & 7.011 & 4.5395 \\
\hline 6.911 & 3.577 & 6.91 & 5.0445 & 8.113 & 4.399 & 7.11 & 1.666 & 7.711 & 6.6005 & 7.111 & 4.7015 & 7.111 & 4.531 \\
\hline 7.01 & 3.5165 & 7.01 & 4.9875 & 8.212 & 4.3195 & 7.211 & 1.652 & 7.811 & 6.5885 & 7.212 & 4.7215 & 7.212 & 4.538 \\
\hline 7.11 & 3.448 & 7.11 & 4.889 & 8.312 & 4.3905 & 7.311 & 1.6285 & 7.911 & 6.6295 & 7.312 & 4.675 & 7.312 & 4.5395 \\
\hline 7.211 & 3.367 & 7.21 & 4.9545 & 8.413 & 4.3 & 7.411 & 1.592 & 8.011 & 6.603 & 7.412 & 4.627 & 7.411 & 4.4765 \\
\hline 7.311 & 3.297 & 7.311 & 4.9005 & 8.512 & 4.2915 & 7.511 & 1.559 & 8.111 & 6.548 & 7.512 & 4.662 & 7.512 & 4.519 \\
\hline 7.411 & 3.221 & 7.41 & 4.8595 & 8.613 & 4.2225 & 7.611 & 1.534 & 8.211 & 6.5075 & 7.612 & 4.6605 & 7.612 & 4.5065 \\
\hline 7.511 & 3.1675 & 7.511 & 4.749 & 8.713 & 4.2695 & 7.712 & 1.5395 & 8.311 & 6.583 & 7.713 & 4.6945 & 7.713 & 4.5215 \\
\hline 7.611 & 3.072 & 7.611 & 4.7695 & 8.813 & 4.307 & 7.811 & 1.486 & 8.412 & 6.559 & 7.812 & 4.6695 & 7.812 & 4.5065 \\
\hline 7.712 & 2.991 & 7.711 & 4.8325 & 8.913 & 4.249 & 7.912 & 1.4565 & 8.512 & 6.461 & 7.913 & 4.672 & 7.912 & 4.5175 \\
\hline 7.811 & 2.903 & 7.811 & 4.759 & 9.013 & 4.234 & 8.012 & 1.4405 & 8.612 & 6.541 & 8.013 & 4.6745 & 8.013 & 4.486 \\
\hline 7.912 & 2.854 & 7.911 & 4.666 & 9.114 & 4.211 & 8.111 & 1.411 & 8.712 & 6.5265 & 8.113 & 4.659 & 8.113 & 4.492 \\
\hline 8.012 & 2.7635 & 8.012 & 4.7235 & 9.214 & 4.1285 & 8.212 & 1.4005 & 8.812 & 6.491 & 8.213 & 4.6345 & 8.213 & 4.4615 \\
\hline 8.111 & 2.6635 & 8.111 & 4.637 & 9.314 & 4.2435 & 8.312 & 1.391 & 8.913 & 6.521 & 8.313 & 4.62 & 8.313 & 4.4145 \\
\hline 8.212 & 2.598 & 8.211 & 4.6145 & 9.414 & 4.159 & 8.412 & 1.319 & 9.012 & 6.5175 & 8.414 & 4.561 & 8.414 & 4.459 \\
\hline 8.312 & 2.5305 & 8.312 & 4.628 & 9.514 & 4.1555 & 8.512 & 1.329 & 9.113 & 6.572 & 8.514 & 4.5565 & 8.514 & 4.467 \\
\hline 8.413 & 2.4615 & 8.412 & 4.6205 & 9.615 & 4.216 & 8.612 & 1.305 & 9.213 & 6.565 & 8.614 & 4.571 & 8.613 & 4.4 \\
\hline
\end{tabular}

\begin{tabular}{|c|c|c|c|c|c|c|c|c|c|c|c|c|c|}
\hline $\begin{array}{l}\text { Time } \\
\text { (min) }\end{array}$ & $\begin{array}{c}\text { AuDO } \\
\text { for } \\
\text { Plankto }\end{array}$ & $\begin{array}{l}\text { Time } \\
\text { (min) }\end{array}$ & $\begin{array}{c}\text { Av DO } \\
\text { for Day } 0 \\
\text { (mgll) }\end{array}$ & $\begin{array}{l}\text { Time } \\
\text { (min) }\end{array}$ & $\begin{array}{c}\text { AvDO } \\
\text { for Day } 1 \\
\text { (mgrll) }\end{array}$ & $\begin{array}{l}\text { Time } \\
\text { (min) }\end{array}$ & $\begin{array}{c}\text { AvDO } \\
\text { for Day } 3 \\
\text { (mgll) }\end{array}$ & $\begin{array}{l}\text { Time } \\
\text { (min) }\end{array}$ & $\begin{array}{c}\text { Av DO } \\
\text { for Day } 8 \\
\text { (mgll) }\end{array}$ & $\begin{array}{l}\text { Time } \\
\text { (min) }\end{array}$ & $\begin{array}{c}\text { Av DO } \\
\text { for Day } \\
10 \text { (mgll) }\end{array}$ & $\begin{array}{l}\text { Time } \\
\text { (min) }\end{array}$ & $\begin{array}{c}\text { Av DO } \\
\text { for Day } \\
14 \text { (mgll) }\end{array}$ \\
\hline 8.512 & 2.41 & 8.512 & 4.5735 & 9.715 & 4.1485 & 8.713 & 1.2725 & 9.313 & 6.5955 & 8.714 & $\begin{array}{l}4.578 \\
\end{array}$ & 8.714 & 4.425 \\
\hline 8.612 & 2.306 & 8.612 & 4.559 & 9.815 & 4.0635 & 8.813 & 1.2375 & 9.413 & 6.5455 & 8.814 & 4.5865 & 8.814 & 4.415 \\
\hline 8.713 & 2.237 & 8.712 & 4.4665 & 9.915 & 4.1085 & 8.913 & 1.2255 & 9.513 & 6.507 & 8.915 & 4.544 & 8.914 & 4.431 \\
\hline 8.813 & 2.1585 & 8.813 & 4.5165 & 10.015 & 4.058 & 9.013 & 1.202 & 9.613 & 6.5845 & 9.014 & 4.513 & 9.014 & 4.3955 \\
\hline 8.913 & 2.096 & 8.913 & 4.4285 & 10.115 & 4.0845 & 9.113 & 1.1745 & 9.714 & 6.5625 & 9.115 & 4.487 & 9.114 & 4.4125 \\
\hline 9.013 & 1.9935 & 9.012 & 4.398 & 10.215 & 4.027 & 9.214 & 1.135 & 9.813 & 6.6375 & 9.215 & 4.462 & 9.215 & 4.37 \\
\hline 9.113 & 1.9365 & 9.113 & 4.4385 & 10.315 & 4.042 & 9.314 & 1.0875 & 9.914 & 6.495 & 9.314 & 4.512 & 9.314 & 4.362 \\
\hline 9.214 & 1.8505 & 9.213 & 4.432 & 10.416 & 3.994 & 9.413 & 1.0885 & 10.014 & 6.51 & 9.415 & 4.505 & 9.415 & 4.4085 \\
\hline 9.314 & 1.7755 & 9.314 & 4.401 & 10.516 & 3.992 & & & 10.114 & 6.435 & 9.515 & 4.4745 & 9.515 & 4.383 \\
\hline 9.414 & 1.6715 & 9.413 & 4.4085 & 10.616 & 4.0125 & & & 10.214 & 6.49 & 9.616 & 4.4795 & 9.615 & 4.351 \\
\hline 9.514 & 1.636 & 9.513 & 4.295 & 10.716 & 4.0035 & & & 10.314 & 6.55 & 9.715 & 4.496 & 9.715 & 4.32 \\
\hline 9.614 & 1.553 & 9.614 & 4.2415 & 10.816 & 3.972 & & & 10.415 & 6.5185 & 9.816 & 4.502 & 9.815 & 4.348 \\
\hline 9.715 & 1.4855 & 9.714 & 4.2525 & 10.916 & 3.9425 & & & 10.515 & 6.533 & 9.916 & 4.448 & 9.916 & 4.345 \\
\hline 9.814 & 1.385 & 9.814 & 4.1935 & 11.016 & 3.8685 & & & 10.614 & 6.549 & 10.016 & 4.4695 & 10.016 & 4.3095 \\
\hline 9.915 & 1.301 & 9.914 & 4.191 & 11.117 & 3.9115 & & & 10.715 & 6.523 & 10.116 & 4.468 & 10.116 & 4.342 \\
\hline 10.015 & 1.2475 & 10.014 & 4.223 & 11.217 & 3.891 & & & 10.815 & 6.502 & 10.216 & 4.4685 & 10.216 & 4.33 \\
\hline 10.115 & 1.156 & 10.115 & 4.102 & 11.316 & 3.881 & & & 10.915 & 6.5035 & 10.317 & 4.4545 & 10.316 & 4.2945 \\
\hline \multirow[t]{14}{*}{10.215} & 1.073 & 10.214 & 4.06 & 11.417 & 3.8825 & & & 11.015 & 6.521 & 10.417 & 4.3805 & 10.417 & 4.3225 \\
\hline & & 10.315 & 4.0035 & 11.517 & 3.8275 & & & 11.115 & 6.5365 & 10.517 & 4.408 & 10.516 & 4.2775 \\
\hline & & 10.415 & 3.973 & 11.618 & 3.8575 & & & 11.216 & 6.5895 & 10.617 & 4.3665 & 10.617 & 4.252 \\
\hline & & 10.514 & 4.0855 & 11.717 & 3.8385 & & & 11.316 & 6.46 & 10.717 & 4.3615 & 10.717 & 4.284 \\
\hline & & 10.615 & 3.994 & 11.818 & 3.8185 & & & 11.416 & 6.453 & 10.818 & 4.3135 & 10.817 & 4.3105 \\
\hline & & 10.715 & 3.8445 & 11.918 & 3.8165 & & & 11.516 & 6.5395 & 10.917 & 4.295 & 10.917 & 4.2345 \\
\hline & & 10.816 & 3.953 & 12.018 & 3.7885 & & & 11.616 & 6.4355 & 11.017 & 4.289 & 11.017 & 4.258 \\
\hline & & 10.915 & 3.9 & 12.118 & 3.7705 & & & 11.717 & 6.542 & 11.118 & 4.2595 & 11.118 & 4.234 \\
\hline & & 11.015 & 3.9155 & 12.218 & 3.8105 & & & 11.816 & 6.5655 & 11.218 & 4.251 & 11.218 & 4.2465 \\
\hline & & 11.116 & 3.871 & 12.319 & 3.775 & & & 11.917 & 6.5665 & 11.318 & 4.24 & 11.317 & 4.1785 \\
\hline & & 11.216 & 3.879 & 12.419 & 3.737 & & & 12.017 & 6.487 & 11.418 & 4.23 & 11.418 & 4.1945 \\
\hline & & 11.316 & 3.7305 & 12.518 & 3.7145 & & & 12.117 & 6.471 & 11.518 & 4.2205 & 11.518 & 4.206 \\
\hline & & 11.416 & 3.7695 & 12.619 & 3.689 & & & 12.217 & 6.568 & 11.619 & 4.226 & 11.618 & 4.2285 \\
\hline & & 11.516 & 3.7295 & 12.719 & 3.6725 & & & 12.317 & 6.4975 & 11.718 & 4.1605 & 11.718 & 4.2255 \\
\hline
\end{tabular}




\begin{tabular}{|c|c|c|c|c|c|c|c|c|c|}
\hline $\begin{array}{l}\text { Time } \\
\text { (min) }\end{array}$ & $\begin{array}{c}\text { Av DO } \\
\text { for Day } 0 \\
\text { (mglt) }\end{array}$ & $\begin{array}{l}\text { Time } \\
\text { (min) }\end{array}$ & $\begin{array}{c}\text { Av DO } \\
\text { for Day } 1 \\
\text { [mglt) }\end{array}$ & $\begin{array}{l}\text { Time } \\
\text { (min) }\end{array}$ & $\begin{array}{c}\text { Av DO } \\
\text { for Day } 8 \\
\text { (mgll) }\end{array}$ & $\begin{array}{l}\text { Time } \\
\text { (min) }\end{array}$ & $\begin{array}{c}\text { Av DO } \\
\text { for Day } \\
10 \text { (mglt) }\end{array}$ & $\begin{array}{l}\text { Time } \\
\text { (min) }\end{array}$ & $\begin{array}{c}\text { Av DO } \\
\text { for Day } \\
14 \text { (mgrl) }\end{array}$ \\
\hline 11.617 & 3.7955 & 12.819 & 3.6855 & 12.418 & 6.4925 & 11.819 & 4.214 & 11.818 & 4.2395 \\
\hline 11.717 & 3.748 & 12.919 & 3.6945 & 12.517 & 6.462 & 11.919 & 4.213 & 11.919 & 4.2175 \\
\hline 11.817 & 3.635 & 13.019 & 3.6595 & 12.617 & 6.485 & 12.019 & 4.1885 & 12.019 & 4.1605 \\
\hline 11.917 & 3.523 & 13.12 & 3.624 & 12.718 & 6.4675 & 12.119 & 4.168 & 12.119 & 4.151 \\
\hline 12.017 & 3.6535 & 13.22 & 3.554 & 12.818 & 6.5395 & 12.219 & 4.175 & 12.219 & 4.17 \\
\hline 12.118 & 3.5295 & 13.32 & 3.573 & 12.918 & 6.567 & 12.32 & 4.191 & 12.319 & 4.1965 \\
\hline 12.217 & 3.52 & 13.42 & 3.547 & 13.018 & 6.4785 & 12.42 & 4.1485 & 12.42 & 4.1295 \\
\hline 12.318 & 3.5215 & 13.521 & 3.5775 & 13.118 & 6.4195 & 12.52 & 4.191 & 12.519 & 4.1645 \\
\hline 12.418 & 3.4855 & 13.62 & 3.573 & 13.219 & 6.519 & 12.62 & 4.202 & 12.62 & 4.148 \\
\hline 12.517 & 3.5455 & 13.72 & 3.529 & 13.318 & 6.4855 & 12.72 & 4.1625 & 12.72 & 4.0995 \\
\hline 12.618 & 3.4955 & 13.821 & 3.5055 & 13.418 & 6.5255 & 12.821 & 4.1735 & 12.821 & 4.1335 \\
\hline 12.718 & 3.419 & 13.921 & 3.512 & 13.519 & 6.489 & 12.92 & 4.1595 & 12.92 & 4.125 \\
\hline 12.818 & 3.4905 & 14.021 & 3.4625 & 13.619 & 6.4035 & 13.021 & 4.167 & 13.02 & 4.0895 \\
\hline 12.918 & 3.4025 & 14.121 & 3.4235 & 13.719 & 6.4645 & 13.121 & 4.1905 & 13.121 & 4.0735 \\
\hline 13.018 & 3.329 & 14.221 & 3.366 & 13.819 & 6.4695 & 13.221 & 4.17 & 13.22 & 4.0955 \\
\hline 13.119 & 3.279 & 14.322 & 3.35 & 13.919 & 6.4255 & 13.321 & 4.1675 & 13.321 & 4.1015 \\
\hline 13.219 & 3.2875 & 14.422 & 3.3205 & 14.02 & 6.4825 & 13.421 & 4.1695 & 13.421 & 4.0825 \\
\hline 13.318 & 3.316 & 14.521 & 3.349 & 14.12 & 6.4125 & 13.522 & 4.134 & 13.521 & 4.1075 \\
\hline 13.419 & 3.223 & 14.622 & 3.372 & 14.22 & 6.4555 & 13.622 & 4.1445 & 13.622 & 4.033 \\
\hline 13.519 & 3.1245 & 14.722 & 3.338 & 14.32 & 6.3935 & 13.722 & 4.1595 & 13.721 & 4.0445 \\
\hline 13.62 & 3.1625 & 14.823 & 3.3205 & 14.42 & 6.4825 & 13.822 & 4.104 & 13.822 & 4.037 \\
\hline 13.719 & 3.165 & 14.922 & 3.278 & 14.521 & 6.4645 & 13.922 & 4.122 & 13.922 & 4.0645 \\
\hline 13.819 & 3.1495 & 15.022 & 3.2855 & 14.62 & 6.5405 & 14.023 & 4.106 & 14.021 & 4.077 \\
\hline 13.92 & 3.056 & 15.123 & 3.309 & 14.72 & 6.4595 & 14.122 & 4.0985 & 14.122 & 4.053 \\
\hline 14.02 & 3.126 & 15.222 & 3.264 & 14.821 & 6.4005 & 14.223 & 4.12 & 14.222 & 4.0175 \\
\hline 14.12 & 3.055 & 15.323 & 3.23 & 14.92 & 6.397 & 14.323 & 4.098 & 14.323 & 4.074 \\
\hline 14.22 & 2.9595 & 15.423 & 3.243 & 15.021 & 6.45 & 14.422 & 4.0925 & 14.422 & 4.0705 \\
\hline 14.32 & 2.9745 & 15.524 & 3.225 & 15.121 & 6.401 & 14.523 & 4.0625 & 14.522 & 4.0505 \\
\hline 14.421 & 2.8985 & 15.623 & 3.2105 & 15.222 & 6.483 & 14.623 & 4.061 & 14.623 & 4.001 \\
\hline 14.521 & 2.9455 & 15.723 & 3.149 & 15.321 & 6.42 & 14.724 & 4.0565 & 14.723 & 4.041 \\
\hline 14.621 & 2.923 & 15.824 & 3.076 & 15.421 & 6.4385 & 14.823 & 4.064 & 14.823 & 3.9905 \\
\hline
\end{tabular}

\begin{tabular}{|c|c|c|c|c|c|c|c|c|c|}
\hline $\begin{array}{l}\text { Time } \\
\text { (min) }\end{array}$ & $\begin{array}{c}\text { Au DO } \\
\text { for Day } 0 \\
\text { (mgll) }\end{array}$ & $\begin{array}{l}\text { Time } \\
\text { (min) }\end{array}$ & \begin{tabular}{|c|} 
Av DO \\
for Day 1 \\
(mgrll) \\
\end{tabular} & $\begin{array}{l}\text { Time } \\
\text { (min) }\end{array}$ & $\begin{array}{c}\text { Av DO } \\
\text { for Day } 8 \\
\text { (mgrll) } \\
\end{array}$ & $\begin{array}{l}\text { Time } \\
\text { (min) }\end{array}$ & \begin{tabular}{|c|} 
Au DO \\
for Day \\
10 (mgrli) \\
\end{tabular} & $\begin{array}{l}\text { Time } \\
\text { (min) }\end{array}$ & \begin{tabular}{|c|} 
Av DO \\
for Day \\
14 (mglt) \\
\end{tabular} \\
\hline 14.721 & 2.875 & 15.924 & $\begin{array}{r}3.103 \\
\end{array}$ & 15.522 & 6.4355 & 14.923 & 4.066 & 14.923 & 3.9845 \\
\hline 14.821 & 2.7995 & 16.024 & 3.026 & 15.622 & 6.374 & 15.024 & 4.0555 & 15.024 & 4.0195 \\
\hline 14.921 & 2.8815 & 16.124 & 3.057 & 15.722 & 6.4445 & 15.124 & 4.017 & 15.124 & 4.0025 \\
\hline 15.021 & 2.722 & 16.224 & 3.012 & 15.822 & 6.446 & 15.224 & 4.044 & 15.224 & 3.98 \\
\hline 15.122 & 2.7285 & 16.325 & 3.0075 & 15.922 & 6.449 & 15.324 & 4.015 & 15.324 & 3.972 \\
\hline 15.222 & 2.709 & 16.424 & 2.9985 & 16.023 & 6.4315 & 15.424 & 4.0345 & 15.424 & 3.977 \\
\hline 15.321 & 2.708 & 16.525 & 3.008 & 16.122 & 6.3525 & 15.525 & 4.03 & 15.525 & 3.9875 \\
\hline 15.422 & 2.68 & 16.625 & 2.966 & 16.223 & 6.4155 & 15.625 & 4.0025 & 15.625 & 3.9425 \\
\hline 15.522 & 2.641 & 16.725 & 2.9475 & 16.323 & 6.5035 & & & 15.724 & 3.976 \\
\hline 15.622 & 2.666 & 16.826 & 2.9625 & 16.423 & 6.4585 & & & 15.825 & 3.961 \\
\hline \multirow[t]{21}{*}{15.722} & 2.558 & 16.925 & 2.9795 & 16.524 & 6.49 & & & 15.925 & 3.9535 \\
\hline & & 17.026 & 2.964 & 16.623 & 6.4355 & & & 16.025 & 3.9325 \\
\hline & & 17.126 & 2.9455 & 16.723 & 6.4635 & & & 16.125 & 3.907 \\
\hline & & 17.226 & 2.918 & 16.824 & 6.4905 & & & 16.225 & 3.896 \\
\hline & & 17.326 & 2.949 & 16.924 & 6.4035 & & & 16.326 & 3.9085 \\
\hline & & 17.426 & 2.9505 & 17.024 & 6.397 & & & 16.426 & 3.924 \\
\hline & & 17.527 & 2.936 & 17.124 & 6.316 & & & 16.526 & 3.8975 \\
\hline & & 17.626 & 2.904 & 17.225 & 6.499 & & & 16.626 & 3.877 \\
\hline & & 17.727 & 2.9015 & 17.324 & 6.401 & & & 16.726 & 3.8985 \\
\hline & & 17.827 & 2.898 & 17.424 & 6.447 & & & 16.826 & 3.8555 \\
\hline & & 17.927 & 2.8735 & 17.525 & 6.44 & & & 16.926 & 3.8765 \\
\hline & & 18.027 & 2.8435 & 17.625 & 6.4805 & & & 17.027 & 3.9105 \\
\hline & & 18.127 & 2.8725 & 17.726 & 6.38 & & & 17.127 & 3.8655 \\
\hline & & 18.228 & 2.8685 & 17.825 & 6.39 & & & 17.227 & 3.846 \\
\hline & & 18.328 & 2.8775 & 17.925 & 6.433 & & & 17.327 & 3.856 \\
\hline & & 18.427 & 2.862 & 18.026 & 6.386 & & & 17.427 & 3.847 \\
\hline & & 18.528 & 2.8205 & 18.125 & 6.38 & & & 17.528 & 3.8075 \\
\hline & & 18.628 & 2.7765 & 18.226 & 6.48 & & & 17.627 & 3.836 \\
\hline & & 18.729 & 2.7785 & 18.326 & 6.414 & & & 17.728 & 3.821 \\
\hline & & 18.828 & 2.82 & 18.426 & 6.4765 & & & 17.828 & 3.841 \\
\hline & & 18.928 & 2.778 & 18.527 & 6.3605 & & & 17.928 & 3.8005 \\
\hline
\end{tabular}

\begin{tabular}{|r|r|r|r|r|r|}
\hline $\begin{array}{c}\text { Time } \\
\text { (min) }\end{array}$ & $\begin{array}{r}\text { Av DO } \\
\text { for Day 1 } \\
\text { (mglL) }\end{array}$ & $\begin{array}{r}\text { Time } \\
\text { (min) }\end{array}$ & $\begin{array}{c}\text { Av DO } \\
\text { for Day } 8 \\
\text { (mglL) }\end{array}$ & $\begin{array}{r}\text { Time } \\
\text { (min) }\end{array}$ & $\begin{array}{c}\text { Av DO } \\
\text { for Day } \\
14 \text { (mglL) }\end{array}$ \\
\hline 19.029 & 2.799 & 18.626 & 6.444 & 18.028 & 3.7955 \\
\hline 19.129 & 2.7695 & 18.727 & 6.3315 & 18.128 & 3.82 \\
\hline 19.229 & 2.768 & 18.827 & 6.341 & 18.229 & 3.754 \\
\hline 19.329 & 2.771 & 18.927 & 6.4305 & 18.329 & 3.76 \\
\hline 19.429 & 2.7705 & 19.027 & 6.314 & 18.429 & 3.7575 \\
\hline 19.53 & 2.7515 & 19.127 & 6.3955 & 18.529 & 3.7355 \\
\hline 19.629 & 2.706 & 19.228 & 6.3575 & 18.629 & 3.7435 \\
\hline 19.73 & 2.738 & 19.327 & 6.2725 & 18.729 & 3.7675 \\
\hline 19.83 & 2.727 & 19.427 & 6.403 & 18.829 & 3.743 \\
\hline 19.931 & 2.734 & 19.528 & 6.3755 & 18.93 & 3.7305 \\
\hline 20.03 & 2.691 & 19.628 & 6.409 & 19.03 & 3.73 \\
\hline 20.13 & 2.663 & 19.728 & 6.3595 & 19.13 & 3.7015 \\
\hline 20.231 & 2.6505 & 19.828 & 6.281 & 19.23 & 3.7005 \\
\hline 20.331 & 2.67 & 19.928 & 6.3115 & 19.33 & 3.7195 \\
\hline 20.431 & 2.641 & 20.029 & 6.342 & 19.431 & 3.7095 \\
\hline 20.531 & 2.6365 & 20.128 & 6.3705 & 19.531 & 3.711 \\
\hline 20.631 & 2.616 & 20.228 & 6.315 & 19.63 & 3.6765 \\
\hline 20.732 & 2.6425 & 20.329 & 6.303 & 19.731 & 3.655 \\
\hline 20.831 & 2.5925 & 20.429 & 6.3405 & 19.831 & 3.661 \\
\hline 20.932 & 2.592 & 20.529 & 6.3225 & 19.931 & 3.687 \\
\hline
\end{tabular}


Oxygen Uptake Rates for Thermal Polymer Gels: Experiment Begun 4-18-04

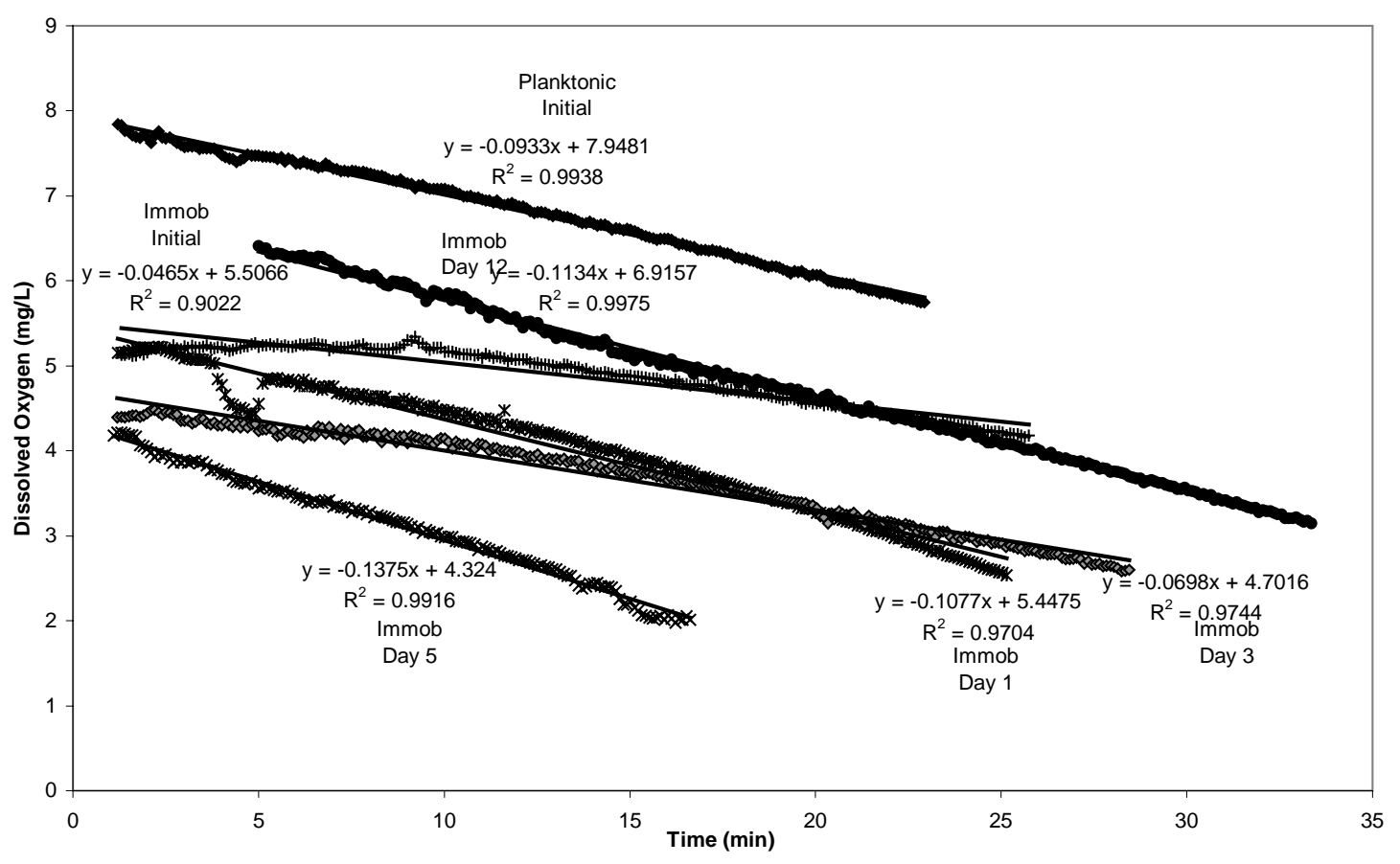

\begin{tabular}{|l|r|r|r|}
\hline Sample & Date & Gel Age (days) & DO Uptake Rate (mg/L/min) \\
\hline Plank Control & $4 / 18 / 04$ & 0 & 0.0933 \\
\hline Gel & $4 / 18 / 04$ & 0 & 0.0465 \\
\hline Gel & $4 / 19 / 04$ & 1 & 0.1077 \\
\hline Gel & $4 / 21 / 04$ & 3 & 0.0698 \\
\hline Gel & $4 / 23 / 04$ & 5 & 0.1375 \\
\hline Gel & $4 / 30 / 04$ & 12 & 0.1134 \\
\hline
\end{tabular}


A.2 Alginate as a carbon source experiment, 5-22-04, Book 2, Page 91

Referenced in Chapter 2, Section 3.1

Planktonic control with HAC

\begin{tabular}{|r|r|}
\hline Time [min] & Average \\
\hline 0.6 & 4.0265 \\
\hline 0.701 & 3.8775 \\
\hline 0.801 & 3.7255 \\
\hline 0.902 & 3.569 \\
\hline 1.002 & 3.403 \\
\hline 1.101 & 3.267 \\
\hline 1.202 & 3.1185 \\
\hline 1.302 & 2.979 \\
\hline 1.403 & 2.8415 \\
\hline 1.502 & 2.6805 \\
\hline 1.602 & 2.542 \\
\hline 1.703 & 2.394 \\
\hline 1.803 & 2.252 \\
\hline 1.903 & 2.096 \\
\hline 2.003 & 1.953 \\
\hline 2.103 & 1.814 \\
\hline 2.204 & 1.6725 \\
\hline 2.303 & 1.531 \\
\hline 2.404 & 1.369 \\
\hline 2.504 & 1.228 \\
\hline 2.604 & 1.091 \\
\hline 2.704 & 0.948 \\
\hline 2.804 & 0.797 \\
\hline 2.905 & 0.6625 \\
\hline & \\
\hline
\end{tabular}

Planktonic control without HAC

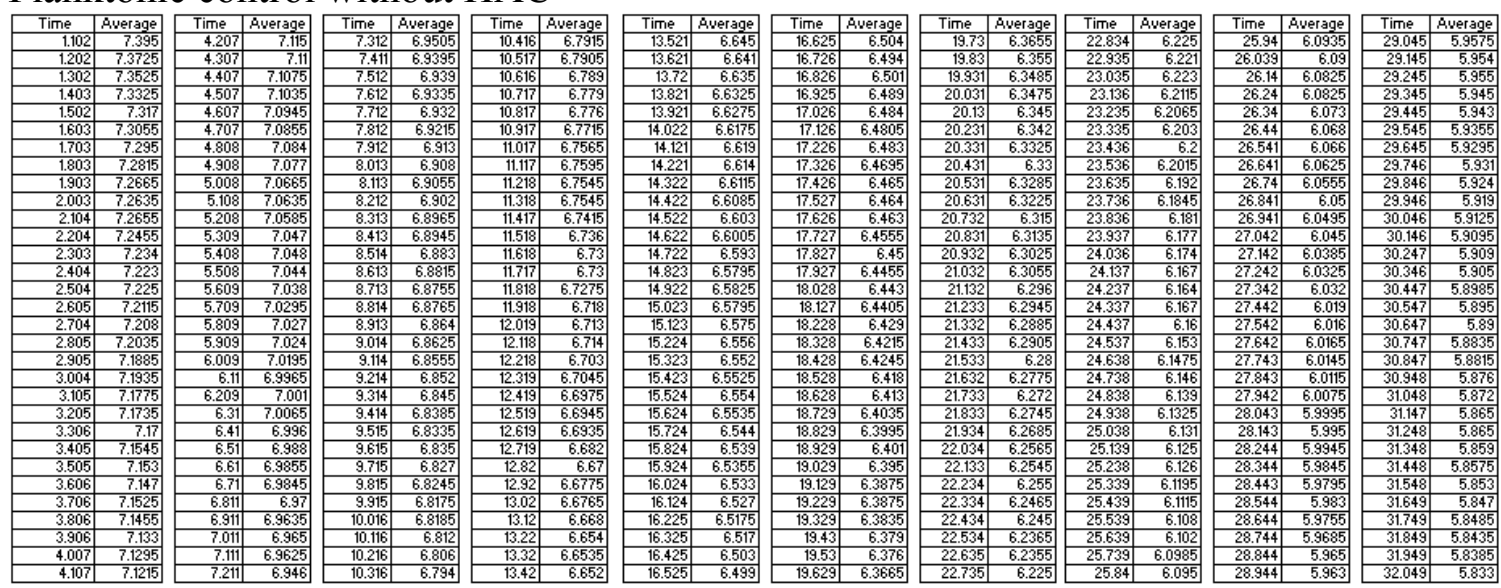




\begin{tabular}{|r|r|}
\hline \multicolumn{1}{|c|}{ Time } & Average \\
\hline 32.15 & 5.827 \\
\hline 32.25 & 5.8255 \\
\hline 32.349 & 5.819 \\
\hline 32.45 & 5.8145 \\
\hline 32.55 & 5.8155 \\
\hline 32.651 & 5.8085 \\
\hline 32.75 & 5.806 \\
\hline 32.85 & 5.8 \\
\hline 32.951 & 5.7935 \\
\hline 33.05 & 5.7925 \\
\hline 33.151 & 5.784 \\
\hline 33.251 & 5.787 \\
\hline 33.352 & 5.784 \\
\hline 33.451 & 5.774 \\
\hline 33.551 & 5.7715 \\
\hline 33.652 & 5.767 \\
\hline 33.752 & 5.762 \\
\hline 33.853 & 5.7585 \\
\hline 33.952 & 5.7565 \\
\hline 34.052 & 5.7535 \\
\hline 34.153 & 5.7445 \\
\hline 34.252 & 5.741 \\
\hline 34.353 & 5.7395 \\
\hline 34.453 & 5.7375 \\
\hline 34.554 & 5.729 \\
\hline 34.653 & 5.725 \\
\hline 34.753 & 5.7155 \\
\hline 34.854 & 5.718 \\
\hline 34.954 & 5.7135 \\
\hline 35.055 & 5.7045 \\
\hline 35.154 & 5.704 \\
\hline
\end{tabular}

\begin{tabular}{|r|r|}
\hline Time & Average \\
\hline 35.254 & 5.699 \\
\hline 35.355 & 5.6945 \\
\hline 35.454 & 5.6865 \\
\hline 35.555 & 5.681 \\
\hline 35.655 & 5.6795 \\
\hline 35.755 & 5.681 \\
\hline 35.855 & 5.6715 \\
\hline 35.955 & 5.666 \\
\hline 36.056 & 5.664 \\
\hline 36.156 & 5.665 \\
\hline 36.256 & 5.663 \\
\hline 36.356 & 5.654 \\
\hline 36.456 & 5.6515 \\
\hline 36.557 & 5.6465 \\
\hline 36.656 & 5.647 \\
\hline 36.757 & 5.6415 \\
\hline 36.857 & 5.632 \\
\hline 36.957 & 5.6305 \\
\hline 37.057 & 5.632 \\
\hline 37.157 & 5.6225 \\
\hline 37.258 & 5.6175 \\
\hline 37.358 & 5.6175 \\
\hline 37.457 & 5.614 \\
\hline 37.558 & 5.604 \\
\hline 37.658 & 5.5975 \\
\hline 37.759 & 5.5965 \\
\hline 37.858 & 5.593 \\
\hline 37.959 & 5.585 \\
\hline 38.059 & 5.5845 \\
\hline 38.159 & 5.5825 \\
\hline 38.259 & 5.579 \\
\hline &
\end{tabular}

\begin{tabular}{|r|r|}
\hline \multicolumn{1}{|c|}{ Time } & Average \\
\hline 38.359 & 5.5755 \\
\hline 38.46 & 5.575 \\
\hline 38.56 & 5.567 \\
\hline 38.659 & 5.561 \\
\hline 38.76 & 5.5585 \\
\hline 38.86 & 5.5535 \\
\hline 38.96 & 5.55 \\
\hline 39.06 & 5.5415 \\
\hline 39.161 & 5.5435 \\
\hline 39.261 & 5.5365 \\
\hline 39.361 & 5.533 \\
\hline 39.461 & 5.531 \\
\hline 39.561 & 5.5255 \\
\hline 39.661 & 5.528 \\
\hline 39.762 & 5.518 \\
\hline 39.861 & 5.51 \\
\hline 39.962 & 5.501 \\
\hline 40.062 & 5.5045 \\
\hline 40.161 & 5.5 \\
\hline 40.262 & 5.4965 \\
\hline 40.362 & 5.4935 \\
\hline 40.463 & 5.489 \\
\hline 40.562 & 5.4875 \\
\hline 40.662 & 5.484 \\
\hline 40.763 & 5.477 \\
\hline 40.863 & 5.478 \\
\hline 40.964 & 5.4695 \\
\hline 41.063 & 5.4645 \\
\hline 41.163 & 5.461 \\
\hline 41.264 & 5.4605 \\
\hline 41.363 & 5.452 \\
\hline & \\
\hline
\end{tabular}

\begin{tabular}{|r|r|}
\hline Time & Average \\
\hline 41.464 & 5.451 \\
\hline 41.564 & 5.446 \\
\hline 41.665 & 5.445 \\
\hline 41.764 & 5.441 \\
\hline 41.864 & 5.436 \\
\hline 41.965 & 5.4325 \\
\hline 42.065 & 5.423 \\
\hline 42.166 & 5.42 \\
\hline 42.265 & 5.42 \\
\hline 42.365 & 5.4145 \\
\hline 42.466 & 5.4095 \\
\hline 42.565 & 5.407 \\
\hline 42.666 & 5.406 \\
\hline 42.766 & 5.396 \\
\hline 42.866 & 5.392 \\
\hline 42.966 & 5.389 \\
\hline 43.066 & 5.3865 \\
\hline 43.167 & 5.3825 \\
\hline 43.267 & 5.3775 \\
\hline
\end{tabular}

Alginate immobilized cells, no HAC, day zero
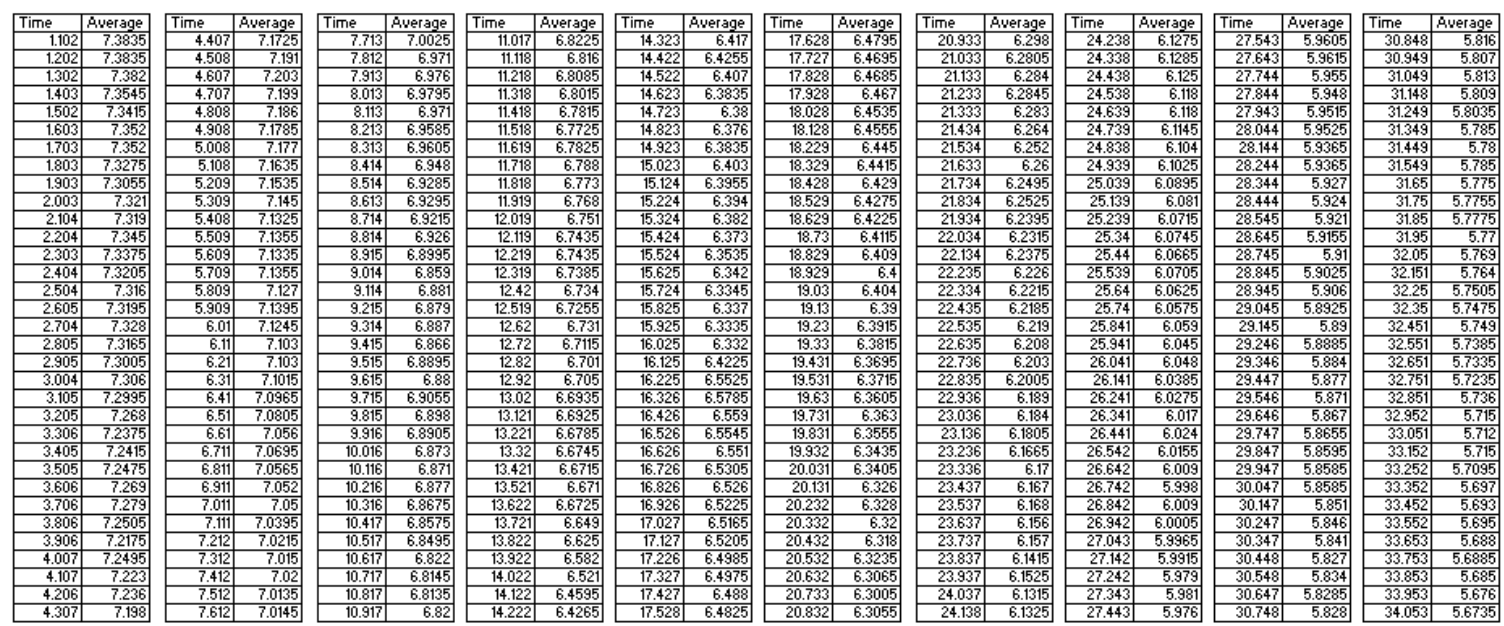


\begin{tabular}{|c|c|c|c|}
\hline Time & Average & Time & Average \\
\hline 34.154 & 5.675 & 37.458 & 5.5265 \\
\hline 34.253 & 5.6645 & 37.559 & 5.519 \\
\hline 34.354 & 5.655 & 37.659 & 5.5155 \\
\hline 34.454 & 5.6525 & 37.759 & 5.506 \\
\hline 34.554 & 5.653 & 37.859 & 5.5095 \\
\hline 34.654 & 5.6505 & 37.959 & 5.507 \\
\hline 34.754 & 5.6415 & 38.06 & 5.506 \\
\hline 34.855 & 5.632 & 38.16 & 5.5 \\
\hline 34.955 & 5.6195 & 38.26 & 5.4875 \\
\hline 35.054 & 5.6235 & 38.36 & 5.4755 \\
\hline 35.155 & 5.616 & 38.461 & 5.4815 \\
\hline 35.255 & 5.6135 & 38.561 & 5.473 \\
\hline 35.355 & 5.6125 & 38.66 & 5.4655 \\
\hline 35.455 & 5.617 & 38.761 & 5.465 \\
\hline 35.555 & 5.6065 & 38.861 & 5.468 \\
\hline 35.656 & 5.594 & 38.961 & 5.4675 \\
\hline 35.756 & 5.5945 & 39.061 & 5.457 \\
\hline 35.856 & 5.596 & 39.161 & 5.448 \\
\hline 35.956 & 5.58 & 39.262 & 5.446 \\
\hline 36.057 & 5.5745 & 39.361 & 5.445 \\
\hline 36.157 & 5.5685 & 39.462 & 5.4455 \\
\hline 36.256 & 5.5615 & 39.562 & 5.433 \\
\hline 36.357 & 5.5605 & 39.662 & 5.425 \\
\hline 36.457 & 5.5575 & 39.763 & 5.424 \\
\hline 36.557 & 5.5585 & 39.862 & 5.4245 \\
\hline 36.657 & 5.548 & 39.963 & 5.4145 \\
\hline 36.757 & 5.5575 & 40.063 & 5.4105 \\
\hline 36.858 & 5.5435 & 40.163 & 5.4065 \\
\hline 36.958 & 5.5365 & 40.263 & 5.4045 \\
\hline 37.058 & 5.5385 & 40.363 & 5.3995 \\
\hline 37.158 & 5.5355 & 40.464 & 5.394 \\
\hline 37.259 & 5.533 & 40.563 & 5.391 \\
\hline 37.359 & 5.534 & 40.664 & 5.384 \\
\hline
\end{tabular}

Alginate immobilized cells, no HAC, day 2
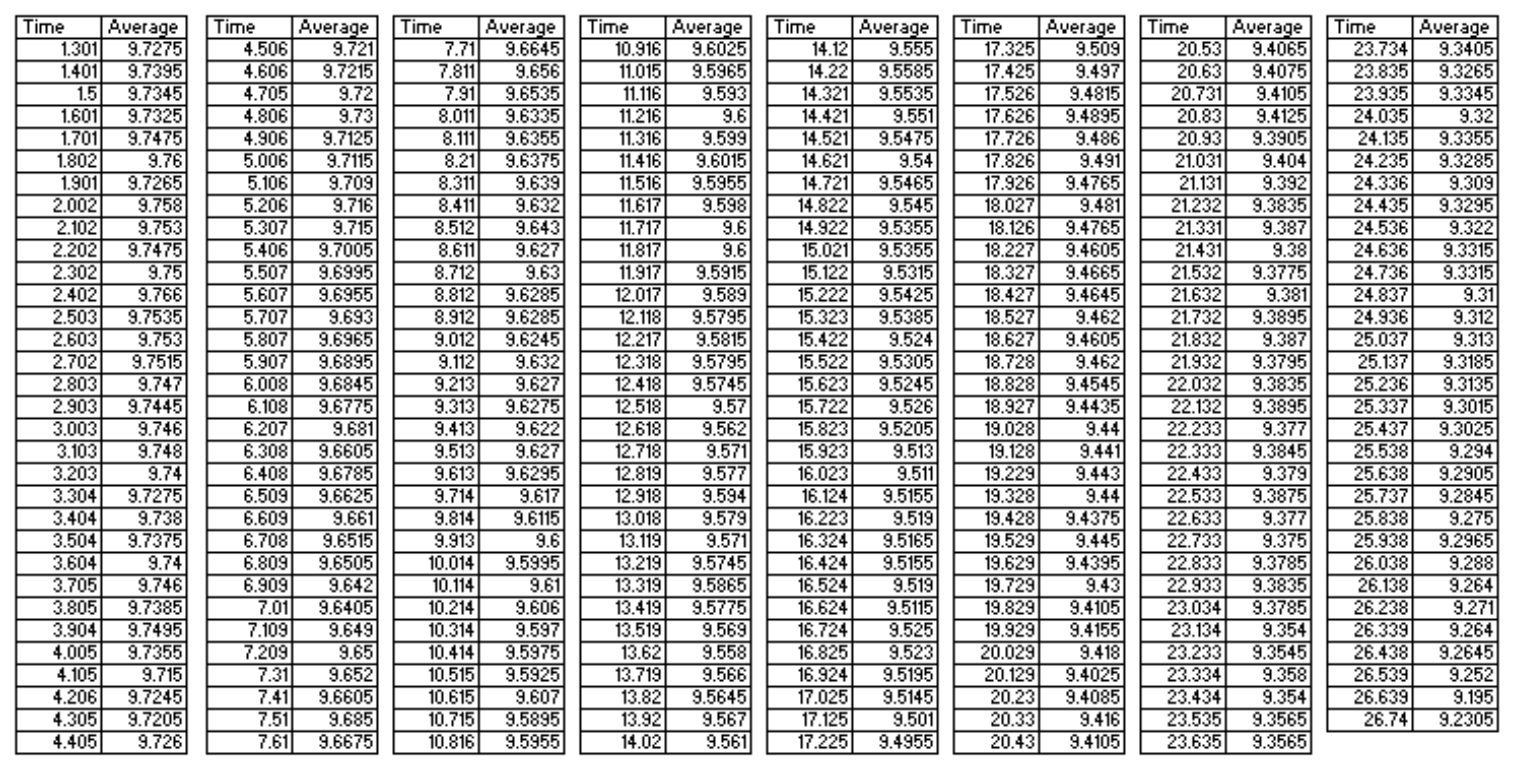
Summary plot from alginate degradation experiment

Oxygen Uptake Rates for Alginate Gels: Experiment Begun 4-18-04

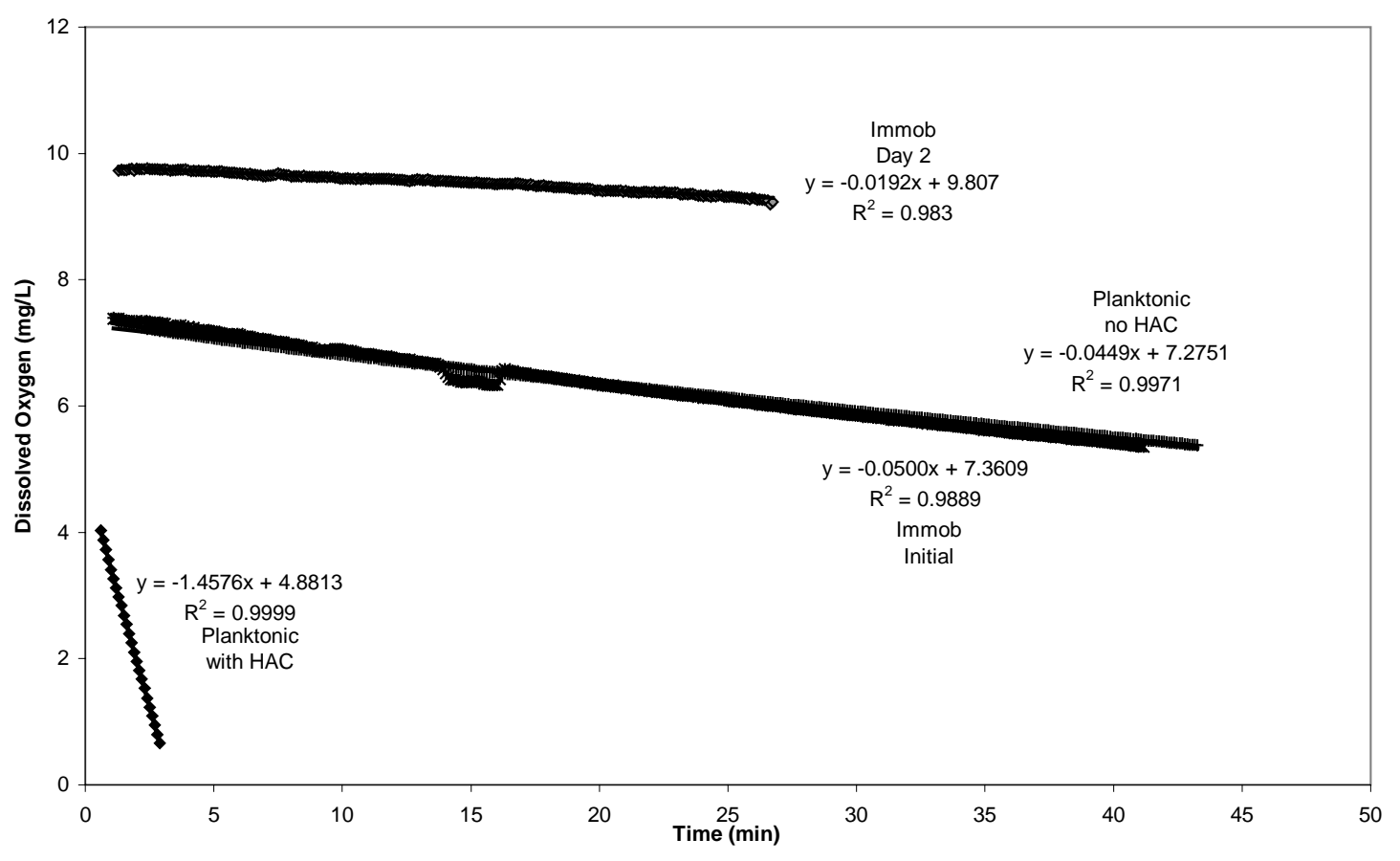

\begin{tabular}{|l|r|r|}
\hline Sample & Date & DO Uptake Rate (mg/L/min) \\
\hline Plank with HAC & $5 / 22 / 04$ & 1.4576 \\
\hline Plank no HAC & $5 / 22 / 04$ & 0.0449 \\
\hline Gel Initial no HAC & $5 / 22 / 04$ & 0.0500 \\
\hline Gel Day 2 no HAC & $5 / 24 / 04$ & 0.0192 \\
\hline
\end{tabular}




\section{A.3 t-tests to determine statistical difference}

$\mathrm{t}$ tests for planktonic potassium efflux experiments: (units $=\mathrm{mg} \mathrm{K}^{+} /$cell): Referenced in Chapter 3

Data:

$\begin{array}{rr}\text { late } \log P A & \text { mid } \log P A \\ 2.13 \mathrm{E}-10 & 5.09 \mathrm{E}-10 \\ 5.46 \mathrm{E}-10 & 5.61 \mathrm{E}-10 \\ 2.52 \mathrm{E}-11 & 3.89 \mathrm{E}-10 \\ 2.06 \mathrm{E}-10 & 3.42 \mathrm{E}-10 \\ 4.89 \mathrm{E}-10 & \\ 3.63 \mathrm{E}-10 & \\ & \\ & \\ & \\ \text { late } \log \mathrm{EC} & \text { mid } \log \mathrm{EC} \\ 4.16 \mathrm{E}-10 & 4.51327 \mathrm{E}-10 \\ 1.87 \mathrm{E}-10 & 6.87023 \mathrm{E}-10 \\ 6.43 \mathrm{E}-10 & 4.78676 \mathrm{E}-10 \\ & 5.93559 \mathrm{E}-10 \\ & 5.58081 \mathrm{E}-10\end{array}$

Compare late $\log$ PA to mid $\log$ PA

t-Test: Two-Sample Assuming Unequal Variances

Compare late $\log \mathrm{EC}$ to mid $\log \mathrm{EC}$

t-Test: Two-Sample Assuming Unequal Variances

\begin{tabular}{|c|c|c|}
\hline & l'aviate t & liaviate $2^{2}$ \\
\hline Mean & $3.07151 \mathrm{E}-10$ & $4.49969 \mathrm{E}-10$ \\
\hline Variance & $3.83649 \mathrm{E}-20$ & $1.04178 \mathrm{E}-20$ \\
\hline Observations & 6 & 4 \\
\hline Hypothesized Mean Di & 0 & \\
\hline $\mathrm{df}$ & 8 & \\
\hline tStat & -1.505553529 & \\
\hline $\mathrm{P}(\mathrm{T}<=\mathrm{t})$ one-tail & 0.085300189 & \\
\hline tCritical one-tail & 1.85954832 & \\
\hline $\mathrm{P}(\mathrm{T}<=\mathrm{t})$ two-tail & 0.170600377 & \\
\hline Critical two-tail & 2.306005626 & \\
\hline
\end{tabular}

\begin{tabular}{|c|c|c|}
\hline & liaviablet & lowiable $2^{2}$ \\
\hline Mean & $4.15329 \mathrm{E}-10$ & $5.53733 \mathrm{E}-10$ \\
\hline Variance & $5.19538 \mathrm{E}-20$ & $8.87291 \mathrm{E}-21$ \\
\hline Observations & 3 & 5 \\
\hline Hypothesized Mean D & 0 & \\
\hline $\mathrm{df}$ & 2 & \\
\hline tStat & -1.001652612 & \\
\hline$P(T<=t)$ one-tail & 0.211007083 & \\
\hline tCritical one-tail & 2.91998731 & \\
\hline $\mathrm{P}(\mathrm{T}<=\mathrm{t})$ two-tail & 0.422014166 & \\
\hline 1 Critical two-tail & 4.302655725 & \\
\hline
\end{tabular}

tcalc < t crit, so accept null hypothesis. No difference exists.

tcalc < t crit, so accept null hypothesis. No difference exists.

Compare late log PA to late log EC

t-Test: Two-Sample Assuming Unequal Variances

Compare mid $\log P A$ to mid $\log E C$

t-Test: Two-Sample Assuming Unequal Variances

\begin{tabular}{|c|c|c|}
\hline & l'aviatle t & liaviatle $2^{2}$ \\
\hline Mean & $3.07151 \mathrm{E}-10$ & $4.15329 \mathrm{E}-10$ \\
\hline Variance & $3.83649 \mathrm{E}-20$ & $5.19538 \mathrm{E}-20$ \\
\hline Observations & 6 & 3 \\
\hline Hypothesized Mean Di & 0 & \\
\hline $\mathrm{df}$ & 4 & \\
\hline t Stat & -0.702517739 & \\
\hline$P(T<=t)$ one-tail & 0.260543522 & \\
\hline tCritical one-tail & 2.131846486 & \\
\hline$P(T<=t)$ two-tail & 0.521087044 & \\
\hline t Critical two-tail & 2.776450856 & \\
\hline
\end{tabular}

\begin{tabular}{|c|c|c|}
\hline & liaviate t & liaviate ${ }^{7}$ \\
\hline Mean & $4.49969 \mathrm{E}-10$ & $5.53733 \mathrm{E}-10$ \\
\hline Variance & $1.04178 \mathrm{E}-20$ & $8.87291 E-21$ \\
\hline Observations & 4 & 5 \\
\hline Hypothesized Mean D & 0 & \\
\hline df & 6 & \\
\hline tStat & -1.568050427 & \\
\hline$P(T<=t)$ one-tail & 0.083958121 & \\
\hline t Critical one-tail & 1.943180905 & \\
\hline $\mathrm{P}[\mathrm{T}<=\mathrm{t}]$ two-tail & 0.167916242 & \\
\hline t Critical two-tail & 2.446913641 & \\
\hline
\end{tabular}




\section{Appendix B: Data for Chapter 3}

\section{B.1 Growth Curve Data}

\section{B.1.1 Psuedomonas aeruginosa}

7-22-03, Book 2, Page 12

\begin{tabular}{|r|r|r|}
\hline \multicolumn{1}{|l|}{ Time } & \multicolumn{1}{|l|}{ Trans 1 } & Abs 1 \\
\hline 0.0 & 99 & 0.004 \\
\hline 1.5 & 99 & 0.004 \\
\hline 3.0 & 99 & 0.004 \\
\hline 5.0 & 98 & 0.009 \\
\hline 6.4 & 96 & 0.018 \\
\hline 8.7 & 91 & 0.041 \\
\hline 11.1 & 86 & 0.066 \\
\hline 13.0 & 80 & 0.097 \\
\hline 15.4 & 76 & 0.119 \\
\hline 17.1 & 72 & 0.143 \\
\hline 19.2 & 68 & 0.167 \\
\hline 21.5 & 66 & 0.180 \\
\hline 23.7 & 64 & 0.194 \\
\hline 35.4 & 55 & 0.260 \\
\hline 39.4 & 53 & 0.276 \\
\hline 42.2 & 51 & 0.292 \\
\hline 45.7 & 50 & 0.301 \\
\hline 61.1 & 50 & 0.301 \\
\hline
\end{tabular}

P. aeruginosa Growth Curve in $5 \mathrm{~L}$ Jug

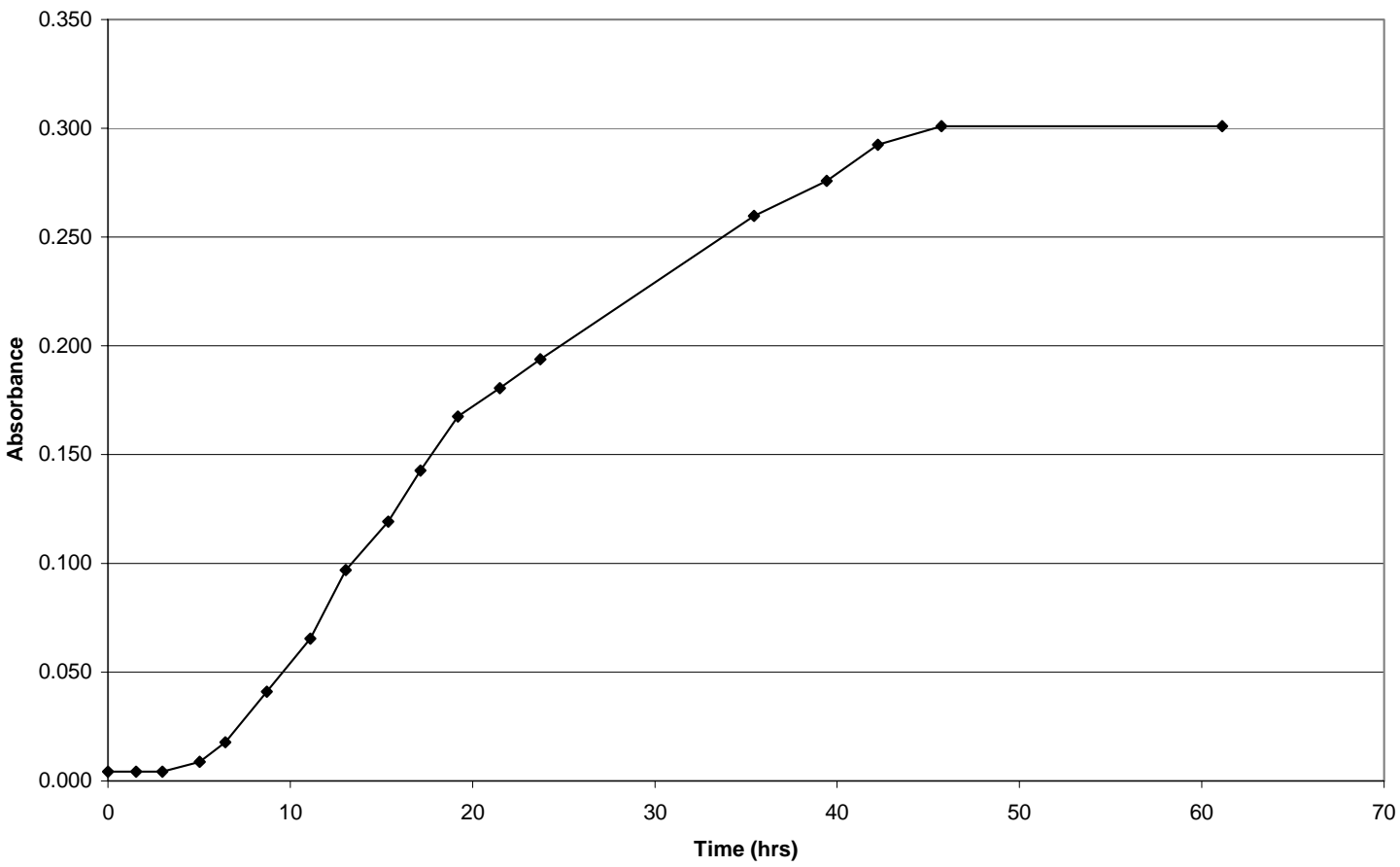


B.1.2 Escherchia coli

8-14-03, Book 2, Page 16

\begin{tabular}{|r|r|r|}
\hline \multicolumn{1}{|l|}{ Time } & Transmittance & Absorbance \\
\hline 0.0 & 98 & 0.0088 \\
\hline 1.6 & 96 & 0.0177 \\
\hline 3.2 & 92 & 0.0362 \\
\hline 4.9 & 88 & 0.0555 \\
\hline 6.4 & 81 & 0.0915 \\
\hline 7.0 & 80 & 0.0969 \\
\hline 9.8 & 74 & 0.1308 \\
\hline 16.1 & 65 & 0.1871 \\
\hline 18.2 & 62 & 0.2076 \\
\hline 20.3 & 58 & 0.2366 \\
\hline 24.2 & 56 & 0.2518 \\
\hline 28.2 & 56 & 0.2518 \\
\hline 30.2 & 56 & 0.2518 \\
\hline
\end{tabular}

E. coli Growth Curve in $5 \mathrm{~L}$ Jug

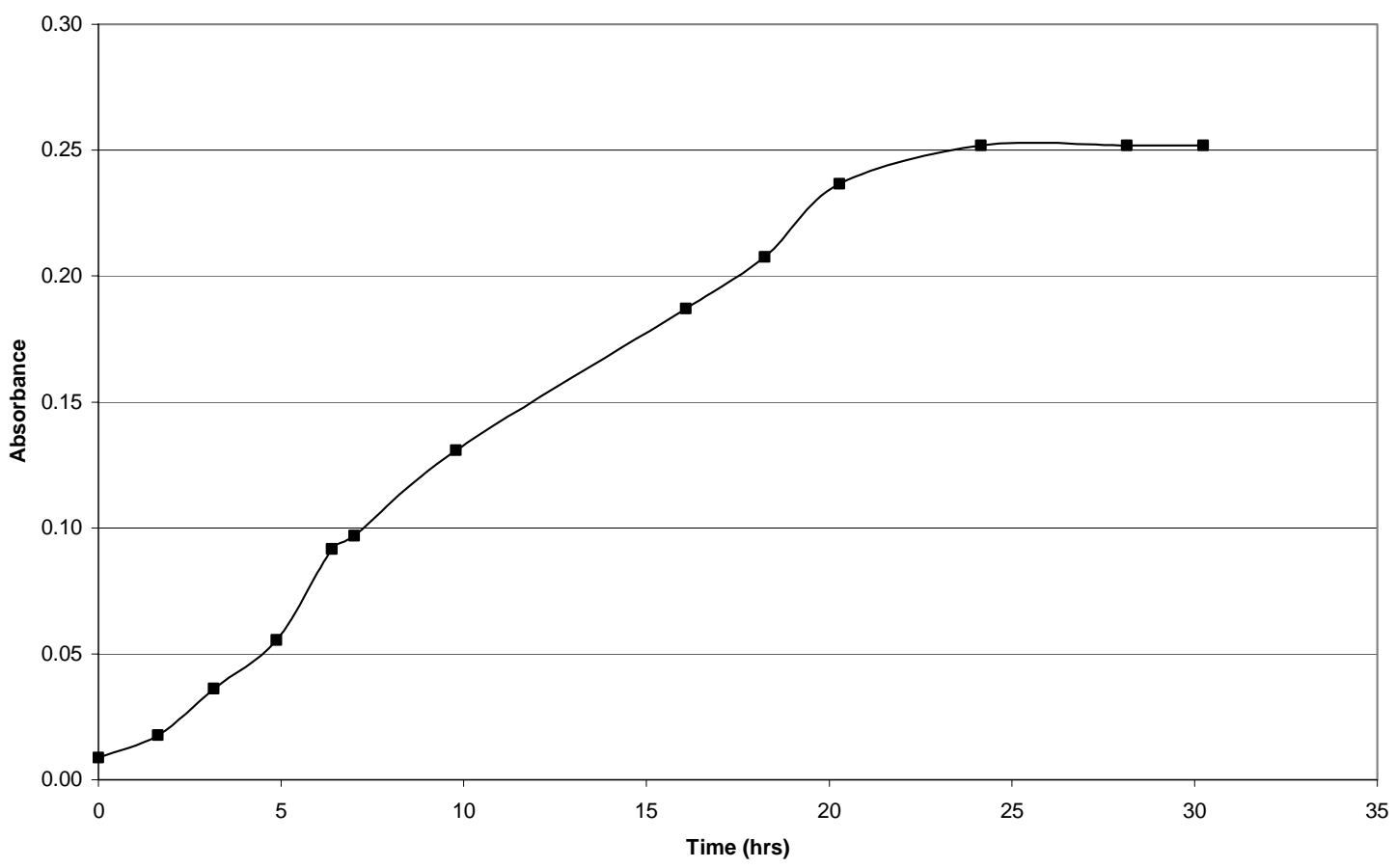




\section{B.2 Data for potassium efflux per cell for planktonic cultures}

\section{B.2.1 Planktonic efflux from $\boldsymbol{P}$. aeruginosa}

Summary table of efflux data for planktonic $P$. aeruginosa

\begin{tabular}{|r|r|r|r|r|r|r|r|r|r|r|r|r|r|}
\hline Trans & \multicolumn{1}{|c|}{ Abs } & \multicolumn{3}{|c|}{ Cell Counts } & Av cell count & StdDev cell count & \multicolumn{2}{|c|}{ delta K } & av delta K & Std Dev delta K & delta K r cell & Error on Efflun \\
\hline 61 & 0.2147 & $1.7 \mathrm{E}+09$ & $1.2 \mathrm{E}+09$ & $1.4 \mathrm{E}+09$ & $1.4 \mathrm{E}+09$ & $2.5 \mathrm{E}+08$ & 3.2 & 2.8 & 3.3 & 3.07 & 0.284 & $2.13 \mathrm{E}-10$ & $4.1 \mathrm{E}-11$ \\
\hline 72 & 0.1427 & $1.3 \mathrm{E}+09$ & $1.1 \mathrm{E}+09$ & $1.1 \mathrm{E}+09$ & $1.2 \mathrm{E}+09$ & $8.1 \mathrm{E}+07$ & 5.5 & 6.5 & 5.7 & 5.88 & 0.501 & $5.09 \mathrm{E}-10$ & $5.6 \mathrm{E}-11$ \\
\hline 60 & 0.2218 & $1.2 \mathrm{E}+09$ & $1.3 \mathrm{E}+09$ & $1.2 \mathrm{E}+09$ & $1.2 \mathrm{E}+09$ & $4.2 \mathrm{E}+07$ & 7.0 & 6.6 & 6.7 & 6.73 & 0.202 & $5.46 \mathrm{E}-10$ & $2.5 \mathrm{E}-11$ \\
\hline 50 & 0.3010 & $9.0 \mathrm{E}+09$ & $7.2 \mathrm{E}+09$ & $8.4 \mathrm{E}+09$ & $8.2 \mathrm{E}+09$ & $9.2 \mathrm{E}+08$ & 2.2 & 2.3 & 1.7 & 2.07 & 0.321 & $2.52 \mathrm{E}-11$ & $4.8 \mathrm{E}-12$ \\
\hline 55 & 0.2596 & $1.3 \mathrm{E}+09$ & $1.1 \mathrm{E}+09$ & $1.2 \mathrm{E}+09$ & $1.2 \mathrm{E}+09$ & $7.6 \mathrm{E}+07$ & 2.5 & 2.6 & 2.5 & 2.48 & 0.058 & $2.06 \mathrm{E}-10$ & $1.4 \mathrm{E}-11$ \\
\hline 91 & 0.0410 & $2.7 \mathrm{E}+08$ & $3.3 \mathrm{E}+08$ & $3.2 \mathrm{E}+08$ & $3.1 \mathrm{E}+08$ & $3.2 \mathrm{E}+07$ & 1.7 & 1.7 & 1.9 & 1.73 & 0.104 & $5.61 \mathrm{E}-10$ & $6.7 \mathrm{E}-11$ \\
\hline 79 & 0.1024 & $7.30 \mathrm{E}+08$ & $6.20 \mathrm{E}+08$ & $6.70 \mathrm{E}+08$ & $6.7 \mathrm{E}+08$ & $5.5 \mathrm{E}+07$ & 2.6 & 3.1 & 2.2 & 2.62 & 0.425 & $3.89 \mathrm{E}-10$ & $7.1 \mathrm{E}-11$ \\
\hline 75 & 0.1249 & $7.70 \mathrm{E}+08$ & $7.70 \mathrm{E}+08$ & $8.60 \mathrm{E}+08$ & $8.0 \mathrm{E}+08$ & $5.2 \mathrm{E}+07$ & 1.8 & 2.7 & 3.7 & 2.73 & 0.950 & $3.42 \mathrm{E}-10$ & $1.2 \mathrm{E}-10$ \\
\hline 66 & 0.1805 & $1.84 \mathrm{E}+09$ & $1.72 \mathrm{E}+09$ & $1.23 \mathrm{E}+09$ & $1.6 \mathrm{E}+09$ & $3.2 \mathrm{E}+08$ & 6.8 & 7.0 & 9.7 & 7.81 & 1.644 & $4.89 \mathrm{E}-10$ & $1.4 \mathrm{E}-10$ \\
\hline 62 & 0.2076 & $1.78 \mathrm{E}+09$ & $1.82 \mathrm{E}+09$ & $1.86 \mathrm{E}+09$ & $1.8 \mathrm{E}+09$ & $4.0 \mathrm{E}+07$ & 6.4 & 6.8 & 6.7 & 6.61 & 0.190 & $3.63 \mathrm{E}-10$ & $1.3 \mathrm{E}-11$ \\
\hline
\end{tabular}

The following sets of data were obtained by acidifying the samples with nitric acid, diluting, and analyzing on the AA. Data shown has been corrected for dilution and for machine drift during analysis. Control flasks are indicated by "C", and dosed flasks by "F." Potassium concentration is reported in $\mathrm{mg} / \mathrm{L}$.

Potassium efflux from transmittance $=61,6-20-03$, Book 1, Page 99

\begin{tabular}{|r|r|r|r|r|r|r|r|r|}
\hline Time & \multicolumn{1}{c}{ C1 } & \multicolumn{1}{c}{ C2 } & C3 & F1 & F2 & F3 & av control & av dose \\
\hline 0 & 0.15 & 0.05 & 0.15 & 0.15 & 0.40 &.. & 0.12 & 0.28 \\
\hline 5 & 0.15 & 0.30 & 0.35 & 1.85 & 1.60 & 1.60 & 0.27 & 1.68 \\
\hline 15 & 0.10 & 0.25 & 0.20 & 2.80 & 2.55 & 2.70 & 0.18 & 2.68 \\
\hline 30 & 0.25 & 0.10 & 0.10 & 3.40 & 3.00 & 3.00 & 0.15 & 3.13 \\
\hline 60 & 0.35 & 0.20 & 0.15 & 3.30 & 3.15 & 3.50 & 0.23 & 3.32 \\
\hline
\end{tabular}

Potassium efflux from transmittance $=72,7-18-03$, Book 2, Page 9

\begin{tabular}{|r|r|r|r|r|r|r|r|r|r|r|}
\hline Time & $\mathrm{C} 1$ & $\mathrm{C} 2$ & $\mathrm{C} 3$ & $\mathrm{~F} 1$ & $\mathrm{~F} 2$ & $\mathrm{~F} 3$ & av control & av dose & std dev cont & std dev dose \\
\hline 0 & 2.30 & 2.35 & 2.65 & 2.90 & 3.10 & 2.70 & 2.43 & 2.90 & 0.189 & 0.200 \\
\hline 5 & 1.75 & 1.85 & 1.60 & 6.05 & 5.70 & 7.25 & 1.73 & 6.33 & 0.126 & 0.813 \\
\hline 15 & 2.15 & 1.85 & 1.65 & 7.70 & 8.00 & 8.80 & 1.88 & 8.17 & 0.252 & 0.569 \\
\hline 30 & 1.70 & 1.35 & 1.70 & 8.75 & 8.60 & 7.95 & 1.58 & 8.43 & 0.202 & 0.425 \\
\hline 60 & 1.55 & 1.60 & 1.60 & 8.40 & 9.55 & 8.40 & 1.58 & 8.78 & 0.029 & 0.664 \\
\hline
\end{tabular}

Potassium efflux from transmittance $=60,7-19-03$, Book 2, Page 10

\begin{tabular}{|r|r|r|r|r|r|r|r|r|r|r|}
\hline Time & $\mathrm{C} 1$ & $\mathrm{C} 2$ & $\mathrm{C} 3$ & $\mathrm{~F} 1$ & $\mathrm{~F} 2$ & $\mathrm{~F} 3$ & av control & av dose & std dev cont & std dev dose \\
\hline 0 & 1.40 & 2.05 & 1.15 & 1.60 & 1.70 & 1.80 & 1.53 & 1.70 & 0.465 & 0.100 \\
\hline 15 & 3.00 & 1.80 & 2.85 & 7.80 & 7.75 & 8.65 & 2.55 & 8.07 & 0.654 & 0.506 \\
\hline 30 & 2.30 & 2.25 & 2.05 & 8.10 & 7.70 & 7.85 & 2.20 & 7.88 & 0.132 & 0.202 \\
\hline
\end{tabular}

Initial $\quad 1.15$

Potassium efflux from transmittance $=50,7-24-04$, Book 2, Page 11

\begin{tabular}{|r|r|r|r|r|r|r|r|r|r|r|}
\hline Time & \multicolumn{1}{l|}{$\mathrm{C} 1$} & $\mathrm{C} 2$ & $\mathrm{C} 3$ & \multicolumn{1}{|c|}{$\mathrm{F} 1$} & $\mathrm{~F} 2$ & $\mathrm{~F} 3$ & av control & av dose & std dev cont & std dev dose \\
\hline 0 & 0.05 & 0.05 & 0.20 & 0.55 & 0.15 & 0.55 & 0.10 & 0.42 & 0.087 & 0.231 \\
\hline 20 & 0.10 & 0.15 & 0.10 & 1.50 & 1.30 & 1.50 & 0.12 & 1.43 & 0.029 & 0.115 \\
\hline 40 & 0.05 & 0.05 & 0.10 & 2.15 & 2.40 & 2.20 & 0.07 & 2.25 & 0.029 & 0.132 \\
\hline 60 & 0.05 & 0.05 & 0.05 & 2.75 & 2.45 & 2.25 & 0.05 & 2.48 & 0.000 & 0.252 \\
\hline
\end{tabular}

Initial $\quad 3.15$ 
Potassium efflux from transmittance $=55,7-29-03$, Book 2, Page 14

\begin{tabular}{|r|r|r|r|r|r|r|r|r|r|r|}
\hline Time & \multicolumn{1}{c}{$\mathrm{C} 1$} & $\mathrm{C} 2$ & $\mathrm{C} 3$ & $\mathrm{~F} 1$ & $\mathrm{~F} 2$ & $\mathrm{~F} 3$ & av control & av dose & std dev cont & std dev dose \\
\hline 0 & 0.20 & 0.30 & 0.15 & 0.25 & 0.20 & 0.20 & 0.22 & 0.22 & 0.076 & 0.029 \\
\hline 20 & 0.25 & 0.30 & 0.15 & 1.60 & 1.40 & 1.55 & 0.23 & 1.52 & 0.076 & 0.104 \\
\hline 40 & 0.20 & 0.30 & 0.20 & 2.25 & 2.45 & 2.25 & 0.23 & 2.32 & 0.058 & 0.115 \\
\hline 60 & 0.20 & 0.15 & 0.15 & 2.70 & 2.75 & 2.65 & 0.17 & 2.70 & 0.029 & 0.050 \\
\hline
\end{tabular}

Initial $\quad 3.15$

Potassium efflux from transmittance $=91,7-31-03$, Book 2, Page 15

\begin{tabular}{|r|r|r|r|r|r|r|r|r|r|r|}
\hline Time & C1 & C2 & C3 & F1 & F2 & F3 & av control & av dose & std dev cont & std dev dose \\
\hline 0 & 2.10 & 1.85 & 2.05 & 2.10 & 2.00 & 1.90 & 2.00 & 2.00 & 0.132 & 0.100 \\
\hline 20 & 1.75 & 2.00 & 1.65 & 2.10 & 1.95 & 2.15 & 1.80 & 2.07 & 0.180 & 0.104 \\
\hline 40 & 1.35 & 1.50 & 1.40 & 2.20 & 2.75 & 2.50 & 1.42 & 2.48 & 0.076 & 0.275 \\
\hline 60 & 1.65 & 0.80 & 0.65 & 2.30 & 2.35 & 2.50 & 1.03 & 2.38 & 0.539 & 0.104 \\
\hline
\end{tabular}

Initial $\quad 3.15$

Potassium efflux from transmittance $=79,11-23-03$, Book 2, Page 53

\begin{tabular}{|r|l|l|l|l|l|l|r|r|r|r|}
\hline Time & $\mathrm{C} 1$ & $\mathrm{C} 2$ & $\mathrm{C} 3$ & $\mathrm{~F} 1$ & $\mathrm{~F} 2$ & $\mathrm{~F} 3$ & av control & av dose & std dev cont & std dev dose \\
\hline 0 & 2.30 & 0.60 & 3.25 & 1.55 & 0.95 & 1.25 & 2.05 & 1.25 & 1.343 & 0.300 \\
\hline 5 & 0.90 & 0.95 & 1.40 & 1.55 & 1.95 & 2.35 & 1.08 & 1.95 & 0.275 & 0.400 \\
\hline 15 & 0.65 & 0.80 & 0.75 & 3.45 & 3.05 & 3.20 & 0.73 & 3.23 & 0.076 & 0.202 \\
\hline 30 & 0.75 & 0.65 & 0.70 & 3.25 & 4.00 & 3.85 & 0.70 & 3.70 & 0.050 & 0.397 \\
\hline
\end{tabular}

Potassium efflux from transmittance $=75,11-23-03$, Book 2, Page 54

\begin{tabular}{|r|l|l|l|l|l|l|r|r|r|r|}
\hline Time & C1 & C2 & C3 & F1 & F2 & F3 & av control & av dose & std dev cont & std deu dose \\
\hline 0 & 0.95 & 0.70 & 1.35 & 1.80 & 1.20 & 0.85 & 1.00 & 1.28 & 0.328 & 0.480 \\
\hline 5 & 3.80 & 0.95 & 2.00 & 2.95 & 2.95 & 1.95 & 2.25 & 2.62 & 1.441 & 0.577 \\
\hline 15 & 1.80 & 0.85 & 0.45 & 4.30 & 3.55 & 3.65 & 1.03 & 3.83 & 0.693 & 0.407 \\
\hline 30 & 2.20 & 1.10 & 1.05 & 3.60 & 3.90 & 4.55 & 1.45 & 4.02 & 0.650 & 0.486 \\
\hline
\end{tabular}

Potassium efflux from transmittance $=66,1-2-04$, Book 2, Page 59

\begin{tabular}{|r|r|r|r|r|r|r|r|r|r|r|}
\hline Time & \multicolumn{1}{l|}{ C1 } & C2 & C3 & F1 & F2 & F3 & av control & av dose & st dev cont & st dev dose \\
\hline 0 & 1.90 & 1.95 & 1.29 & 1.80 & 2.54 & 1.51 & 1.71 & 1.95 & 0.369 & 0.530 \\
\hline 20 & 1.34 & 1.90 & 1.59 & 5.08 & 5.62 & 5.18 & 1.61 & 5.30 & 0.281 & 0.287 \\
\hline 40 & 1.80 & 2.77 & 2.72 & 8.17 & 8.71 & 9.01 & 2.43 & 8.63 & 0.546 & 0.423 \\
\hline 60 & 7.00 & 2.10 & 3.13 & 8.56 & 9.50 & 11.21 & 4.08 & 9.76 & 2.584 & 1.343 \\
\hline
\end{tabular}

Initital 2.36

Potassium efflux from transmittance $=62,1-17-04$, Book 2, Page 63

\begin{tabular}{|r|r|r|r|r|r|r|r|r|r|r|}
\hline Time & \multicolumn{1}{l|}{ C1 } & C2 & C3 & F1 & F2 & F3 & av control & av dose & st dev cont & st dev dose \\
\hline 0 & 0.51 & 0.85 & 1.43 & 0.89 & 0.95 & 0.55 & 0.93 & 0.80 & 0.466 & 0.214 \\
\hline 20 & 0.58 & 1.89 & 1.58 & 1.79 & 3.72 & 3.92 & 1.35 & 3.14 & 0.684 & 1.178 \\
\hline 40 & 3.47 & 0.55 & 0.62 & 5.35 & 4.82 & 6.42 & 1.55 & 5.53 & 1.666 & 0.815 \\
\hline 60 & 2.01 & 0.93 & 1.70 & 7.29 & 7.72 & 8.82 & 1.55 & 7.94 & 0.555 & 0.790 \\
\hline
\end{tabular}

Initital $\quad 2.15$ 


\section{B.2.2 Planktonic efflux from $\boldsymbol{E}$. coli}

Summary table of efflux data for planktonic E. coli

\begin{tabular}{|c|c|c|c|c|c|c|c|c|c|c|c|c|c|}
\hline Trans & Abs & & Cell Counts & & Av cell count & StdDev cell count & & Helta & & au delta $\mathrm{K}$ & Std Dev delta K & delta K t cell & Error on Efflux \\
\hline 56 & 0.252 & $1.0 \mathrm{E}+09$ & $1.1 \mathrm{E}+09$ & 1.1E+09 & $1.1 \mathrm{E}+09$ & $\begin{array}{r}4.0 \mathrm{E}+07 \\
\end{array}$ & 4.6 & 4.3 & 4.4 & 4.38 & $\begin{array}{r}0.153 \\
\end{array}$ & \begin{tabular}{|r|}
$4.161 \mathrm{E}-10$ \\
\end{tabular} & $2.16 \mathrm{E}-11$ \\
\hline 56 & 0.252 & $1.9 \mathrm{E}+09$ & $2.1 \mathrm{E}+09$ & $2.1 \mathrm{E}+0 \mathrm{9}$ & $2.1 \mathrm{E}+09$ & $9.6 \mathrm{E}+07$ & 3.6 & 4.1 & 3.9 & 3.83 & 0.275 & $1.870 \mathrm{E}-10$ & $1.61 \mathrm{E}-11$ \\
\hline 78 & 0.108 & 1.1E+09 & $1.3 \mathrm{E}+09$ & $1.0 \mathrm{E}+09$ & $1.1 \mathrm{E}+09$ & $1.4 \mathrm{E}+08$ & 4.9 & 5.0 & 5.5 & 5.10 & 0.304 & $4.513 \mathrm{E}-10$ & $6.27 \mathrm{E}-11$ \\
\hline 70 & 0.155 & $9.1 \mathrm{E}+08$ & $8.2 \mathrm{E}+08$ & $8.9 \mathrm{E}+08$ & $8.7 \mathrm{E}+08$ & $4.7 \mathrm{E}+07$ & 5.7 & 5.8 & 6.6 & 6.00 & 0.477 & $6.870 \mathrm{E}-10$ & $6.61 \mathrm{E}-11$ \\
\hline 55 & 0.260 & $1.68 \mathrm{E}+09$ & $1.44 E+09$ & $1.43 \mathrm{E}+09$ & $1.5 \mathrm{E}+0 \mathrm{9}$ & $1.4 \mathrm{E}+08$ & 9.4 & 9.8 & 10.1 & 9.75 & 0.377 & $6.429 \mathrm{E}-10$ & $6.50 \mathrm{E}-11$ \\
\hline 76 & 0.119 & $4.20 \mathrm{E}+08$ & $4.40 \mathrm{E}+08$ & $5.00 \mathrm{E}+08$ & $4.5 \mathrm{E}+08$ & $4.2 \mathrm{E}+07$ & 2.1 & 2.2 & 2.3 & 2.17 & 0.092 & $4.787 \mathrm{E}-10$ & $4.84 \mathrm{E}-11$ \\
\hline 86 & 0.066 & $1.10 \mathrm{E}+09$ & $8.00 \mathrm{E}+08$ & $1.05 E+09$ & $9.8 \mathrm{E}+08$ & $1.6 \mathrm{E}+08$ & 5.8 & 6.1 & 5.7 & 5.84 & 0.201 & $5.936 \mathrm{E}-10$ & $9.91 \mathrm{E}-11$ \\
\hline 89 & 0.051 & $1.28 \mathrm{E}+09$ & $1.32 E+09$ & $1.42 E+09$ & $1.3 E+09$ & $7.2 E+07$ & 6.2 & 6.5 & 9.7 & 7.48 & 1.970 & $5.581 \mathrm{E}-10$ & $1.50 \mathrm{E}-10$ \\
\hline
\end{tabular}

The following sets of data were obtained by acidifying the samples with nitric acid, diluting, and analyzing on the AA. Data shown has been corrected for dilution and for machine drift during analysis. Control flasks are indicated by "C", and dosed flasks by "F." Potassium concentration is reported in $\mathrm{mg} / \mathrm{L}$.

Potassium efflux from transmittance $=56,8-15-03$, Book 2, Page 17

\begin{tabular}{|r|r|r|r|r|r|r|r|r|r|r|}
\hline Time & \multicolumn{1}{c}{ C1 } & \multicolumn{1}{l}{ C2 } & \multicolumn{1}{l}{ C3 } & F1 & F2 & F3 & av control & av dose & st dev cont & st dev dose \\
\hline 0 & 0.40 & 0.30 & 0.25 & 0.25 & 0.35 & 0.30 & 0.32 & 0.30 & 0.466 & 0.214 \\
\hline 20 & 0.35 & 0.10 & 0.40 & 3.40 & 3.20 & 2.80 & 0.28 & 3.13 & 0.684 & 1.178 \\
\hline 40 & 0.20 & 0.35 & 0.25 & 4.25 & 4.20 & 4.55 & 0.27 & 4.33 & 1.666 & 0.815 \\
\hline 60 & 0.25 & 0.30 & 0.20 & 4.70 & 4.60 & 4.90 & 0.25 & 4.73 & 0.555 & 0.79 \\
\hline
\end{tabular}

Initial $\quad 0.35$

Potassium efflux from transmittance $=56,8-20-03$, Book 2, Page 18

\begin{tabular}{|r|r|r|r|r|r|r|r|r|r|r|}
\hline Time & C1 & C2 & C3 & F1 & F2 & F3 & av control & av dose & st dev cont & st dev dose \\
\hline 0 & 0.35 & 0.30 & 0.25 & 0.45 & 0.35 & 0.75 & 0.30 & 0.52 & 0.466 & 0.214 \\
\hline 20 & 0.50 & 0.25 & 0.30 & 1.35 & 1.45 & 1.80 & 0.35 & 1.53 & 0.684 & 1.178 \\
\hline 40 & 0.40 & 0.45 & 0.45 & 3.70 & 3.50 & 3.80 & 0.43 & 3.67 & 1.666 & 0.815 \\
\hline 60 & 0.40 & 0.40 & 0.25 & 4.25 & 4.50 & 3.95 & 0.35 & 4.23 & 0.555 & 0.79 \\
\hline
\end{tabular}

Initial $\quad 0.40$

Potassium efflux from transmittance $=78,8-22-03$, Book 2, Page 20

\begin{tabular}{|r|r|r|r|r|r|r|r|r|r|r|}
\hline Time & \multicolumn{1}{l|}{ C1 } & \multicolumn{1}{l}{ C2 } & \multicolumn{1}{l}{ F1 } & F2 & F3 & au control & av dose & st dev cont & st dev dose \\
\hline 0 & 0.20 & 0.15 & 0.15 & 0.40 & 2.95 & 1.70 & 0.17 & 1.68 & 0.466 & 0.214 \\
\hline 20 & 0.30 & 0.25 & 0.15 & 4.75 & 4.25 & 4.55 & 0.23 & 4.52 & 0.684 & 1.178 \\
\hline 40 & 0.30 & 0.40 & 0.30 & 5.05 & 5.10 & 4.65 & 0.33 & 4.93 & 1.666 & 0.815 \\
\hline 60 & 0.20 & 0.30 & 0.40 & 4.55 & 4.70 & 5.60 & 0.30 & 4.95 & 0.555 & 0.79 \\
\hline
\end{tabular}

Initial $\quad 0.15$

Potassium efflux from transmittance $=70,8-23-03$, Book 2, Page 21

\begin{tabular}{|r|r|r|r|r|r|r|r|r|r|r|}
\hline Time & \multicolumn{1}{c}{$\mathrm{C} 1$} & $\mathrm{C} 2$ & $\mathrm{C} 3$ & $\mathrm{~F} 1$ & $\mathrm{~F} 2$ & $\mathrm{~F} 3$ & av control & av dose & st dev cont & st dev dose \\
\hline 0 & 0.55 & 0.55 & 0.50 & 0.45 & 1.25 & 0.70 & 0.53 & 0.80 & 0.466 & 0.214 \\
\hline 20 & 0.60 & 0.80 & 0.45 & 4.75 & 5.55 & 5.10 & 0.62 & 5.13 & 0.684 & 1.178 \\
\hline 40 & 0.50 & 0.60 & 0.30 & 6.05 & 6.65 & 7.45 & 0.47 & 6.72 & 1.666 & 0.815 \\
\hline 60 & 0.65 & 0.45 & 0.35 & 6.60 & 6.40 & 9.25 & 0.48 & 7.42 & 0.555 & 0.79 \\
\hline
\end{tabular}

Initial $\quad 0.90$ 
Potassium efflux from transmittance $=55,9-25-03$, Book 2, Page 33

\begin{tabular}{|r|r|r|r|r|r|r|r|r|r|r|}
\hline Time & \multicolumn{1}{c}{$\mathrm{C} 1$} & $\mathrm{C} 2$ & $\mathrm{C} 3$ & $\mathrm{~F} 1$ & $\mathrm{~F} 2$ & $\mathrm{~F} 3$ & av control & av dose & st dev cont & st dev dose \\
\hline 0 & 1.10 & 1.90 & 0.70 & 0.85 & 1.60 & 1.85 & 1.23 & 1.43 & 0.466 & 0.214 \\
\hline 20 & 0.35 & 0.90 & 0.75 & 4.50 & 4.55 & 4.75 & 0.67 & 4.60 & 0.684 & 1.178 \\
\hline 40 & 0.85 & 1.15 & 1.25 & 10.15 & 8.60 & 8.40 & 1.08 & 9.05 & 1.666 & 0.815 \\
\hline 60 & 0.65 & 0.55 & 0.75 & 10.10 & 10.55 & 10.85 & 0.65 & 10.50 & 0.555 & 0.79 \\
\hline
\end{tabular}

Potassium efflux from transmittance $=76,12-10-03$, Book 2, Page 56

\begin{tabular}{|r|r|r|r|r|r|r|r|r|r|r|}
\hline Time & \multicolumn{1}{c}{ C1 } & C2 & C3 & F1 & F2 & F3 & av control & av dose & st dev cont & st dev dose \\
\hline 0 & 0.17 & 0.47 & 1.16 & 0.27 & 0.74 & 0.79 & 0.60 & 0.60 & 0.466 & 0.214 \\
\hline 20 & 0.52 & 0.93 & 1.22 & 1.43 & 1.55 & 1.55 & 0.89 & 1.51 & 0.684 & 1.178 \\
\hline 40 & 0.76 & 0.64 & 0.35 & 2.42 & 2.07 & 2.36 & 0.58 & 2.29 & 1.666 & 0.815 \\
\hline 60 & 1.28 & 0.93 & 1.10 & 3.18 & 2.48 & 2.60 & 1.10 & 2.75 & 0.555 & 0.79 \\
\hline
\end{tabular}

Init $\quad 0.33$

Potassium efflux from transmittance $=86,12-12-03$, Book 2, Page 57

\begin{tabular}{|r|r|r|r|r|r|r|r|r|r|r|}
\hline Time & \multicolumn{1}{c}{ C1 } & \multicolumn{1}{l}{ C2 } & \multicolumn{1}{l}{ C3 } & \multicolumn{1}{l}{ F1 } & F2 & F3 & au control & au dose & st dev cont & st deu dose \\
\hline 0 & 3.24 & 0.50 & 0.68 & 0.76 & 0.37 & 0.65 & 1.47 & 0.59 & 0.466 & 0.214 \\
\hline 20 & 3.58 & 1.38 & 1.96 & 4.48 & 4.15 & 4.42 & 2.31 & 4.35 & 0.684 & 1.178 \\
\hline 40 & 1.61 & 1.08 & 1.61 & 5.04 & 5.92 & 5.31 & 1.43 & 5.42 & 1.666 & 0.815 \\
\hline 60 & 1.03 & 0.85 & 0.91 & 6.09 & 6.37 & 5.98 & 0.93 & 6.15 & 0.555 & 0.79 \\
\hline
\end{tabular}

Initial $\quad 0.70$

Potassium efflux from transmittance $=89,1-6-04$, Book 2, Page 60

\begin{tabular}{|r|r|r|r|r|r|r|r|r|r|r|}
\hline Time & \multicolumn{1}{c}{$\mathrm{C} 1$} & $\mathrm{C} 2$ & $\mathrm{C} 3$ & $\mathrm{~F} 1$ & $\mathrm{~F} 2$ & $\mathrm{~F} 3$ & av control & av dose & st dev cont & st dev dose \\
\hline 0 & 0.77 & 0.77 & 0.82 & 0.97 & 0.61 & 0.72 & 0.79 & 0.77 & 0.466 & 0.214 \\
\hline 20 & 0.68 & 1.07 & 1.75 & 5.36 & 5.36 & 4.95 & 1.17 & 5.22 & 0.684 & 1.178 \\
\hline 40 & 0.73 & 1.02 & 0.77 & 6.23 & 6.58 & 6.33 & 0.84 & 6.38 & 1.666 & 0.815 \\
\hline 60 & 0.73 & 0.87 & 0.68 & 7.14 & 7.55 & 10.46 & 0.76 & 8.39 & 0.555 & 0.79 \\
\hline
\end{tabular}

Initial 1.04 


\section{B.3 Data for efflux from alginate-immobilized $P$. aeruginosa}

The following data were obtained by acidifying the samples with nitric acid, diluting, and analyzing on the AA. Data shown has been corrected for dilution and for machine drift during analysis. Control flasks are indicated by "C", and dosed flasks by "F." Potassium concentration is reported in $\mathrm{mg} / \mathrm{L}$. Days after immobilization are given (e.g., day $0=$ immediately after immobilization and day $1=24$ hours after immobilization). Cell counts were performed by serial dilutions and plating. Volumes shown with cell counts indicate total volume of culture after resuspension. Total cells $=$ average cell count $\mathrm{x}$ resuspension volume. This total was divided equally into six flasks to give cells per flask.

Efflux 2, Day 1

2-4-04, Book 2, Page 69

Presented in Chapter 3, Table 1 and Figure 6

\begin{tabular}{|r|r|r|r|r|r|r|r|r|r|r|}
\hline Time & \multicolumn{1}{|c|}{ C1 } & C2 & C3 & F1 & F2 & F3 & Av Cont & Av Dose & st dev cont & st dev dose \\
\hline 0 & 0.56 & 0.62 & 0.16 & 1.16 & 1.72 & 1.61 & 0.45 & 1.50 & 0.251 & 0.296 \\
\hline 20 & 0.17 & 1.29 & 0.88 & 1.50 & 2.22 & 2.34 & 0.78 & 2.02 & 0.569 & 0.455 \\
\hline 40 & 0.51 & 0.34 & 0.77 & 1.33 & 2.39 & 3.29 & 0.54 & 2.34 & 0.219 & 0.979 \\
\hline 60 & 0.51 & 1.24 & 0.83 & 2.73 & 2.22 & 3.84 & 0.86 & 2.93 & 0.366 & 0.829 \\
\hline 120 & 0.84 & 0.62 & 0.10 & 2.39 & 1.83 & 3.45 & 0.52 & 2.56 & 0.380 & 0.823 \\
\hline
\end{tabular}

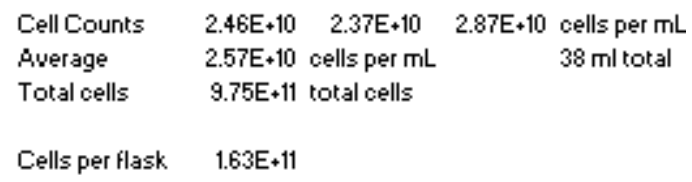

Efflux 3, Day 5

1-27-04, Book 2, Page 67

Presented in Chapter 3, Figure 7

\begin{tabular}{|c|c|c|c|c|c|c|c|c|c|c|}
\hline Time & C1 & $\mathrm{C} 2$ & $\mathrm{C} 3$ & F1 & $\mathrm{F} 2$ & F3 & Áv Cont & Án Dose & st dev cont & st dev dose \\
\hline 0 & 0.63 & 0.43 & 1.34 & 0.66 & 0.24 & 2.19 & 0.80 & 1.03 & 0.4764 & 1.0258 \\
\hline 20 & 0.12 & 1.70 & 0.33 & 0.62 & 0.24 & 2.04 & 0.72 & 0.97 & 0.8602 & 0.9497 \\
\hline 40 & 0.84 & 0.12 & 2.25 & 0.62 & 1.99 & 2.79 & 1.07 & 1.80 & 1.0828 & 1.1001 \\
\hline 60 & 0.22 & 0.17 & 0.37 & 2.01 & 0.84 & 2.19 & 0.26 & 1.68 & 0.1048 & 0.7328 \\
\hline 120 & 2.26 & 0.43 & 1.14 & 2.30 & 1.49 & 3.94 & 1.28 & 2.58 & 0.9258 & 1.2485 \\
\hline
\end{tabular}

Data not included in thesis:

1-26-04, Book 2, Page 66

Efflux 1, Day 0

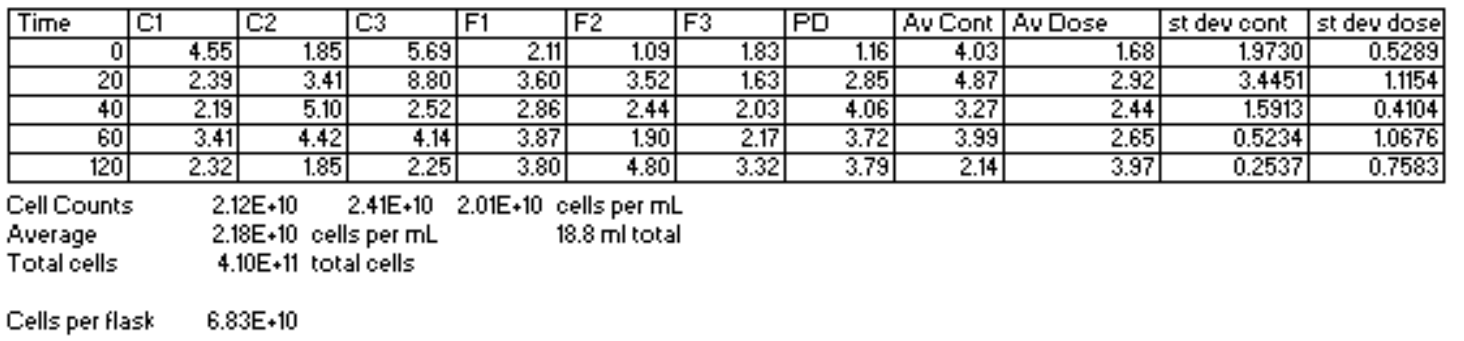


Efflux 2, Day 4

\begin{tabular}{|r|r|r|r|r|r|r|r|r|r|r|}
\hline Time & C1 & C2 & C3 & F1 & F2 & $F 3$ & su Cont & Av Dose & st dev cont & st dev dose \\
\hline 0 & 0.91 & 0.96 & 0.55 & 0.08 & 0.79 & 0.48 & 0.81 & 0.45 & 0.2220 & 0.3526 \\
\hline 20 & 0.50 & 0.65 & 0.08 & 0.92 & 0.89 & 1.04 & 0.41 & 0.95 & 0.2951 & 0.0815 \\
\hline 40 & 1.57 & 0.75 & 0.19 & 2.01 & 0.73 & 0.89 & 0.84 & 1.21 & 0.6959 & 0.6961 \\
\hline 60 & 0.40 & 0.55 & 0.66 & 0.86 & 0.99 & 0.79 & 0.53 & 0.88 & 0.1297 & 0.1030 \\
\hline 120 & 0.50 & 0.70 & 0.97 & 1.91 & 0.99 & 4.76 & 0.72 & 2.55 & 0.2348 & 1.9694 \\
\hline
\end{tabular}

\section{1-27-04, Book 2, Page 67}

Efflux 1, Day 0

\begin{tabular}{|c|c|c|c|c|c|c|c|c|c|c|c|}
\hline Time & C1 & $\mathrm{C} 2$ & C3 & F1 & $\mathrm{F} 2$ & F3 & $\mathrm{PD}$ & Av Cont & Av Dose & st dev cont & st dev dose \\
\hline 0 & 5.80 & 5.44 & 5.45 & 3.85 & 4.85 & 5.32 & 1.85 & 5.56 & 4.68 & 0.2027 & 0.7499 \\
\hline 20 & 7.30 & 4.37 & 4.19 & 7.65 & 5.45 & 7.59 & 2.59 & 5.28 & 6.90 & 1.7460 & 1.2511 \\
\hline 40 & 8.51 & 3.87 & 3.65 & 7.92 & 5.39 & 6.52 & 4.45 & 5.34 & 6.61 & 2.7451 & 1.2685 \\
\hline 60 & 6.87 & 5.30 & 3.72 & 5.65 & 6.05 & 7.65 & 1.39 & 5.29 & 6.45 & 1.5748 & 1.0587 \\
\hline 120 & 10.01 & 5.73 & 5.79 & 7.85 & 9.99 & 8.59 & 1.59 & 7.17 & 8.81 & 2.4572 & 1.0843 \\
\hline
\end{tabular}

Cell Counts $\quad 9.40 \mathrm{E}+10 \quad 1.07 \mathrm{E}+118.90 \mathrm{E}+10$ cells per $\mathrm{mL}$

Average $\quad 9.67 \mathrm{E}+10$ cells per $\mathrm{mL} \quad 38 \mathrm{ml}$ total

Total cells $3.67 \mathrm{E}+12$ total cells

Cells per flask $\quad 6.12 \mathrm{E}+11$

Efflux 2, Day 3

\begin{tabular}{|r|r|r|r|r|r|r|r|r|r|r|}
\hline Time & C1 & C2 & C3 & F1 & F2 & F3 & Av Cont & Av Dose & st dev cont & st dev dose \\
\hline 0 & 0.84 & 0.43 & 1.01 & 0.11 & 0.22 & 1.91 & 0.76 & 0.75 & 0.2987 & 1.0066 \\
\hline 20 & 1.19 & 0.07 & 0.16 & 1.11 & 1.35 & 2.57 & 0.47 & 1.68 & 0.6239 & 0.7842 \\
\hline 40 & 0.28 & 0.33 & 0.46 & 1.56 & 1.45 & 3.08 & 0.35 & 2.03 & 0.0955 & 0.9121 \\
\hline 60 & 0.38 & 0.07 & 0.31 & 1.96 & 1.30 & 1.86 & 0.25 & 1.70 & 0.1609 & 0.3576 \\
\hline 120 & 0.38 & 0.22 & 1.01 & 1.81 & 1.30 & 2.52 & 0.54 & 1.88 & 0.4167 & 0.6148 \\
\hline
\end{tabular}

2-4-04, Book 2, Page 69

Efflux 1, Day 0

\begin{tabular}{|c|c|c|c|c|c|c|c|c|c|c|c|}
\hline Time & C1 & $\mathrm{C} 2$ & $\mathrm{C} 3$ & $\mathrm{~F} 1$ & $\mathrm{~F} 2$ & F3 & $\mathrm{PD}$ & Av Cond & Av Dose & st dev cont & st dev dose \\
\hline 0 & 0.13 & 0.44 & 1.45 & 0.57 & 1.12 & 2.81 & 1.25 & 0.67 & 1.50 & 0.694 & 1.168 \\
\hline 20 & 0.18 & 1.49 & 0.79 & 1.18 & 3.71 & 2.92 & 13.25 & 0.82 & 2.60 & 0.658 & 1.295 \\
\hline 40 & 1.34 & 0.07 & 2.34 & 2.18 & 6.57 & 3.93 & 25.5 & 1.25 & 4.23 & 1.138 & 2.213 \\
\hline 60 & 2.60 & 0.39 & 1.62 & 3.79 & 5.39 & 3.15 & 12.75 & 1.54 & 4.11 & 1.108 & 1.158 \\
\hline 120 & 0.65 & 0.86 & 0.23 & 2.84 & 3.43 & 3.71 & 14.25 & 0.58 & 3.33 & 0.321 & 0.441 \\
\hline
\end{tabular}

Cell Counts $\quad 2.46 \mathrm{E}+10 \quad 2.37 \mathrm{E}+10 \quad 2.87 \mathrm{E}+10$ cells per $\mathrm{mL}$

Average $\quad 2.57 \mathrm{E}+10$ cells per $\mathrm{mL} \quad 15 \mathrm{ml}$ total

Total cells $\quad 3.85 \mathrm{E}+11$ total cells

Cells per flask $\quad 6.42 \mathrm{E}+10$

Efflux 2, Day 2

\begin{tabular}{|r|r|r|r|r|r|r|r|r|r|r|}
\hline Time & \multicolumn{1}{l|}{ C1 } & \multicolumn{1}{c|}{ C2 } & \multicolumn{1}{c}{ C3 } & F1 & F2 & F3 & Av Cont & Av Dose & st dev cont & st dev dose \\
\hline 0 & 0.56 & 0.62 & 0.16 & 1.16 & 1.72 & 1.61 & 0.45 & 1.50 & 0.251 & 0.296 \\
\hline 20 & 0.17 & 1.29 & 0.88 & 1.50 & 2.22 & 2.34 & 0.78 & 2.02 & 0.569 & 0.455 \\
\hline 40 & 0.51 & 0.34 & 0.77 & 1.33 & 2.39 & 3.29 & 0.54 & 2.34 & 0.219 & 0.979 \\
\hline 60 & 0.51 & 1.24 & 0.83 & 2.73 & 2.22 & 3.84 & 0.86 & 2.93 & 0.366 & 0.829 \\
\hline 120 & 0.84 & 0.62 & 0.10 & 2.39 & 1.83 & 3.45 & 0.52 & 2.56 & 0.380 & 0.823 \\
\hline
\end{tabular}

Efflux 3, Day 5 


\begin{tabular}{|r|r|r|r|r|r|r|r|r|r|r|}
\hline Time & \multicolumn{1}{l|}{ C1 } & C2 & C3 & F1 & F2 & F3 & Av Cont & Av Dose & st dev cont & st dev dose \\
\hline 0 & 0.49 & 0.38 & 1.33 & 1.16 & 1.05 & 0.33 & 0.73 & 0.85 & 0.519 & 0.455 \\
\hline 20 & 1.27 & 0.72 & 0.88 & 1.39 & 1.67 & 1.89 & 0.96 & 1.65 & 0.287 & 0.252 \\
\hline 40 & 1.27 & 0.21 & 0.66 & 0.83 & 2.84 & 1.22 & 0.72 & 1.63 & 0.533 & 1.066 \\
\hline 60 & 0.72 & 0.16 & 0.55 & 1.44 & 5.19 & 2.06 & 0.47 & 2.90 & 0.287 & 2.007 \\
\hline 120 & 2.39 & 0.94 & -.9 & 1.22 & 4.24 & 1.67 & 1.67 & 2.37 & $\cdots$ & 1.628 \\
\hline
\end{tabular}

\section{B.4 Data for thermallly reversible gel-immobilized $P$. aeruginosa}

The following data were obtained by acidifying the samples with nitric acid, diluting, and analyzing on the AA. Data shown has been corrected for dilution and for machine drift during analysis. Control flasks are indicated by "C", and dosed flasks by "F." Potassium concentration is reported in $\mathrm{mg} / \mathrm{L}$. Days after immobilization are given (e.g., day $0=$ immediately after immobilization and day $1=24$ hours after immobilization). Cell counts were performed by serial dilutions and plating. Volumes shown with cell counts indicate total volume of culture after resuspension. Total cells $=$ average cell count $\mathrm{x}$ resuspension volume. This total was divided equally into six flasks to give cells per flask.

Efflux 1, Day One, 4-19-04, Book 2, Page 86

Presented in Chapter 3, Table 1 and Figure 8

\begin{tabular}{|r|r|r|r|r|r|r|r|r|r|r|}
\hline Time & C1 & C2 & C3 & F1 & F2 & F3 & Av Cont & Av Dose & st dev cont & st dev dose \\
\hline-5 & 2.27 & 2.80 & 2.28 & 2.45 & 3.50 & 2.50 & 2.45 & 2.81 & 0.3026 & 0.5909 \\
\hline 0 & 2.21 & 2.16 & 2.34 & 2.95 & 2.55 & 3.22 & 2.24 & 2.91 & 0.0914 & 0.3355 \\
\hline 20 & 2.05 & 2.59 & 2.06 & 9.34 & 5.27 & 5.83 & 2.23 & 6.81 & 0.3052 & 2.2044 \\
\hline 40 & 1.74 & 2.53 & 1.73 & 5.67 & 3.88 & 4.66 & 2.00 & 4.74 & 0.4628 & 0.8964 \\
\hline 60 & 1.36 & 1.52 & 1.62 & 5.12 & 4.05 & 4.94 & 1.50 & 4.70 & 0.1282 & 0.5711 \\
\hline 80 & 0.94 & 3.01 & 1.34 & 5.73 & 4.38 & 4.94 & 1.76 & 5.02 & 1.1003 & 0.6750 \\
\hline 100 & 0.99 & 1.10 & 2.17 & 5.01 & 5.77 & 4.88 & 1.42 & 5.22 & 0.6536 & 0.4821 \\
\hline 120 & 0.78 & 2.53 & 0.84 & 5.95 & 4.44 & 5.11 & 1.38 & 5.17 & 0.9963 & 0.7567 \\
\hline
\end{tabular}

\begin{tabular}{|c|c|c|c|c|}
\hline Cell Counts & $3.19 E+09$ & $3.54 \mathrm{E}+09$ & $3.42 E+09$ & cells per mL \\
\hline Average & $3.38 \mathrm{E}+09$ & cells per $\mathrm{mL}$ & & $6.0 \mathrm{ml}$ total \\
\hline Total cells & $2.03 \mathrm{E}+10$ & total cells & & \\
\hline Cells per flask & $3.38 E+09$ & & & \\
\hline
\end{tabular}

5-24-04, Book 2, Page 92

Presented in Chapter 3, Figure 9

Efflux 1, Day 3

\begin{tabular}{|r|r|r|r|r|r|r|r|r|r|r|}
\hline Time & C1 & C2 & C3 & F1 & F2 & F3 & Av Cont & Av Dose & st dev cont & st dev dose \\
\hline-5 & 6.83 & 7.31 & 6.66 & 10.51 & 6.04 & 5.16 & 6.93 & 7.23 & 0.3331 & 2.8708 \\
\hline 0 & 7.67 & 7.15 & 7.10 & 11.55 & 9.95 & 7.36 & 7.31 & 9.62 & 0.3177 & 2.1163 \\
\hline 20 & 5.31 & 5.99 & 6.06 & 11.94 & 9.62 & 8.49 & 5.78 & 10.02 & 0.4163 & 1.7581 \\
\hline 40 & 4.15 & 6.31 & 6.11 & 9.19 & 9.57 & 8.33 & 5.52 & 9.03 & 1.1943 & 0.6368 \\
\hline 60 & 4.46 & 6.06 & 5.29 & 8.21 & 9.46 & 8.43 & 5.27 & 8.70 & 0.7978 & 0.6639 \\
\hline 80 & 4.46 & 6.33 & 5.18 & 7.88 & 9.29 & 8.86 & 5.33 & 8.68 & 0.9435 & 0.7227 \\
\hline 100 & 2.88 & 5.40 & 4.85 & 8.43 & 9.13 & 8.06 & 4.38 & 8.54 & 1.3222 & 0.5463 \\
\hline 120 & 2.25 & 5.12 & 4.30 & 8.43 & 9.46 & 8.76 & 3.89 & 8.88 & 1.4786 & 0.5249 \\
\hline
\end{tabular}

$\begin{array}{ll}\text { Cell Counts } & 4.60 \mathrm{E}+10 \quad 4.00 \mathrm{E}+10 \quad 4.30 \mathrm{E}+10 \text { cells per } \mathrm{mL} \\ \text { Average } & 4.30 \mathrm{E}+10 \text { cells per } \mathrm{mL}\end{array}$

$16 \mathrm{ml}$ total divided into 8 batches

Cells per flask $\quad 8.60 \mathrm{E}+10$ 
Data not included in thesis:

3-31-04, Book 2, Page 82

Efflux 1, Day 1

\begin{tabular}{|r|r|r|r|r|r|r|r|r|r|r|}
\hline Time & C1 & C2 & C3 & F1 & F2 & F3 & Av Cont & Av Dose & st dev cont & st dev dose \\
\hline 0 & 0.62 & 1.19 & 1.59 & 2.37 & 2.20 & 1.98 & 1.13 & 2.18 & 0.4905 & 0.1945 \\
\hline 20 & 0.88 & 0.46 & 4.87 & 3.42 & 2.63 & 3.77 & 2.07 & 3.28 & 2.4348 & 0.5847 \\
\hline 40 & 0.30 & 0.46 & 1.87 & 3.31 & 2.85 & 2.90 & 0.88 & 3.02 & 0.8628 & 0.2530 \\
\hline 60 & 0.20 & 0.30 & 1.37 & 3.31 & 3.07 & 2.96 & 0.62 & 3.11 & 0.6478 & 0.1815 \\
\hline 80 & 0.20 & 0.20 & 1.48 & 3.37 & 3.18 & 3.67 & 0.63 & 3.40 & 0.7400 & 0.2464 \\
\hline 100 & 0.41 & 0.25 & 0.76 & 3.81 & 3.34 & 3.56 & 0.47 & 3.57 & 0.2598 & 0.2372 \\
\hline 120 & 0.51 & 0.25 & 0.48 & 4.59 & 3.29 & 3.56 & 0.41 & 3.81 & 0.1423 & 0.6890 \\
\hline
\end{tabular}

Cell Counts $\quad 6.90 \mathrm{E}+10 \quad 5.30 \mathrm{E}+10 \quad 6.10 \mathrm{E}+10$ cells per $\mathrm{mL}$

Average $\quad 6.10 \mathrm{E}+10$ cells per $\mathrm{mL}$

Total cells $2.32 \mathrm{E}+12$ total cells

$11.5 \mathrm{ml}$ total, 8 batches

Cells per flask $\quad 3.33 \mathrm{E}+12$

Efflux 2, Day 3

\begin{tabular}{|r|r|r|r|r|r|r|r|r|r|r|}
\hline Time & C1 & C2 & C3 & F1 & F2 & F3 & Av Cont & Av Dose & st dev cont & st dev dose \\
\hline-5 & 0.08 & 0.55 & 0.12 & 0.35 & 0.17 & 0.23 & 0.25 & 0.25 & 0.2613 & 0.0907 \\
\hline 0 & 0.08 & 0.97 & 0.07 & 1.13 & 0.85 & 1.02 & 0.37 & 1.00 & 0.5186 & 0.1439 \\
\hline 20 & 0.40 & 0.97 & 0.57 & 1.30 & 1.02 & 1.64 & 0.65 & 1.32 & 0.2952 & 0.3111 \\
\hline 40 & 0.34 & 1.71 & 0.40 & 1.02 & 1.86 & 1.02 & 0.82 & 1.30 & 0.7694 & 0.4880 \\
\hline 60 & 0.08 & 0.55 & 0.07 & 1.58 & 1.19 & 1.13 & 0.23 & 1.30 & 0.2768 & 0.2469 \\
\hline 80 & 0.13 & 0.97 & 0.12 & 1.13 & 1.58 & 1.24 & 0.41 & 1.32 & 0.4872 & 0.2338 \\
\hline 100 & 0.19 & 0.61 & 0.63 & 1.30 & 1.30 & 1.58 & 0.47 & 1.39 & 0.2484 & 0.1623 \\
\hline 120 & 0.19 & 0.08 & 0.29 & 1.36 & 1.47 & 1.41 & 0.19 & 1.41 & 0.1043 & 0.0553 \\
\hline
\end{tabular}

Efflux 3, Day 7

\begin{tabular}{|r|r|r|r|r|r|r|r|r|r|r|}
\hline \multicolumn{1}{l|}{ Time } & \multicolumn{1}{l|}{ C1 } & C2 & C3 & F1 & F2 & F3 & Av Cont & Av Dose & st dev cont & st dev dose \\
\hline-5 & 0.34 & 0.51 & 0.94 & 0.33 & 0.36 & 0.13 & 0.60 & 0.28 & 0.3095 & 0.1239 \\
\hline 0 & 1.53 & 0.45 & 1.66 & 0.22 & 1.39 & 1.16 & 1.21 & 0.93 & 0.6612 & 0.6204 \\
\hline 20 & 2.03 & 1.19 & 0.55 & 0.55 & 0.82 & 0.53 & 1.26 & 0.64 & 0.7433 & 0.1600 \\
\hline 40 & 0.40 & 0.28 & 0.28 & 2.60 & 1.96 & 2.42 & 0.32 & 2.33 & 0.0671 & 0.3271 \\
\hline 60 & 0.34 & 0.45 & 1.27 & 0.61 & 0.42 & 0.42 & 0.69 & 0.48 & 0.5085 & 0.1084 \\
\hline 80 & 0.56 & 0.40 & 0.77 & 0.61 & 0.76 & 0.65 & 0.58 & 0.67 & 0.1893 & 0.0804 \\
\hline 100 & 1.36 & 0.40 & 0.17 & 0.50 & 0.36 & 0.53 & 0.64 & 0.46 & 0.6314 & 0.0902 \\
\hline 120 & 0.23 & 0.11 & 0.06 & 0.50 & 0.65 & 0.65 & 0.13 & 0.60 & 0.0868 & 0.0874 \\
\hline
\end{tabular}

4-18-04, Book 2, Page 84 and 86

Efflux 2, Day 3

\begin{tabular}{|r|r|r|r|r|r|r|r|r|r|r|}
\hline Time & $\mathrm{C} 1$ & $\mathrm{C} 2$ & $\mathrm{C} 3$ & $\mathrm{~F} 1$ & $\mathrm{~F} 2$ & $\mathrm{~F} 3$ & Av Cont & Su Dose & st dev cont & st dev dose \\
\hline $\mathbf{5}$ & 5.43 & 5.64 & 3.36 & 3.30 & 8.43 & 8.93 & 4.81 & 6.88 & 1.2600 & 3.1182 \\
\hline 0 & 8.14 & 5.47 & 3.26 & 3.39 & 8.14 & 8.71 & 5.62 & 6.75 & 2.4401 & 2.9237 \\
\hline 20 & 6.64 & 5.51 & 2.80 & 3.92 & 8.64 & 10.64 & 4.98 & 7.74 & 1.9750 & 3.4521 \\
\hline 40 & 6.05 & 5.26 & 2.92 & 4.11 & 8.71 & 8.57 & 4.75 & 7.13 & 1.6293 & 2.6195 \\
\hline 60 & 5.22 & 5.22 & 2.83 & 4.08 & 8.57 & 12.00 & 4.42 & 8.22 & 1.3820 & 3.9738 \\
\hline 80 & 4.60 & 7.39 & 2.58 & 5.23 & 9.43 & 9.93 & 4.85 & 8.20 & 2.4155 & 2.5791 \\
\hline 100 & 4.18 & 4.76 & 2.64 & 4.45 & 8.71 & 15.14 & 3.86 & 9.44 & 1.0968 & 5.3822 \\
\hline 120 & 4.60 & 4.30 & 2.42 & 4.20 & 8.79 & 9.14 & 3.77 & 7.38 & 1.1806 & 2.7557 \\
\hline
\end{tabular}


Efflux 3, Day 5

\begin{tabular}{|c|c|c|c|c|c|c|c|c|c|c|}
\hline Time & C1 & $\mathrm{C} 2$ & $\mathrm{C3}$ & F1 & F2 & F3 & Av Cont & Av Dose & st dev cont & St deu dose \\
\hline-5 & 5.93 & 7.50 & 4.08 & 5.15 & 8.33 & 9.63 & 5.84 & 7.70 & 1.7111 & 2.3032 \\
\hline 0 & 6.64 & 7.21 & 5.44 & 5.72 & 8.83 & 9.73 & 6.43 & 8.09 & 0.9065 & 2.1016 \\
\hline 20 & 6.93 & 7.79 & 3.58 & 7.08 & 10.53 & 12.23 & 6.10 & 9.95 & 2.2216 & 2.6233 \\
\hline 40 & 5.29 & 7.71 & 4.08 & 7.30 & 10.53 & 11.73 & 5.69 & 9.85 & 1.8505 & 2.2936 \\
\hline 60 & 5.14 & 7.71 & 3.08 & 6.87 & 10.53 & 13.23 & 5.31 & 10.21 & 2.3211 & 3.1935 \\
\hline 80 & 5.21 & 5.71 & 2.87 & 7.37 & 10.33 & 13.23 & 4.60 & 10.31 & 1.5202 & 2.9315 \\
\hline 100 & 4.50 & 5.29 & 2.94 & 6.94 & 11.13 & 11.33 & 4.24 & 9.80 & 1.1947 & 2.4797 \\
\hline 120 & 3.29 & 4.21 & 1.37 & 6.22 & 10.53 & 11.53 & 2.96 & 9.43 & 1.4520 & 2.8193 \\
\hline
\end{tabular}

